\title{
Coal hydrotreatment with coal-derived solvents to produce carbon product precursors
}

\author{
Madhavi Nallani Chakravartula \\ West Virginia University
}

Follow this and additional works at: https://researchrepository.wvu.edu/etd

\section{Recommended Citation}

Nallani Chakravartula, Madhavi, "Coal hydrotreatment with coal-derived solvents to produce carbon product precursors" (2005). Graduate Theses, Dissertations, and Problem Reports. 4178.

https://researchrepository.wvu.edu/etd/4178

This Thesis is protected by copyright and/or related rights. It has been brought to you by the The Research Repository @ WVU with permission from the rights-holder(s). You are free to use this Thesis in any way that is permitted by the copyright and related rights legislation that applies to your use. For other uses you must obtain permission from the rights-holder(s) directly, unless additional rights are indicated by a Creative Commons license in the record and/ or on the work itself. This Thesis has been accepted for inclusion in WVU Graduate Theses, Dissertations, and Problem Reports collection by an authorized administrator of The Research Repository @ WVU. For more information, please contact researchrepository@mail.wvu.edu. 


\title{
COAL HYDROTREATMENT WITH COAL-DERIVED SOLVENTS TO PRODUCE CARBON PRODUCT PRECURSORS
}

\author{
Madhavi Nallani Chakravartula \\ Thesis submitted to the \\ College of Engineering and Mineral Resources \\ at West Virginia University \\ in partial fulfillment of the requirements \\ for the degree of \\ Master of Science \\ in \\ Chemical Engineering \\ John W. Zondlo, Ph.D., Chair \\ Peter G. Stansberry, Ph.D. \\ Alfred H.Stiller, Ph.D. \\ Department of Chemical Engineering \\ Morgantown, West Virginia \\ 2005
}

Keywords: Coal Liquefaction, Carbon Product Precursors, Pitch, and Coke 


\section{ABSTRACT \\ Coal Hydrotreatment with Coal-Derived Solvents to Produce Carbon Product Precursors}

Madhavi Nallani Chakravartula

It is known that many specialty carbon products can be produced from coal. Direct liquefaction (hydrotreatment) is one of the most promising processes for coal conversion. In this present work, liquefaction of Marfork coal was examined at $350^{\circ} \mathrm{C}$, $400^{\circ} \mathrm{C}$ and $450^{\circ} \mathrm{C}$ and an initial pressure of 500 psig of Nitrogen or Hydrogen using coalderived solvents Carbon Black Base (CBB) and Heavy Creosote Oil (HCO) and their hydrogenated forms. Unlike model solvents such as Tetralin, coal-derived solvents are cheaper, readily available and recoverable. The solvents were first hydrogenated using unconverted residue from coal hydrotreatment and $\mathrm{NiO} / \mathrm{MoO}_{3}$ on alumina as catalysts. Coal hydrotreatment experiments were conducted to determine the effectiveness of the solvents as hydrogen donors. The products obtained are exhaustively extracted in Tetrahydrofuran (THF), filtered to separate THF insolubles (unconverted coal), and after THF removal, vacuum distilled to separate pitch material (distillation bottom) and recycle solvent (overhead). It was observed that the coal conversion increased when hydrogenated solvent was used. Ash content, coke yield and softening point were used to characterize the pitch product for potential use as a carbon-product precursor. These samples were also examined for coke microstructure under the polarized optical microscope. It was observed that the cokes produced with both the fresh solvents CBB and $\mathrm{HCO}$ are more isotropic than those produced with the hydrogenated solvents. 


\section{ACKNOWLEDGEMENTS}

This research is made possible through grant DE-FC26-03NT41873 from the Department of Energy. The author would like to thank the Department of Energy for providing support and funds for this research program.

The author would like to thank her research advisor, Dr. John W. Zondlo, for his guidance and support. This work would not have been possible with out his encouragement. The author would like to thank her committee member Dr. Peter Stansberry for his hands-on help in the lab with experimentation. The author would also like to thank her other committee member Dr. Alfred Stiller for his valuable suggestions in writing the manuscript. Also, the contribution of other graduate students is highly appreciated, especially Manoj Katakdaunde, Mitchell Clendenin, Nathan King, Jason Hissam and Morgan Summers.

The author wishes to thank her parents, Ranganath and Sarada Nallani Chakravartula, and her extended family without whose support this dream would not have been pursued. The author would like to give special thanks to her friend Suneetha Burla for making this experience less difficult to go through. 


\section{TABLE OF CONTENTS}

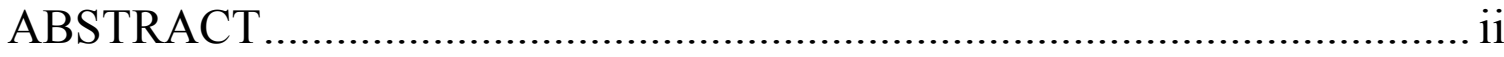

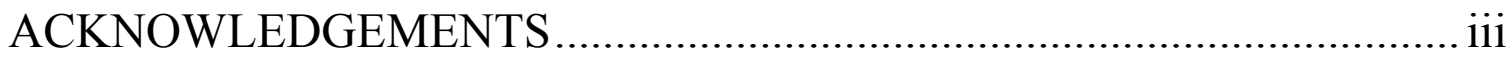

TABLE OF CONTENTS......................................................................... iv

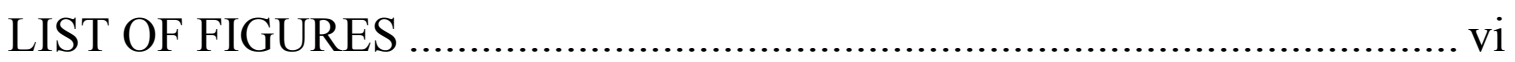

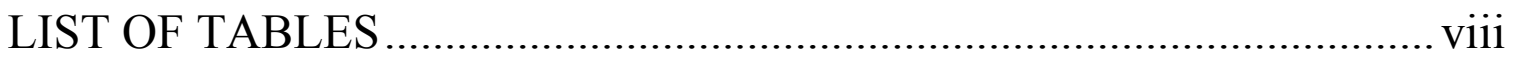

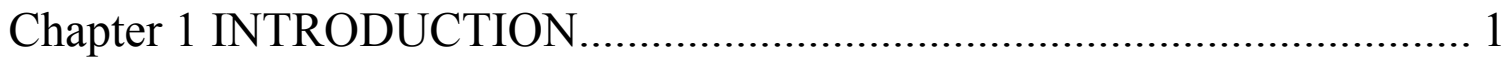

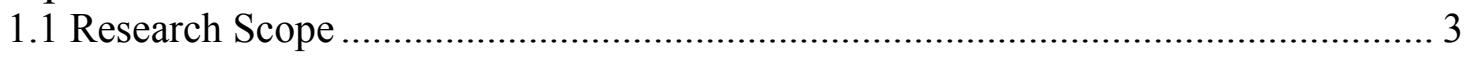

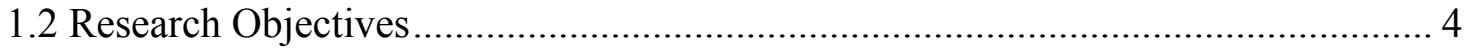

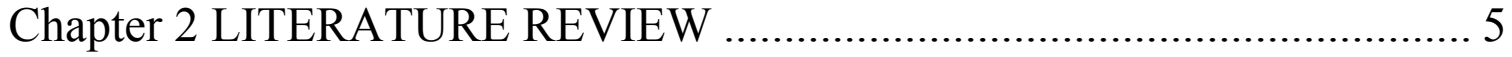

2.1 Coal -Origin, Classification and Structure........................................................... 5

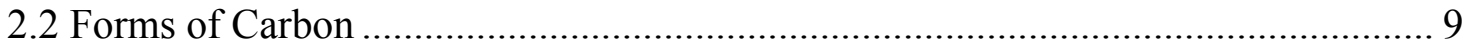

2.3 Coal Conversion Processes ………….......................................................... 12

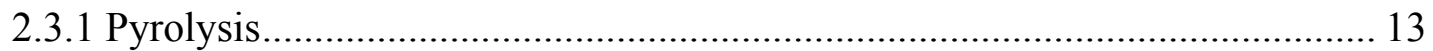

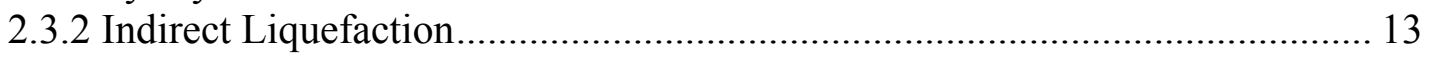

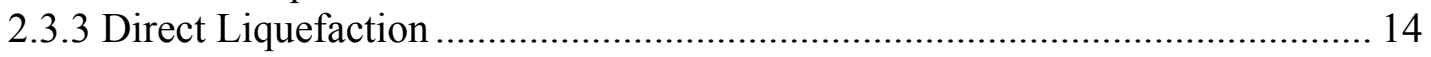

2.4 Mechanism of Coal Liquefaction.................................................................... 14

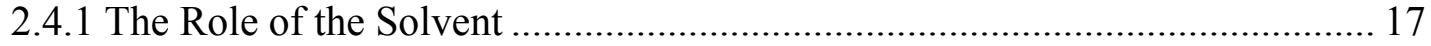

2.4.2 Effect of Coal Rank on Coal Liquefaction .................................................... 21

2.4.3 Hydrogen Pressure and Consumption......................................................... 22

2.4.4 Temperature and Pressure Effects …………………............................... 23

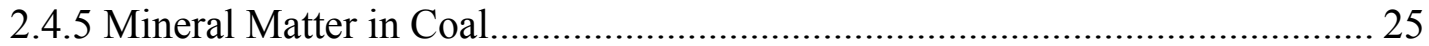

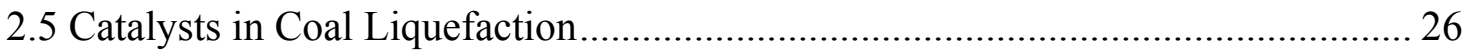

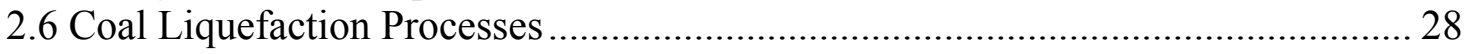

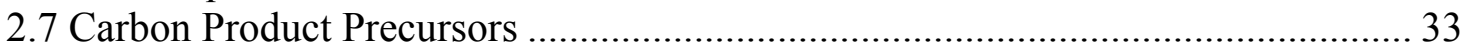

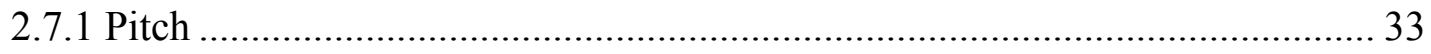

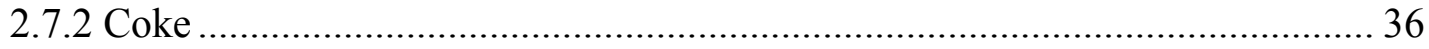

Chapter 3 EXPERIMENTAL PROCEDURE ........................................... 40

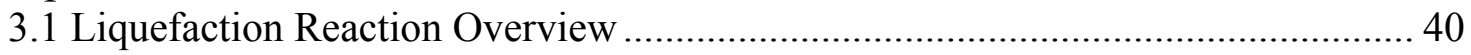

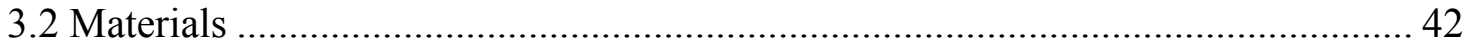

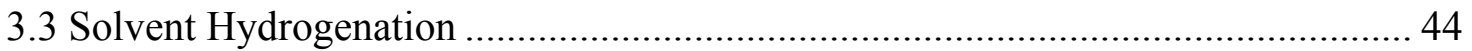

3.3.1 Using Mineral matter (MM) obtained from coal as a catalyst......................... 45

3.3.2 Using $\mathrm{NiO} / \mathrm{MiO}_{3}$ supported on alumia as a catalyst ........................................ 45

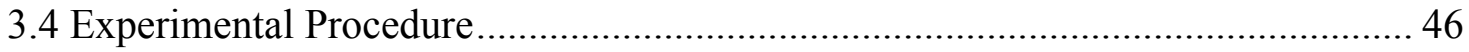

3.4.1 Reactor Preparation.................................................................................. 46

3.4.2 Reactor Purging and Gas Charging............................................................. 48

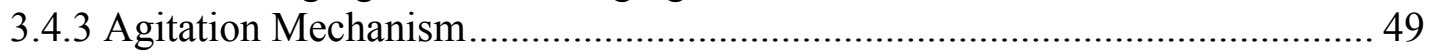

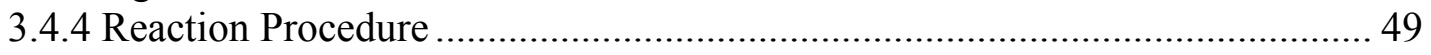

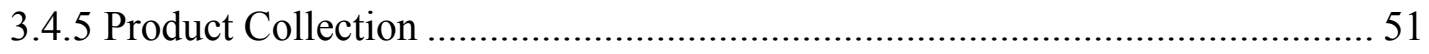

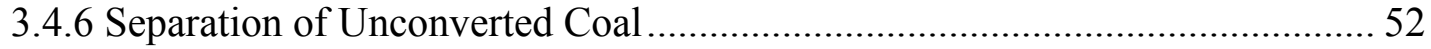

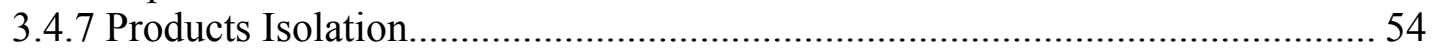

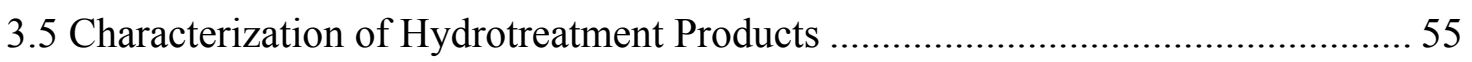

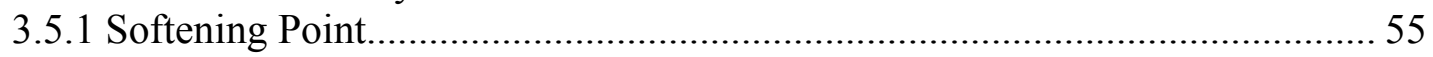




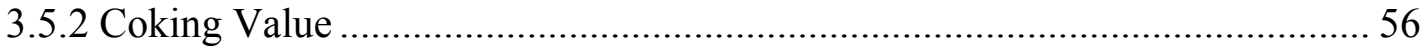

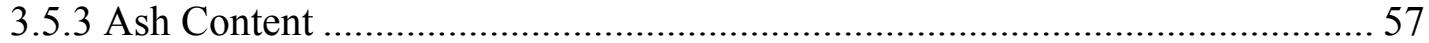

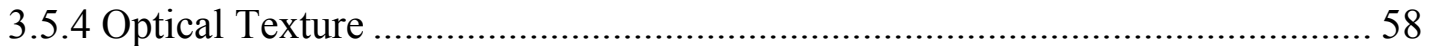

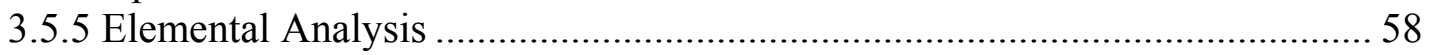

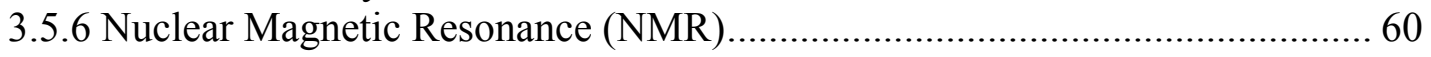

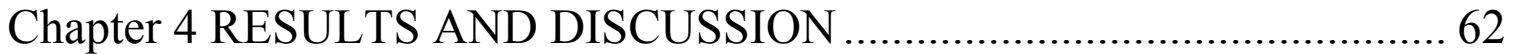

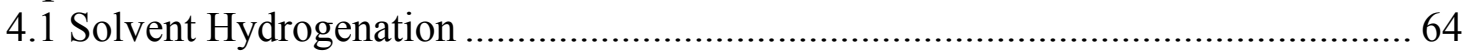

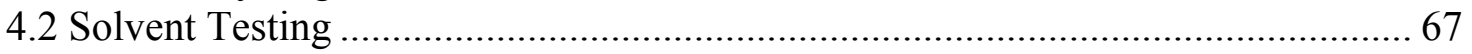

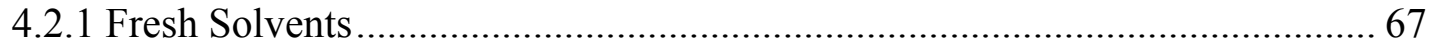

4.2.2 Solvent Pretreatment .................................................................................... 69

4.2.3 Blends of Fresh and Hydrogenated Solvents .................................................. 71

4.2.4 Recovered Solvent and Successive Hydrotreatment reactions ........................ 74

4.3 Effect of Reaction Atmosphere........................................................................... 78

4.4 Hydrotreatment Reactions Pressure Profiles ....................................................... 78

4.5 Effect of Reaction Temperature and Pressure …………..................................... 81

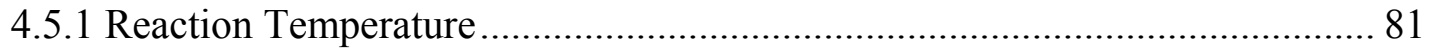

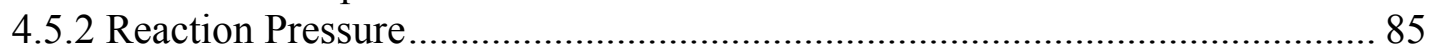

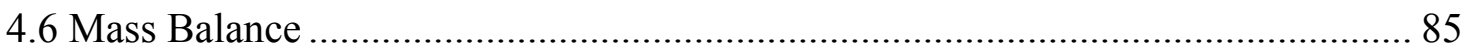

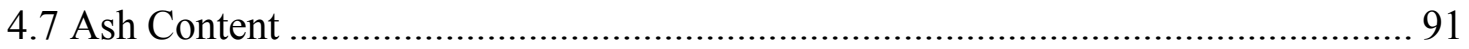

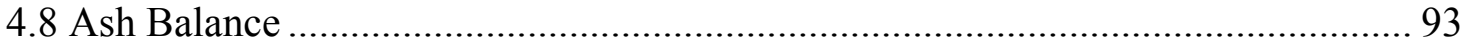

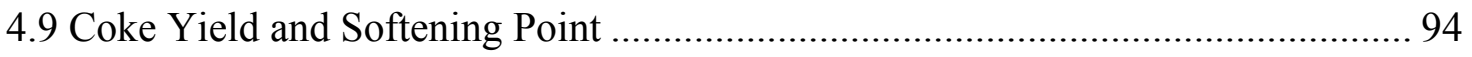

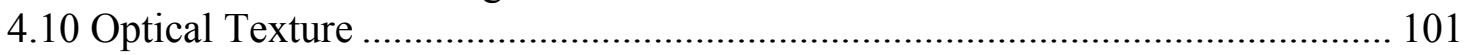

4.11 Elemental Analysis ............................................................................... 108

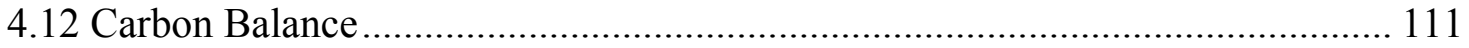

4.13 Nuclear Magnetic Resonance ………............................................................ 111

Chapter 5 CONCLUSIONS AND FUTURE RECOMMENDATIONS ... 115

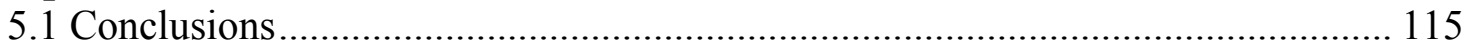

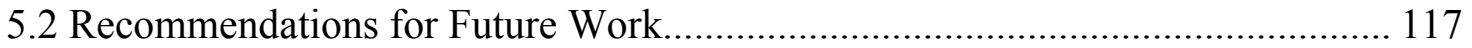

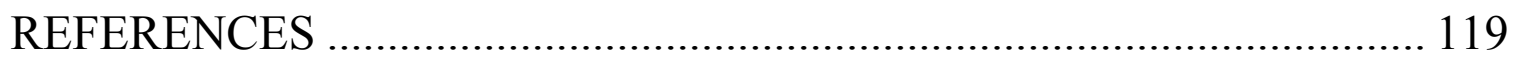

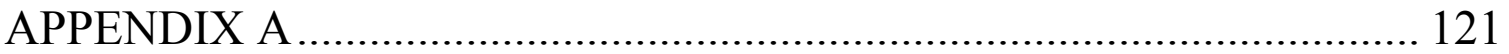

APPENDIX B: Material Safety Data Sheets ............................................ 129 


\section{$\underline{\text { LIST OF FIGURES }}$}

Figure 2. 1 Typical Molecular Unit In Bituminous Coal................................................ 9

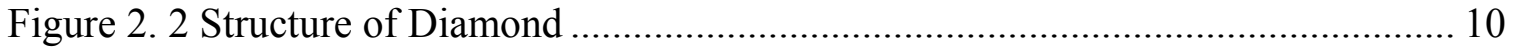

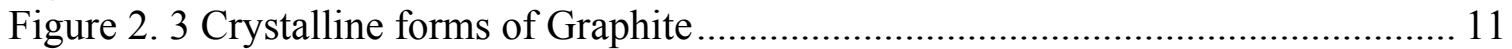

Figure 2. 4 Structure of Fullerene .......................................................................... 12

Figure 2. 5 Chemistry involved in Direct Liquefaction of Coal ..................................... 15

Figure 2. 6 Conceptual Reactions Sequences in Coal Liquefaction ................................ 16

Figure 2. 7 Free Radical Mechanism showing the three different paths ......................... 18

Figure 2. 8 Speculative Mechanism to explain the dependence of coal dissolution on

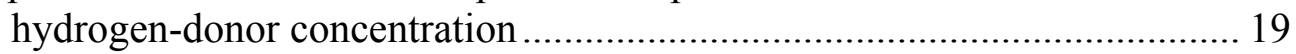

Figure 2. 9 A Possible Mechanism for H-shuttling ..................................................... 20

Figure 2. 10 Yield of Pyridine-soluble Extract vs. Rank of Coal .................................... 21

Figure 2. 11 Hydrogen consumption at short times for coals of various Ranks ............... 22

Figure 2. $12 \mathrm{Coal}$ conversion versus hydrogen transferred at $355^{\circ} \mathrm{C}$ to $440^{\circ} \mathrm{C}$................ 23

Figure 2. 13 Influence of Pressure and Temperature on Coal hydrogenation using

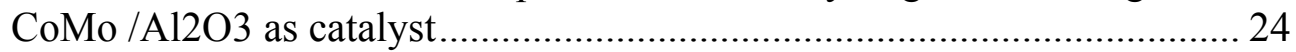

Figure 2. 14 Flow Scheme of SRC Process ………………....................................... 29

Figure 2. 15 Flow Scheme of EDS Process …………............................................. 30

Figure 2. 16 Flow Scheme of H-Coal Process ............................................................ 32

Figure 3. 1 Process Flow Sheet showing the procedure followed for hydrotreatment

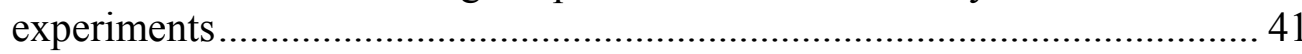

Figure 3. 2 Overall view of the $50 \mathrm{ml}$ tubing bomb microreactor ................................ 47

Figure 3. 3 Sand Bath Reactor with Agitation Mechanism ........................................... 50

Figure 3. 4 Products collection into a flask............................................................... 51

Figure 3. 5 Reflux condensing Apparatus................................................................... 53

Figure 3. 6 Vacuum Distillation Apparatus for the collection of light products and the isolation of the heavy products ................................................................ 54

Figure 3. 7 Elemental Analyzer -Flash EA 1112 Series ............................................. 59

Figure 3. 8 Nuclear Magnetic Resonance (NMR) Spectrometer..................................... 61

Figure 4. 1 Pressure profile for hydrogenation of $\mathrm{CBB}$ using $\mathrm{NiO} / \mathrm{MoO}_{3}$ as catalyst at

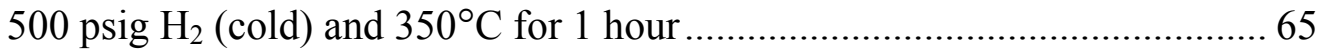

Figure 4. 2 Pressure profile for hydrogenation of $\mathrm{HCO}$ using unconverted coal as catalyst at $500 \mathrm{psig} \mathrm{H}_{2}$ (cold) and $400^{\circ} \mathrm{C}$ for 1 hour.......................................6 66

Figure 4. 3 Percent of Coal Conversion with fresh as-received solvents ......................... 68

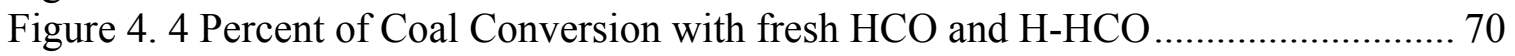

Figure 4. 5 Percent of Coal Conversion with fresh $\mathrm{CBB}$ and $\mathrm{H}-\mathrm{CBB}$ at $400^{\circ} \mathrm{C}$ and 500 psig $\mathrm{N}_{2}$ or $\mathrm{H}_{2}$ (cold) ............................................................................ 72

Figure 4. 6 Percent of Coal Conversion with blends of fresh $\mathrm{CBB}$ and $\mathrm{H}-\mathrm{CBB}$ at $400^{\circ} \mathrm{C}$

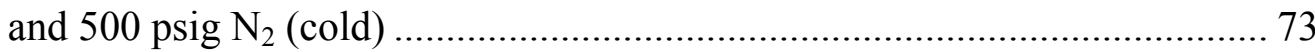

Figure 4. 7 Relationship between percent hydrogenated CBB and percent coal-alone conversion at $400^{\circ} \mathrm{C}$ and $500 \mathrm{psig}_{2}$ (cold) ............................................. 75

Figure 4. 8 Percent of coal-alone conversion with recovered H- CBB and with successive hydrotreatment reactions at $400^{\circ} \mathrm{C}$ and 500 psig $\mathrm{N}_{2}$ (cold) .......... 77 
Figure 4. 9 Percent of coal-alone conversion with fresh $\mathrm{HCO}$ and $\mathrm{CBB}$ at $400^{\circ} \mathrm{C}$ and 500 psig $\mathrm{N}_{2}$ or $\mathrm{H}_{2}$ (cold).

Figure 4. 10 Pressure profile for hydrotreatment reaction with fresh $\mathrm{HCO}$ and $\mathrm{CBB}$ at $400^{\circ} \mathrm{C} 500$ psig $\mathrm{N}_{2}$ (cold)

Figure 4. 11 Pressure profile for hydrotreatment reaction with fresh $\mathrm{HCO}$ and $\mathrm{CBB}$ at

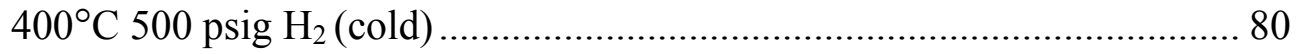

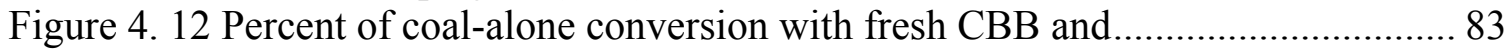

Figure 4. 13 Percent of coal-alone conversion with fresh CBB .................................. 84

Figure 4. 14 Pressure profile for hydrotreatment reaction with fresh $\mathrm{CBB}$ at different temperatures and 500 psig $\mathrm{N}_{2}$ (cold) ............................................... 86

Figure 4. 15 Pressure profile for hydrotreatment reaction with fresh $\mathrm{CBB}$ at different temperatures and 500 psig $\mathrm{H}_{2}$ (cold)

Figure 4. 16 Dependence of Softening points of the pitch on the coal hydrotreatment temperature for fresh and hydrogenated solvents in $\mathrm{N}_{2}$ and/or $\mathrm{H}_{2}$ atmospheres.

Figure 4. 17 Relationship between percent $\mathrm{H}-\mathrm{CBB}$ in $\mathrm{CBB}$ and softening point of pitches produced from coal hydrotreatment at.

Figure 4. 18 Relationship between coke yield and softening point of the pitches produced from coal hydrotreatment at $400^{\circ} \mathrm{C}$ and 500 psig $\mathrm{N}_{2}$ or $\mathrm{H}_{2}$ (cold)....

Figure 4. 19 A and B Optical micrographs of cokes from the coal hydrotreatment with solvents $\mathrm{HCO}$ and $\mathrm{CBB}$ respectively at $500 \mathrm{psig}_{2}$ (cold) and $400^{\circ} \mathrm{C}, 160 \mathrm{X}$, polarized light tinted plate

Figure 4. $20 \mathrm{~A}$ and B Optical micrographs of cokes from the coal hydrotreatment with solvents $\mathrm{HCO}$ and $\mathrm{CBB}$ at $500 \mathrm{psig}_{2}$ (cold) and $400^{\circ} \mathrm{C}, 160 \mathrm{X}$, polarized light tinted plate

Figure 4. $21 \mathrm{~A}$ and B Optical micrographs of cokes from the coal hydrotreatment with solvents $\mathrm{H}-\mathrm{HCO}$ and $\mathrm{H}-\mathrm{CBB}$ at $500 \mathrm{psig}_{2}$ (cold) and $400^{\circ} \mathrm{C}, 160 \mathrm{X}$, polarized light tinted plate

Figure 4. $22 \mathrm{~A}, \mathrm{~B}$ and C Optical micrographs of cokes from the coal hydrotreatment with solvents recovered $\mathrm{H}-\mathrm{CBB}$, pass 1 and pass 2 at $500 \mathrm{psig}_{2}$ (cold) and $400^{\circ} \mathrm{C}, 160 \mathrm{X}$, polarized light tinted plate

Figure 4. 23 Optical micrographs of cokes from the coal hydrotreatment with solvent $\mathrm{CBB}$ at $350^{\circ} \mathrm{C}$ and $450^{\circ} \mathrm{C}$ and 500 psig $\mathrm{H}_{2} / \mathrm{N}_{2}$ (cold), $160 \mathrm{X}$, polarized light tinted plate

Figure 4. $24 \mathrm{~A}$ and B Optical micrographs of cokes from the coal hydrotreatment with solvent $\mathrm{H}-\mathrm{CBB}$ at $350^{\circ} \mathrm{C}$ and $450^{\circ} \mathrm{C}$ and $500 \mathrm{psig} \mathrm{N}_{2}$ (cold), $160 \mathrm{X}$, polarized light tinted plate

Figure 4. 25 NMR Spectra for fresh H-CBB 113

Figure 4. 26 NMR Spectra for recovered H-CBB 


\section{LIST OF TABLES}

Table 2. 1 The ASTM Classification of Coal by Rank [3] ............................................... 7

Table 2. 2 Average Composition of coals varying In Rank [4] ...................................... 8

Table 2. 3 Definition of Primary liquids [2] ............................................................ 16

Table 2. 4 Fundamental Properties Important In Coal Liquefaction [2].......................... 17

Table 2. 5 Comparisons of Coal Liquefaction Processes [23] ......................................... 33

Table 2. 6 Carbon forms of Delayed Coke ……………….......................................... 37

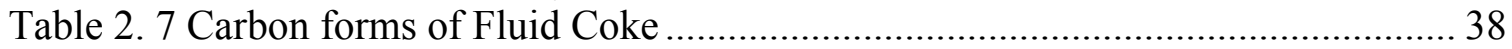

Table 3. 1 Characteristics of Marfork Coal .................................................................. 43

Table 3. 2 Elemental Analysis of as-received, coal-derived solvents.............................. 44

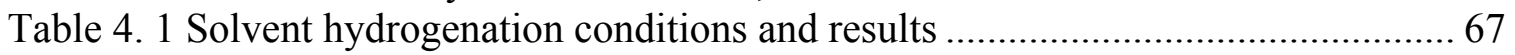

Table 4. 2 Amount of Fresh and Recovered Solvents used ........................................... 76

Table 4. 3 Overall Mass Balances of hydrotreatment reactions with fresh solvents ........ 88

Table 4. 4 Overall Mass Balances of hydrotreatment reactions with hydrogenated solvents

Table 4. 5 Overall Mass Balances with recovered solvents and successive hydrotreatment reactions........................................................................ 90

Table 4. 6 Overall Mass Balances of hydrotreatment reactions at different temperatures 90

Table 4. 7 Ash contents of THF Insolubles and pitches with fresh and hydrogenated

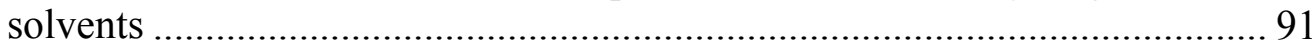

Table 4. 8 Ash contents of THF Insolubles and pitches with combinations of fresh and hydrogenated solvents

Table 4. 9 Ash contents of THF Insolubles and pitches with hydrotreatment reactions at different temperatures................................................................ 92

Table 4. 10 Ash contents of THF Insolubles and pitches with recovered and successive hydrotreatment reactions

Table 4. 11 Ash Balances of hydrotreatment reaction runs ............................................ 95

Table 4. 12 Coke yield and softening points of the pitch fraction for coal hydrotreatment with fresh as received solvents in $\mathrm{N}_{2}$ and $\mathrm{H}_{2}$ reaction atmospheres at $400^{\circ} \mathrm{C} 96$

Table 4. 13 Coke yield and softening points of the pitch fraction for coal hydrotreatment with hydrogenated solvents in $500 \mathrm{psig} \mathrm{N}_{2}$ (cold) at $400^{\circ} \mathrm{C}$

Table 4. 14 Coke yield and softening points of the pitch fraction for coal hydrotreatment with recovered solvents and with successive hydrotreatment ........................ 98

Table 4. 15 Elemental compositions of fresh solvent, THF Insolubles, pitch and recycle solvent from hydrotreatment reactions with fresh, as-received solvents in $\mathrm{N}_{2}$ and $\mathrm{H}_{2}$ atmospheres at $400^{\circ} \mathrm{C}$

Table 4. 16 Elemental compositions of fresh solvent, THF insolubles, pitch and recycle solvent from hydrotreatment reactions with hydrogenated solvents in $\mathrm{N}_{2}$ atmosphere at $400^{\circ} \mathrm{C}$

Table 4. 17 Elemental carbon balance of hydrotreatment reactions with fresh, as-received solvents in $\mathrm{N}_{2}$ and $\mathrm{H}_{2}$ atmospheres 


\section{Chapter 1 INTRODUCTION}

Coal is one of the Earth's most abundant natural resources. Increasing energy demands and dwindling petroleum reserves have stimulated interest in developing liquid fuels and other products from coal. Production of high-value, non-fuel products also is rapidly expanding due to increased demand for these coal-based speciality materials.

Carbon is used in the production of many materials that are important in our daily life. For decades the majority of carbon feedstock has been derived from petroleum. Petroleum reserves are far smaller than those of coal. Also, the sulfur and metals content in crude oil is increasing day by day. So, coal-derived materials may gain some advantage over the petroleum-based materials eventually. Most carbon feedstocks from coal were derived as byproducts from the metallurgical coke industry. The volatiles produced during the carbonization of coal are condensed into coal tar. Upon distillation, Coal-tars also have been used successfully for the manufacture of many useful products such as fertilizers, ammonia, BTX, creosote and coal tar pitch. Carbon-based materials such as carbon anodes, carbon-fibers, carbon fiber reinforced plastics, carbon-carbon composites, activated carbons and high performance graphite have been produced using coal-tar pitch.

Coal-tar is obtained as a byproduct in the production of metallurgical coke from coal. The process uses coke ovens. Due to the environmental regulations placed on the coke ovens, new recovery-type coke ovens may not be installed in US in future [1]. Also, the amount of coal tar produced from one ton of coal is on the order of only $4 \mathrm{wt} \%$ of the 
original weight of coal. This strongly suggests a need to produce theses materials from coal directly.

Direct hydrotreatment is one of the most promising processes for coal conversion. It involves reaction of coal with solvent and/or hydrogen at elevated temperatures with or without the use of a catalyst. The precursors for carbon products need specific characteristics and the use of hydrotreating technology for coal processing was found to offer the capability of tailoring the properties of the liquefaction products by changing the reaction conditions.

The current research was supported by DOE to develop pilot scale studies producing carbon product precursors from coal hydrotreatment. The two main focus areas are the evaluation of the potential hydrotreatment solvents and evaluation of the best conditions for operating the pilot scale operations. Tetralin has been shown to be a good solvent for coal conversion, but the solvent is not recoverable, as it is converted to naphthalene during the reaction. This cannot be further recycled as a solvent unless it is externally separated and rehydrogenated. Also, it is very expensive and hence not feasible for use at the commercial scale. Alternatively, a coal-derived liquid can be used as the solvent in the process. This will have the following advantages:

1. Coal-derived solvents are good physical solvents for coal and coal products due to their chemical similarity, and this solubility effect enhances the conversion of coal to useful products.

2. Coal-derived solvents have low sulfur content and these result in low sulfur content in the end products. 
3. The possibility exists for producing a recyclable solvent, which can be taken as a cut of the total liquid product slate.

4. Production of a completely coal-derived carbon product precursor is possible, thus eliminating the dependence on petroleum.

Pitch and Coke are the two main carbon product precursors. Depending on the feedstock and treatment method used, the precursor products produced find different applications. Binder pitch can be used as a binder for anodes in the aluminum smelting industry. Impregnation pitch can be used for treating carbon/graphite electrodes and brick refractories to give them the higher density, mechanical strength, and electrical conductivity that they will need to withstand severe operating conditions. Isotropic coke contains granular structure and is used to produce nuclear grade graphite. Anisotropic coke contains crystalline structure and is used in producing anodes and graphite electrodes.

\subsection{Research Scope}

In the present work, coal was first hydrotreated in the presence of a hydrogendonor solvent and then separated to hydrogen rich liquids and carbon rich solids. These carbon rich solids are termed as pitch. This pitch was further processed to form coke. The hydrogen rich liquids, which resemble the original hydrogen-donor solvent, were used in the succeeding reactions as the solvent. The use of pre-hydrogenated solvent in the hydrotreatmet reaction was also tested. The overall objective of this project is the evaluation of several different coal-derived H-donor solvents for use in the mild hydrogenation of coal with the aim of maximizing conversion of coal to useful products. 
These solvents include heavy creosote oil and carbon black base. They were obtained from Koppers Industries.

\subsection{Research Objectives}

The purpose of this research is to produce and evaluate coal-based carbon product precursors. The specific goals of the work can be divided into the following tasks:

1. Determine the conversion of coal produced as a result of reaction with both "asreceived" and "hydrotreated" coal-derived solvents and thus evaluate the effectiveness of the solvents as hydrogen donors in the conversion of coal to carbon products.

2. Determine the effectiveness as catalysts of both mineral matter from coal (unconverted residue) and a commercial $\mathrm{NiO} / \mathrm{MoO}_{3}$ catalyst with respect to solvent hydrogenation.

3. Separate pitch material and hydrogen-donor solvent from the hydrotreated products by vacuum distillation.

4. Evaluate the products of the hydrotreatment for their use as carbon-product precursor using standard test procedures such as coking value, softening point, ash content, and optical texture.

5. Test the recovered solvent as a potential recycled hydrogen-donor solvent.

6. Produce pitch samples with a range of softening points 


\section{Chapter 2 \\ LITERATURE REVIEW}

In this chapter, some of the general concepts related to the present research goals will be discussed. A general description of coal, its formation, structure and classification along with the concepts that govern the liquefaction process are presented.

\subsection{Coal -Origin, Classification and Structure}

Coal is a solid, brittle, more or less distinctly stratified combustible carbonaceous rock. Coal is a complex mixture of organic substances containing carbon, hydrogen and oxygen together with small amounts of nitrogen and sulfur. It also contains mineral matter in the form of clay, silica, carbonates, sulfides and other inorganic complexes. Coal originated predominantly from plant matter. In the first phase of coalification, this plant matter, deposited in the sedimentary strata, was subjected to a bacterial action and several chemical alterations. In the second phase, called the geochemical or metamorphic stage, the decaying matter transformed through a series of chemical changes, leading to an increase in the carbon content and decrease in the oxygen content. The product first formed was humic acid. This was then further converted into the various types of coal that are mined today. Depending on the time, temperature and pressure to which it has been subjected, different degrees of coalification or ranks of coal are achieved.

Rank of a coal is the degree of maturation and is a qualitative measure of carbon content. Lignite and subbituminous coals are referred to as low rank coals, whereas bituminous and anthracite coals are referred to as high rank coals. A primary 
classification of coal lists the coals, regardless of age, origin, and type, arranging them in an ascending order of carbon content to form a continuous coal series. This classification, in effect, is rudimentary and is viewed as follows.

$$
\text { Peat } \rightarrow \text { Lignite } \rightarrow \text { Subbituminous coal } \rightarrow \text { Bituminous coal } \rightarrow \text { Anthracite }
$$

This series does not imply a genetic connection between its members, but is consistent with the notion that lignite in time becomes subbituminous coal and that this in turn is converted into bituminous coal [2]. Coal rank increases with the decrease in the atomic H/C (Hydrogen-to-Carbon) ratio. The ASTM, American Society for Testing and Materials, gives a classification of coal, which is based on the amount of fixed carbon and volatile matter and the heating value. The test is specified on ASTM standard D 38866. Volatile matter is the products, exclusive of moisture, that are given off as gas or vapors when coal is heated according to various prescribed methods in an inert atmosphere. Volatile matter is mainly composed of combustible gases and some combustible liquids. Fixed carbon is the solid combustible residue left after the moisture and volatile matter have been driven off by heating. It is calculated by subtracting the sum of moisture, ash and volatile matter from 100 percent, where ash is the inorganic residue that remains after complete incineration of coal. Heating value is the amount of heat produced by the complete combustion of a unit quantity of fuel. Classification of coal based on volatile matter, fixed carbon and heating value is shown in Table 2.1

The predominant functional groups found in coal are those containing oxygen. They include phenols and alcohols, ethers, carboxylic acids and carbonyls. Quantitative determination of the various oxygen functionalities has been reviewed by several authors. 
Table 2. 1 The ASTM Classification of Coal by Rank [3]

\begin{tabular}{|c|c|c|c|c|}
\hline Class & 1.1 Group & Fixed Carbon & $\begin{array}{cc}1.2 & \text { Volatile } \\
& \text { matter }\end{array}$ & Heating Value \\
\hline Anthracite & $\begin{array}{l}\text { Metaanthracite } \\
\text { Anthracite } \\
\text { Semianthracite }\end{array}$ & $\begin{array}{c}.>98 \\
92-98 \\
86-92\end{array}$ & $\begin{array}{c}<2 \\
2-8 \\
8-14\end{array}$ & - \\
\hline Bituminous & $\begin{array}{l}\text { Low-volatile } \\
\text { Medium volatile } \\
\text { High volatile A } \\
\text { High volatile B } \\
\text { High volatile C }\end{array}$ & $\begin{array}{c}78-86 \\
69-78 \\
<69\end{array}$ & $\begin{array}{c}14-22 \\
22-31 \\
>31\end{array}$ & $\begin{array}{c}>14,000 \\
13,000-14,000 \\
10,500-13,000\end{array}$ \\
\hline Subbitumious & $\begin{array}{l}\text { Subbituminous A } \\
\text { Subbituminous B } \\
\text { Subbituminous C }\end{array}$ & & & $\begin{array}{c}10,000-11,500 \\
9,500-10,500 \\
8,300-9,500\end{array}$ \\
\hline Lignite & $\begin{array}{l}\text { Lignite A } \\
\text { Lignite B }\end{array}$ & & & $\begin{array}{c}6,300-8,300 \\
<6,300\end{array}$ \\
\hline
\end{tabular}

Note: This classification system is based on ASTM standard D 388-66, which is published annually by ASTM in their compilation of standards. The fixed carbon and volatile matter, reported as percentages, are determined on a dry, mineral-free basis. 
Typical compositions of the functional groups in lignite, subbituminous and bituminous coals are shown in Table 2.2

Table 2. 2 Average Composition of coals varying In Rank [4]

\begin{tabular}{|c|c|c|c|c|c|c|c|c|}
\hline & & & \multicolumn{5}{|c|}{ \# of Oxygen containing } \\
Coal & \%C & $\begin{array}{c}\text { No. of } \\
10 \mathrm{C} \\
\text { aromatic } \\
\text { rings }\end{array}$ & $\begin{array}{c}\text { Ave. } \\
\text { Mol. } \\
\text { Wt. }\end{array}$ & \multicolumn{5}{|c|}{ Functional Groups } \\
\cline { 5 - 10 } & & & & $\mathrm{COOH}$ & $\mathrm{OH}$ & $-\mathrm{O}-$ & $\mathrm{C}=\mathrm{O}$ & $\mathrm{OCH}_{3}$ \\
\hline Lignite & 70.0 & 1.7 & 513 & 1.5 & 2.8 & 0.8 & 0.5 & 0.2 \\
\hline Subbituminous & 77.5 & 2.0 & 461 & 0.6 & 1.8 & 1.1 & 0.3 & 0.1 \\
\hline Bituminous & 85.0 & 2.3 & 419 & 0 & 0.9 & 0.9 & 0.1 & 0 \\
\hline
\end{tabular}

Whitehurst et al. [4] have conducted several studies to correlate percentage oxygen in the coal to the carbon content of coal. The relative amounts of each of these functional groups were calculated and with several such correlations, Wiser [5] proposed a complex coal structure. This model is shown in Figure 2.1. Weak bonds in the structure are indicated by arrows. These weak bonds are broken during coal hydrotreatment to form smaller, soluble fragments. It is noted that bituminous coals consist of more planar aromatic ring structures, whereas the subbituminous coal contains a highly condensed aliphatic structure. 


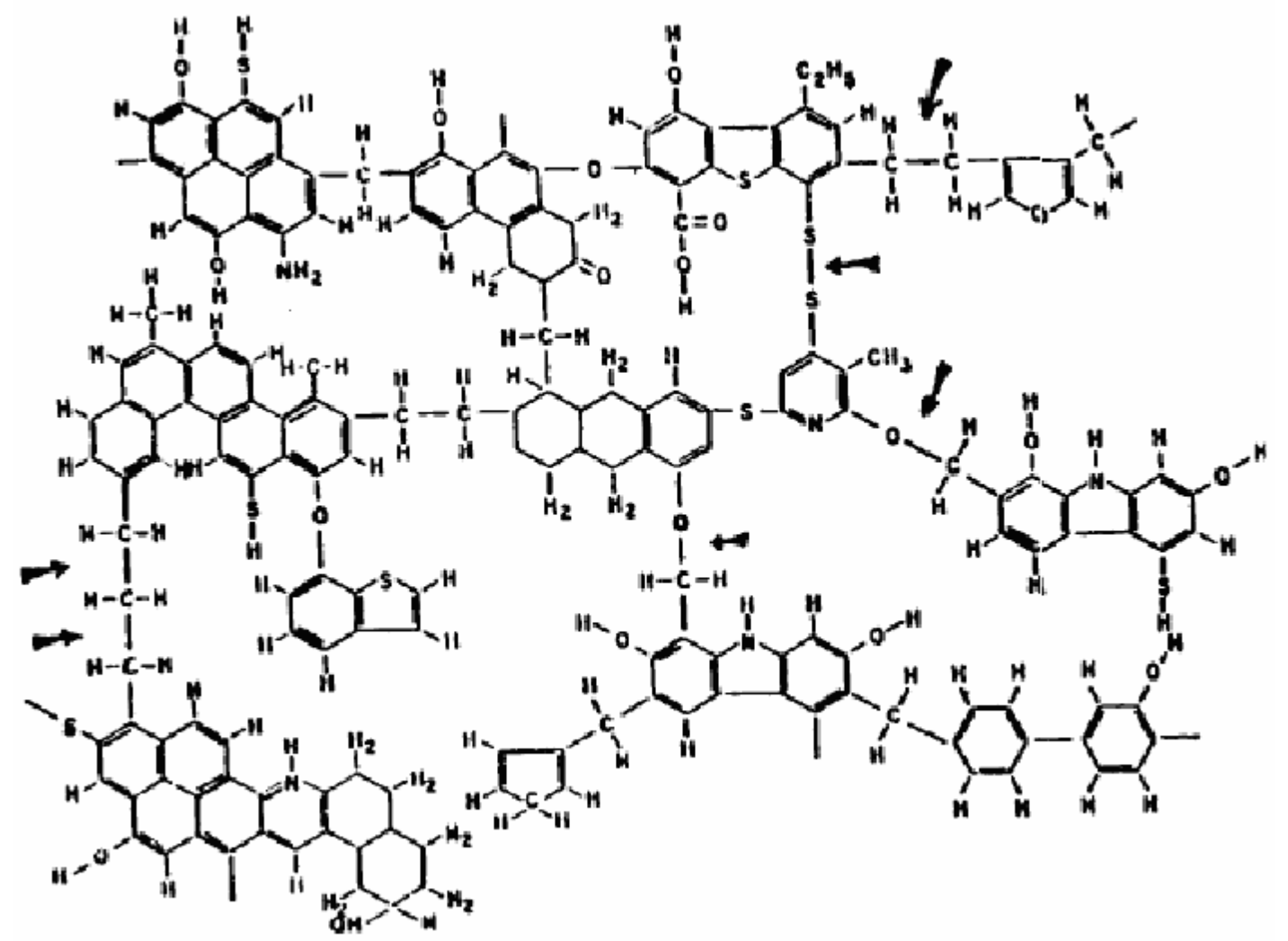

Figure 2. 1 Typical Molecular Unit In Bituminous Coal [6]

\subsection{Forms of Carbon}

Carbon is the sixth most abundant element in the universe. In addition, carbon is a very special element because it plays a dominant role in the chemistry of life. Carbon occurs in great abundance in coal, petroleum and carbonates such as limestone. Elemental carbon can show different allotropic forms. The allotropic form of carbon without a defined crystalline structure is called amorphous carbon. Charcoal, lamp black and some forms of carbon black and coke are examples of such amorphous forms of carbon. The structure of some coke is more regular and closer to graphite than the other amorphous 
forms of carbon. The other allotropes of carbon with definite crystalline forms also exist. They are diamond, graphite and fullerene.

Diamond is a solid network form of elemental carbon. In diamond, every carbon atom is $\mathrm{sp}^{3}$ hybridized, forming a tetrahedral structure. Each of these $\mathrm{sp}^{3}$ arranged carbon atoms bonds with four other carbon atoms, which in turn form bonds with four other carbon atoms and so on forming an infinite three-dimensional array. The structural form of diamond is shown in Figure 2.2. This three-dimensional network extends throughout the crystal and makes diamond the hardest naturally occurring substance. The very strong lattice-work in diamond can only be destroyed or disrupted by very powerful forces. Diamonds are chemically inert and have a high melting point. Due to very strong C-C covalent bonds, no free electrons are available for electrical conductivity. This makes them very good insulators. The lattice of diamonds can vibrate with very high frequencies. These vibrations assist in carrying heat resulting in high thermal conductivity. Being high thermal conductors and low electrical conductors, diamonds find many uses in small microwave integrated circuits.

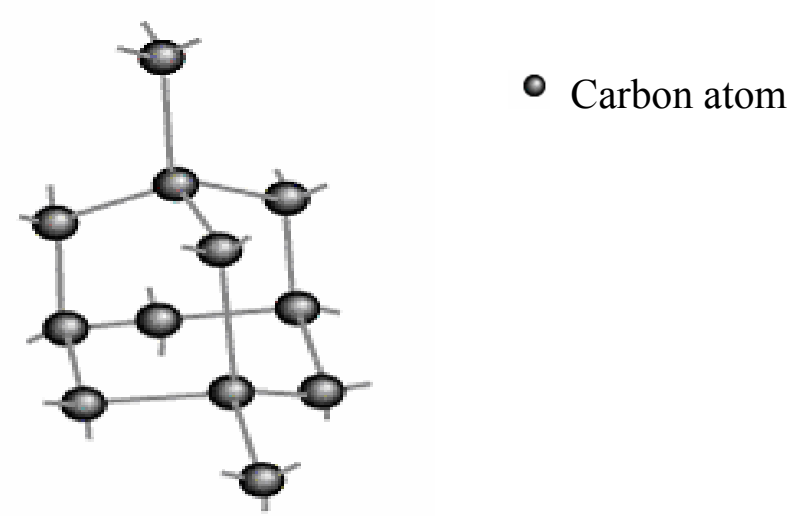

Figure 2. 2 Structure of Diamond 
Graphite is the soft allotropic form of carbon. Every carbon atom in the graphite structure is $\mathrm{sp}^{2}$ hybridized, forming a sheet-like crystal structure. The graphite structure is shown in Figure 2.3. Each carbon atom is tightly bound to three other carbon atoms. These carbon atoms form planar layers or sheets of infinitely linked carbon atoms in a way that the distance between the atoms in one plane is much smaller compared to the distance between the planes itself. For this reason, very little bonding exists between the layers. Moreover, these layers of carbon can slide over each other easily, making graphite a useful lubricant. Graphite usually exists in two different forms called tetrahedral and rhombohedral, which differ slightly in their crystalline structures. Naturally occurring graphite consists of mixture of these two forms.
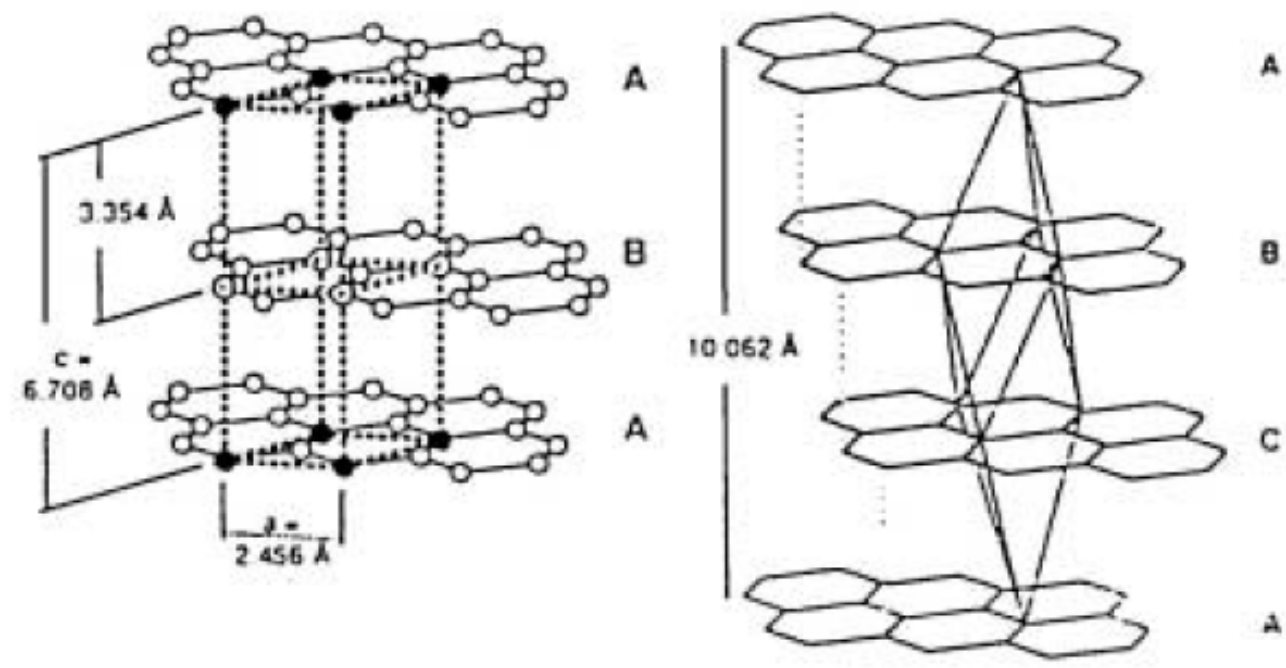

Hexagonal Unit Cell

Rhombohedral stacking

Figure 2. 3 Crystalline forms of Graphite [7] 
Fullerene was discovered in late1980's by Richard Smalley. In this form, the carbon atoms are joined together in sheets of hexagonal rings (as seen in graphite), but some of the carbon rings have five or more atoms in them forming pentagons and hexagons. Ten C-6 rings join with twenty C-5 rings to form a hollow sphere structure shown. Fullerenes can be used to improve resolution of photocopies, and as lubricants and catalysts.

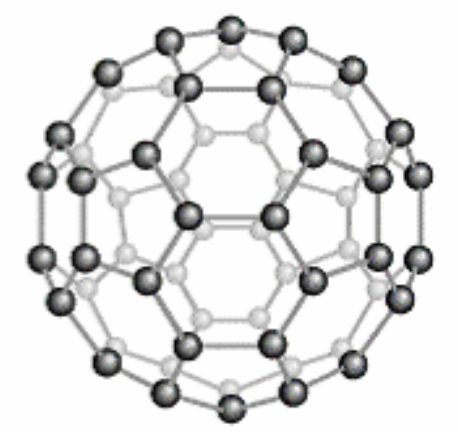

Figure 2. 4 Structure of Fullerene

\subsection{Coal Conversion Processes}

For coal to be viable as a feedstock for carbon materials, its molecular weight needs to be reduced. For this purpose, various aromatic-aliphatic, aromatic-aromatic and carbon-heteroatom bonds have to be broken. This suggests that the main objective of the hydrotreatment of coal is to increase the $\mathrm{H} / \mathrm{C}$ ratio. This can be attained either by addition of hydrogen or by rejection of carbon. There are three chief processes for coal conversion: pyrolysis, indirect liquefaction and direct liquefaction. 


\subsubsection{Pyrolysis}

In the pyrolysis process, coal is heated above $400^{\circ} \mathrm{C}$ in the absence of oxygen and thermally decomposed to produce hydrogen rich liquids, gases and a carbon rich residue called char. This is done in the absence of oxygen to eliminate the possibility of any undesirable combustion reactions. Pyrolysis is a component of most coal conversion processes including combustion, gasification and liquefaction.

Pyrolysis occurs in two stages. As the coal is heated, the first stage of decomposition is associated with the breaking of bonds between the aromatic cluster units. The aliphatic side chains break away from the cluster units in the temperature range of $400^{\circ} \mathrm{C}-450^{\circ} \mathrm{C}$. Tars and gases are given off from this thermal decomposition of the coal structure. The free radicals formed during the first stage tend to combine resulting in the polymerization of the mass and the formation of char or coke [8]. As heating progresses, volatile matter continues to be released. This volatile matter is usually withdrawn from the reaction vessel and condensed to form liquid products called coal-tar. Coal-tar is further processed and desulphurized to produce valuable products. The char produced contains the mineral matter that was present in the original coal sample.

\subsubsection{Indirect Liquefaction}

In Indirect Liquefaction, coal is first gasified to produce synthesis gas, i.e., $\mathrm{CO}$ and $\mathrm{H}_{2}$, which is then converted in the presence of a Fisher-Tropsch or other catalyst into various higher hydrocarbons [9]. This method has the advantage of minimizing the mineral matter and other impurities in the final product and also has the ability to produce 
a wide variety of liquid products selectively, depending on the choice of the FisherTropsch catalyst and reaction conditions.

However, the coal when gasified with oxygen and steam produces many byproducts and the synthesis gas must be purified before it is recombined to form liquid products. The process is very expensive in terms of thermal efficiency.

\subsubsection{Direct Liquefaction}

Direct liquefaction involves thermal treating of coal in the presence of a solvent and/or hydrogen with or without the use of a catalyst. In this process, hydrogen is directly added to the coal. Hydrogen deficient products (such as aromatic products) are saturated and the free radicals are terminated with hydrogen, which is readily available. This process has higher thermal efficiency than the indirect process.

\subsection{Mechanism of Coal Liquefaction}

Curran et al. [10] suggested that the transfer of hydrogen from a slurry vehicle (solvent) to coal could be described as a free radical reaction in which the coal molecules are thermally cleaved into free radicals, which are then capped in the most thermodynamically favorable process. It has been suggested that coal liquefaction can be viewed as a three-step process involving dissolution, hydrogen transfer, and hydrogenation. Coal consists of highly crosslinked macromolecular networks connected by relatively weak linkages. During the dissolution step, these weak linkages are broken down resulting in the formation of free radicals. In presence of a H-donor solvent, the free radicals are capped to form stable species that typically have molecular weights in 
the range of 300-1000. If a hydrogen-donor solvent is not present, the free radicals can recombine among themselves and stabilize by condensation forming compounds of higher molecular weight and hence char (see Figure 2.5).

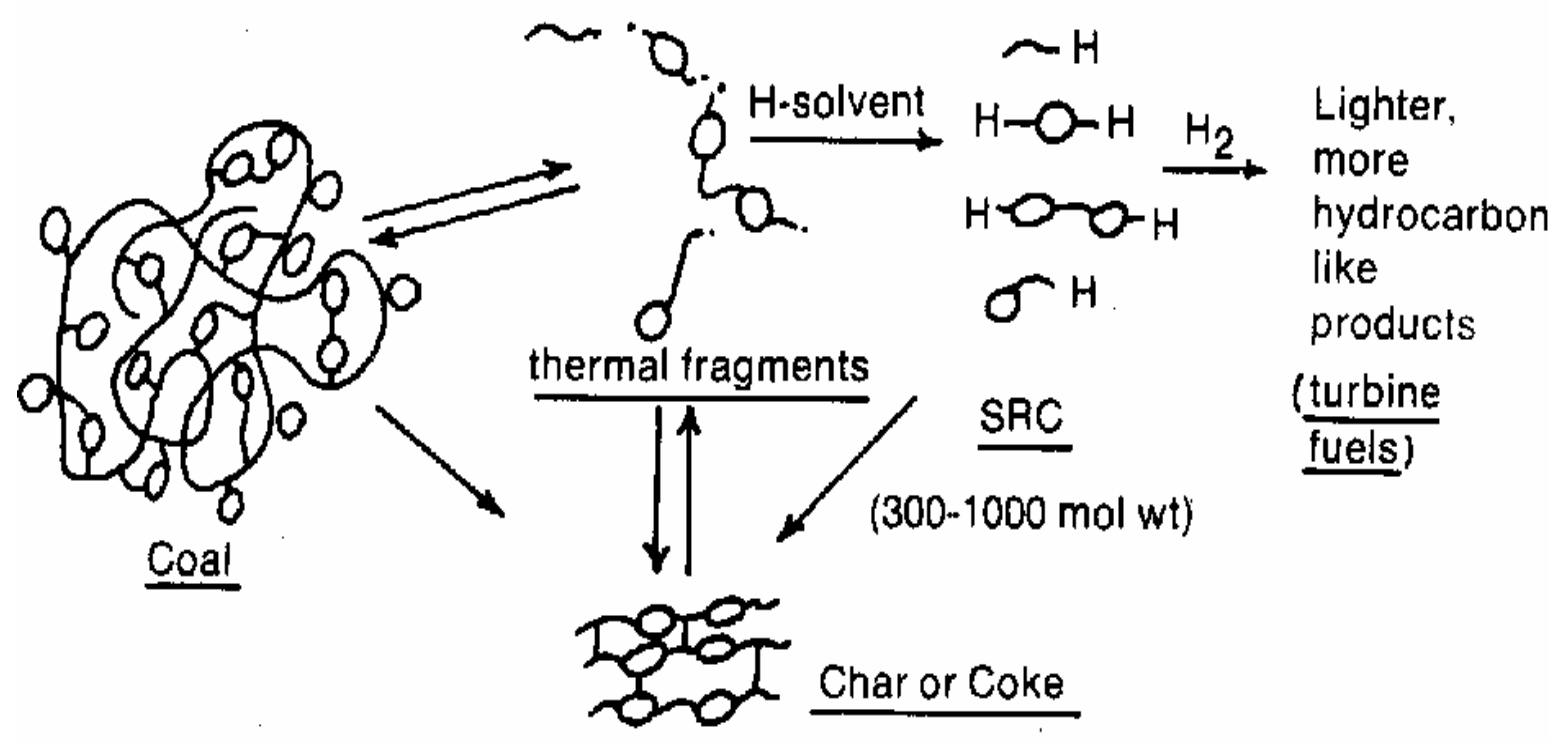

Figure 2. 5 Chemistry involved in Direct Liquefaction of Coal [11]

On a macroscopic level, coal conversion can be viewed as a progressive hydrogenation through a series shown below

Coal $\rightarrow$ preasphaltenes $\rightarrow$ asphaltenes $\rightarrow$ oils

Oils are composed of carbenes and carboids. The four classes of compounds mentioned above are arbitrarily defined by their solubility in various solvents as shown in Table 2.3. 
Table 2. 3 Definition of Primary liquids [2]

\begin{tabular}{|l|c|c|}
\hline & Soluble In & Insoluble In \\
\hline Carbenes & Carbon disulfide & n-Pentane \\
\hline Carboids & n-Hexane & Carbon disulfide \\
\hline Asphaltenes & Benzene and toluene & n-Hexane \\
\hline Preasphaltenes & Tetrahydrofuran & Benzene \\
\hline
\end{tabular}

Berkowitz [2] suggested that the overall conversion process contains both progressive and regressive reactions indicating a potential reversibility of the liquefaction reaction. The hypothesized sequence is illustrated in the Figure 2.6.

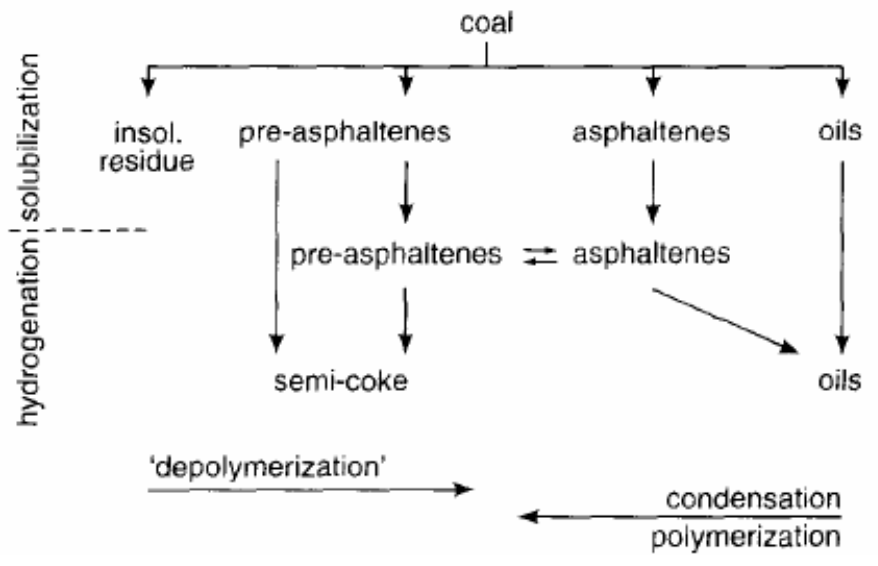

Figure 2. 6 Conceptual Reactions Sequences in Coal Liquefaction [2]

With the aid of this conceptual model, liquefaction can be viewed as a two-stage process. The first stage is coal solubilization, which depends on the nature and intensity of H-transfer reactions. The second stage is a "secondary" hydrogenation, which drives the liquefaction process towards lower molecular weight liquids [2]. 
The macromolecular complexity of coal makes the chemistry quite diverse. However, laboratory and pilot plant trials have interpreted the properties that affect conversion efficiency. These are shown in Table 2.4.

\subsubsection{The Role of the Solvent}

Physical Solubilization: The physical solvation properties of the solvent play an important role in the liquefaction phenomenon. Polar solvents that contain components such as polyaromatics, phenols, pyridines, quinolines and their derivatives are good physical solvents for coal conversion.

Table 2. 4 Fundamental Properties Important In Coal Liquefaction [2]

\begin{tabular}{|c|c|c|}
\hline Property & Influence & Desired level \\
\hline Rank & Liquid yield & Medium \\
\hline Ash content & Operations and handling & Low \\
\hline Moisture content & Thermal efficiency & Low \\
\hline Hydrogen content & $\begin{array}{l}\text { Liquids yield and hydrogen } \\
\text { consumption }\end{array}$ & High \\
\hline Oxygen content & $\begin{array}{l}\text { Gas make and hydrogen } \\
\text { consumption }\end{array}$ & Low \\
\hline Extractability $^{\mathrm{a}}$ & Liquids yield and quality & High \\
\hline Aliphatic character & Liquids yield and quality & High \\
\hline Reactive macerals $^{b}$ & Liquids yield & High \\
\hline Particle size & Operations & Fine/ very fine \\
\hline
\end{tabular}

an effect, "solubility" in potent solvents

${ }^{\mathrm{b}}$ Principally vitrinites and exinites 
Hydrogen donation from the solvent: The principal sources of hydrogen are partially hydrogenated hydrocarbons. Wiser [12] concluded that when a bond cleaves, at least three different pathways are available for product formation and that the availability of hydrogen- donors will determine the preferred path [4] (see Figure 2.7).

1. H-abstraction

2. Rearrangement and elimination

3. Addition to aromatics or polymerization of free radicals
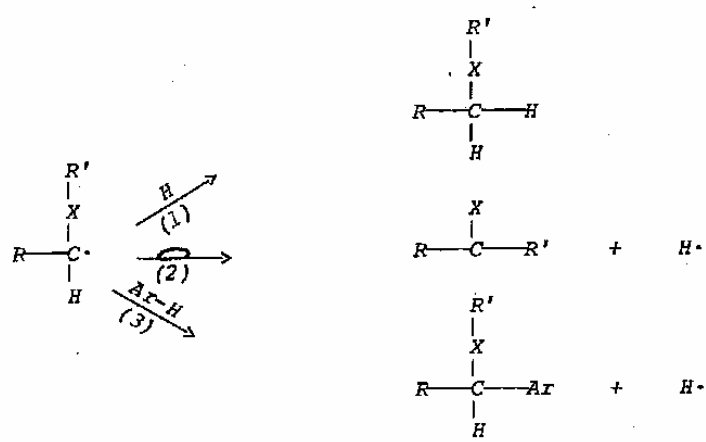

Figure 2. 7 Free Radical Mechanism showing the three different paths

The rate of coal dissolution is strongly affected by the interaction of the H-donor with insoluble intermediates by a mechanism as illustrated in Figure 2.8. This mechanism suggests that thermal bond rupture occurs first, followed by interaction of a $\mathrm{H}$-donor with the radicals that are formed. Since there is a strong tendency for bond reformation, it is not probable that two bond ruptures occur in close proximity. Therefore, the first bond rupture and $\mathrm{H}$ - donor interaction sequence is completed before the second one, etc., until product solubility is achieved.

H-Shuttling: H-donors are not the sole controlling species in coal liquefaction. Coal and solvent-refined coal also have been reported to be significant sources of hydrogen during 
coal liquefaction [13]. It has been proven that the presence of a nondonor, polyaromatic solvent such as naphthalene, can effectively provide a means of hydrogen redistribution to such an extent that over $80 \%$ of reactive macerals of coal (vitrinite) can be converted to pyridine-soluble products without the need for hydroaromatic compounds in the solvent or gaseous hydrogen.

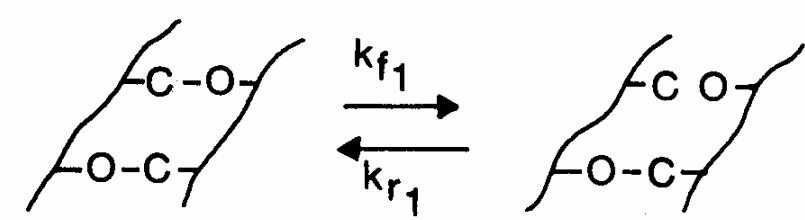

Insoluble

$$
\text { Insoluble }
$$
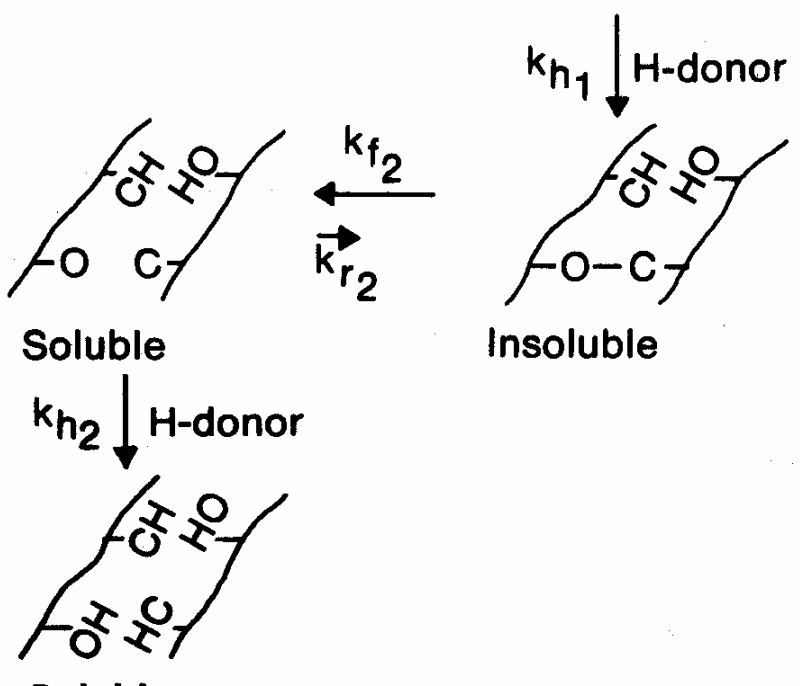

Soluble

Figure 2. 8 Speculative Mechanism to explain the dependence of coal dissolution on hydrogen-donor concentration [13]

A proposed mechanism for this hydrogen shuttling is shown in the Figure 2.9. According to this mechanism, hydrogen transfer occurs from relatively hydrogen-rich portions of the coal structure to hydrogen-lean species via hydrogenation and 
dehydrogenation of the nondonor solvent. In such a sequence, no net change would occur in the shuttler or the overall $\mathrm{H} / \mathrm{C}$ ratio, but there is an intrinsic limit on the extent to which such a reaction is useful. This is due to the reason that the quantity of labile hydrogen available from coal is very limited and is rapidly consumed. Consequently, further thermal fragmentation results in a situation where the hydrogen demand far exceeds the labile-hydrogen capacity of the coal. Further hydrogen transfer then occurs at the expense of char formation.

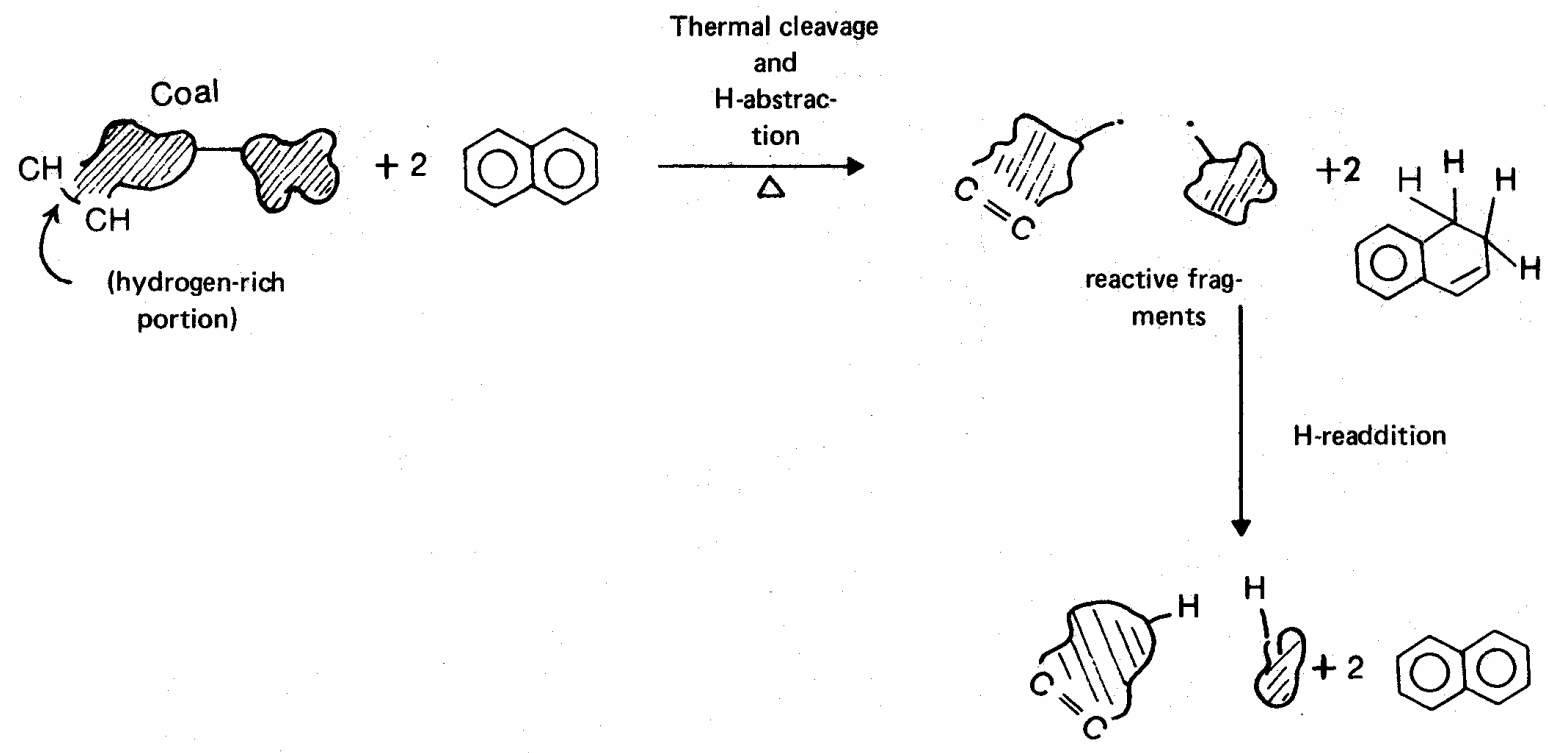

Figure 2. 9 A Possible Mechanism for H-shuttling [6]

Molecules that are not labile either for hydrogen acceptance from coal or for hydrogen abstraction by the coal fragments such as pyridine can not promote coal solubilization even at long times. Single ring aromatic compounds in general would have these limitations. Several studies have shown that the hydrogen shuttling is more efficient 
for high boiling, polycondensed aromatic ring systems. H-donors and H-shuttlers act synergically and yield an effective solvent in cases where the concentration of $\mathrm{H}$-donors is limited [6].

\subsubsection{Effect of Coal Rank on Coal Liquefaction}

Assessing the effect of coal rank on the liquefaction process is complicated as the same ranks of coals obtained from different regions are very different based on their petrographic composition. Several studies were conducted to investigate the dependence of coal rank on coal liquefaction. It was found that the yield of pyridine soluble extract passes through a maximum of approximately $83 \%$ carbon in coal (see Figure 2.10).

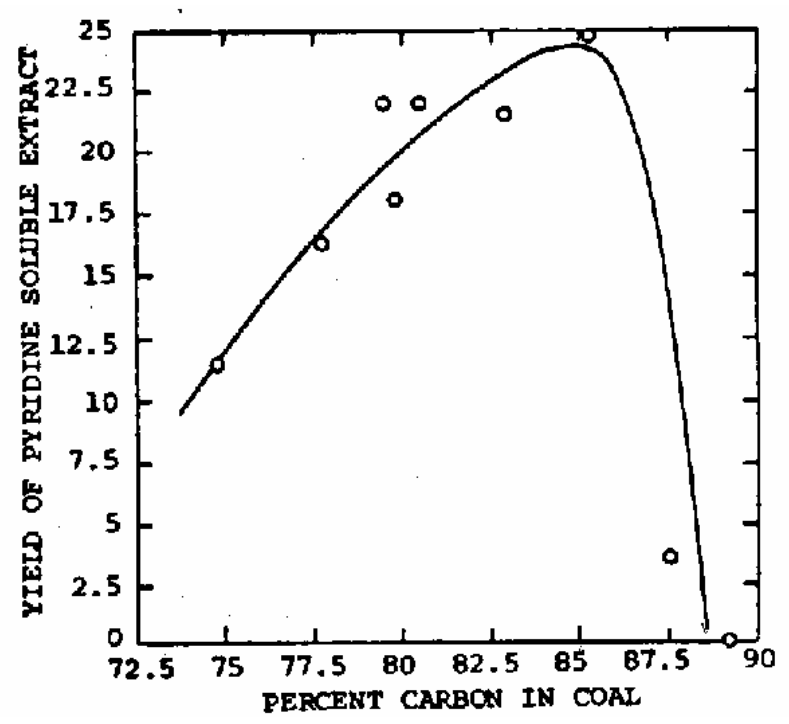

Figure 2. 10 Yield of Pyridine-soluble Extract vs. Rank of Coal (\% MAF Carbon) [4]

It can be seen from the figure that for coals with more than $88 \%$ carbon content i.e., high-rank coals, the yield decreases indicating that such coals are not suitable for liquefaction. 


\subsubsection{Hydrogen Pressure and Consumption}

During the liquefaction process, the hydrogen required can be obtained from the solvent, gaseous hydrogen or the coal itself, the hydroaromatic content of the solvent being the most effective source. Whitehurst et al. [14] showed that in situations where the presence of such hydroaromatic content is limited, gaseous $\mathrm{H}_{2}$ or coal become the dominant sources. This is illustrated in Figure 2.11 for a series of coals reacted in the presence of a solvent containing only $8.5 \%$ of tetralin for a very short time. It can be understood from the figure that hydrogen gas can be the dominant source of hydrogen for low rank coals even at short times where the demand for hydrogen is largest.

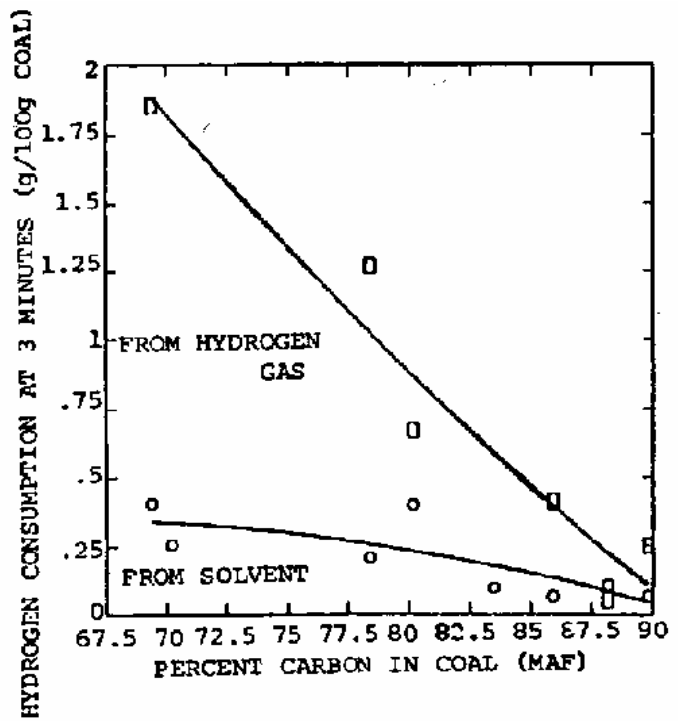

Figure 2. 11 Hydrogen consumption at short times for coals of various Ranks [14]

Weller and co-workers [15] found that when coal was extracted with tetralin at $455^{\circ} \mathrm{C}$ and 4:1 Solvent/Coal ratio, the percentage of benzene-insolubles was reduced to $13.8 \%$ with 1000 psi $\mathrm{H}_{2}$ pressure and only to $25.3 \%$ with 1000 psi $\mathrm{N}_{2}$ pressure. This shows that the conversion is greatly influenced by the presence of gaseous Hydrogen. 
Curran et al. [16] derived a relationship between coal conversion and the amount of hydrogen transferred with various donor solvents as plotted in Figure 2.12. It can be seen that the coal conversion increased with the increase in amount of hydrogen transferred. Also, less than $0.2 \%$ of hydrogen was transferred for the first $50 \%$ coal conversion and about $1.4 \%$ of hydrogen was utilized for a conversion of about $92 \%$. This indicates that even though the amount of hydrogen that can be transferred increases with the increases in the severity of the conditions, there was not an appreciable change in coal conversion. Curran et al. and Neavel [17] found that the maximum amount of coal conversion is obtained with $2.6-2.7 \%$ of hydrogen transferred.

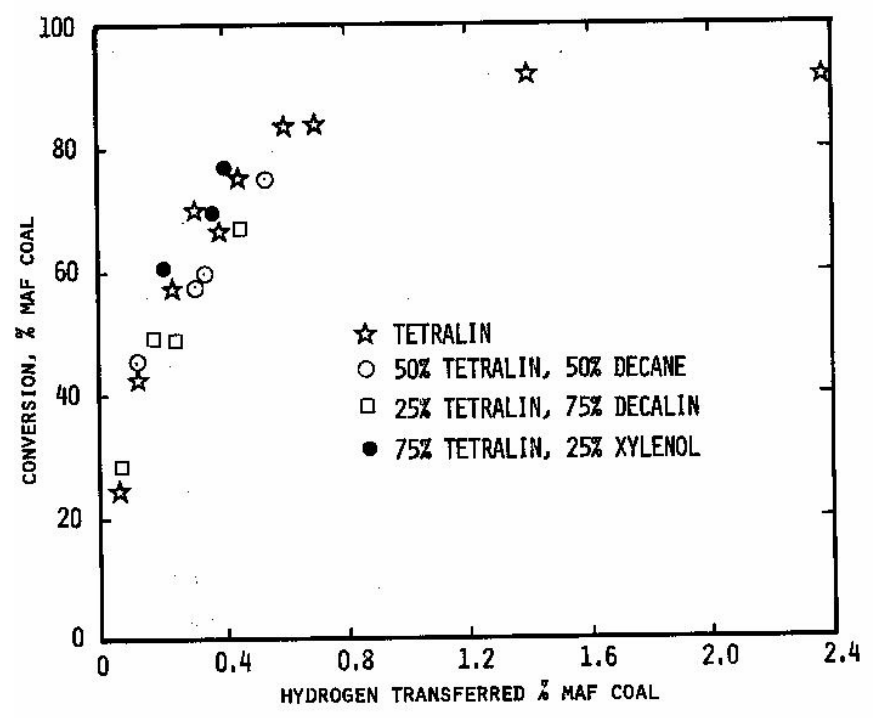

Figure 2. $12 \mathrm{Coal}$ conversion versus hydrogen transferred at $355^{\circ} \mathrm{C}$ to $440^{\circ} \mathrm{C}$

\subsubsection{Temperature and Pressure Effects}

Increasing the reaction temperature during the liquefaction process, increases the rates of coal dissolution, hydrogen consumption, heteroatom rejection and gas and char formation. It is always critical to make a balance between achieving the desired reactions 
and reducing char formation. It has been discussed previously that the hydrogen pressure is very important in the liquefaction process when the solvents used are weak H-donors. However, increasing the temperature and $\mathrm{H}_{2}$ pressure beyond a certain critical value results in no further improvement in the coal conversion.

This is illustrated by Caballero et al. [18] in the study of coal liquefaction using anthracene oil as solvent and $\mathrm{CoMo} / \mathrm{Al}_{2} \mathrm{O}_{3}$ as catalyst. The effect of temperature and pressure on the liquefaction reaction is shown in Figures 2.13 (a) and (b).

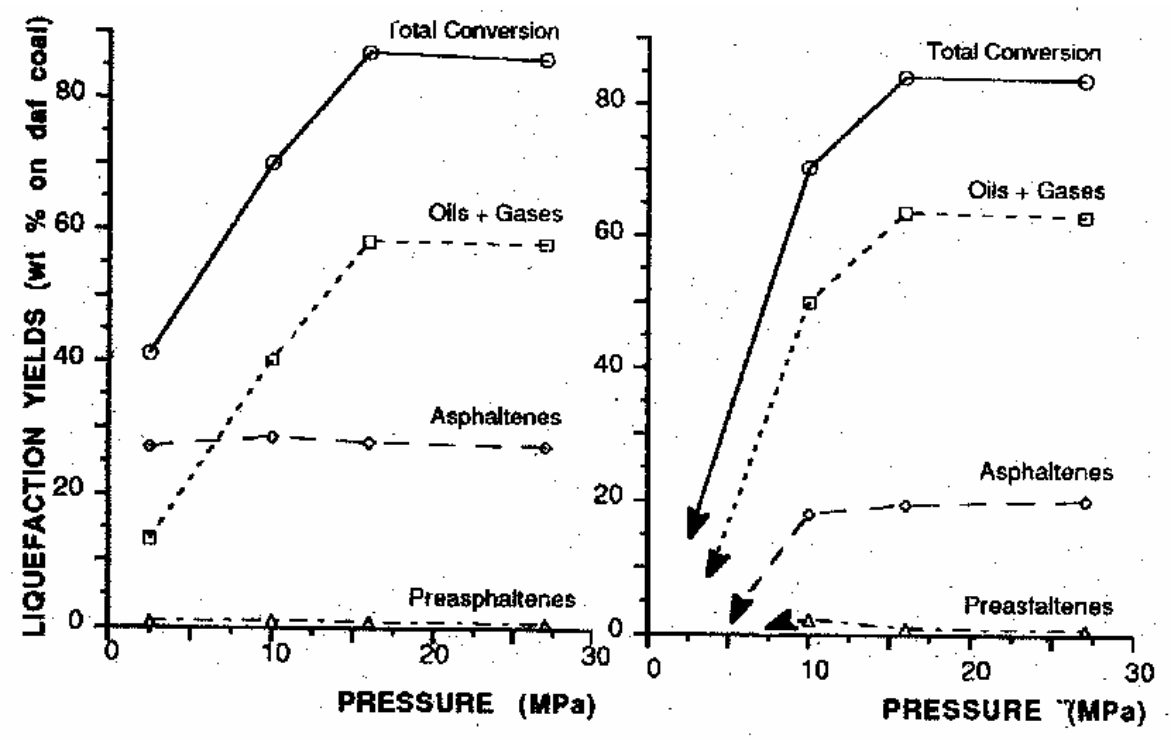

(a) at $425{ }^{\circ} \mathrm{C}$

(b) at $450{ }^{\circ} \mathrm{C}$

\section{Figure 2. 13 Influence of Pressure and Temperature on Coal hydrogenation using CoMo /Al2O3 as catalyst [15]}

Figure 2.13 (a) shows that the total conversion increases as the pressure is raised from 2.7 to $16 \mathrm{MPa}$. This shows that the solvent used in those reaction conditions does not provide enough hydrogen to stabilize the free radicals and hence the presence of hydrogen gas is necessary. When the pressure is increased beyond $16 \mathrm{MPa}$, no further increase in conversion is attained. Similar results are obtained for the reaction at $450{ }^{\circ} \mathrm{C}$ 
(Figure 2.13 (b)) but were much more pronounced than at $425{ }^{\circ} \mathrm{C}$. The reason behind this is that at $450{ }^{\circ} \mathrm{C}$, there is a greater demand for hydrogen due to stronger thermal cracking

\subsubsection{Mineral Matter in Coal}

The term "Mineral Matter (MM)" is conventionally used to mean all forms of mineral matter associated with coal. It was speculated that mineral matter helps in catalyzing coal liquefaction by enhancing the hydrogen transfer from the gas to the liquid phase. The catalytic effect of MM on the hydrogenation of model compounds has been studied by many researchers. The Germans found that addition of iron oxide to slurry feed improved coal liquefaction [19].

Whitehurst et al. [4] reported improved rates of solvent-solvent hydrogen transfer reactions when iron pyrites were used as a catalyst. For many coals, the pyrite content correlates to nearly total sulfur content present in them. The catalytic effect of mineral matter on the effect of hydrogenation was further studied using various experimental approaches like studying the reactivity of a variety of coals of similar rank and petrographic composition but of widely varying mineral matter. The mineral matter was first removed from coal by gravity separation or by chemical demineralization before coal hydrogenation. Improved rates of conversion were reported when the mineral matter was not separated. 


\subsection{Catalysts in Coal Liquefaction}

Catalysts aid in hydrogen transfer, which in turn increases the overall conversion and thus may improve the economics of the process. Previous studies carried out to determine the influence of catalysts on coal liquefaction showed that there is an intimate relationship between the catalyst and solvent effects. Direct liquefaction encompasses a number of catalytic processes and reactions. Some of them are listed below.

- Hydrogenation

- Cracking

- Hydrodesulfurization (HDS)

- Hydrodenitrogenation

A major emphasis in future development of coal liquefaction technology is on catalyst development.

The earliest catalytic hydrogenation processs was the Bergius process. Tin oxalate and tungsten sulfide catalysts were used in the liquid phase and gas phase hydrogenations respectively [20]. Wen et al. (1979) found a higher degree of hydrogenation using catalysts. However, some difficulty was noted in the catalyst selection mainly because of the following reasons:

1. Complexity of the coal structure

2. Severe reaction conditions (high temperature and high pressure) that are detrimental to the stability of the catalyst.

3. Separation of catalyst from the unconverted coal 
The selection of the catalyst has two approaches: using cheap, less active catalysts like iron sulfides and oxides, or highly active, much more expensive transition metal catalysts like molybdenum on an alumina support (Schindler, 1989). Iron catalysts have the advantage of being used as a once-through catalyst and are not toxic enough to create disposal problems. But their activity is not very high. The supported transition metal catalysts are very expensive and need to be recycled but are very active catalysts.

$\mathrm{FeS}_{2}$ (pyrite, PY) has been postulated to be one of the active forms of an iron catalyst in the liquefaction reaction. The other non-stoichiometric forms of iron sulfur compounds are collectively termed as pyrrhotites $(\mathrm{PH}), \mathrm{FeS}_{\mathrm{x}}$ with $\mathrm{x} \approx 1$. Ogawa et al. (1986) suggested that $\mathrm{PY}$ is more active than $\mathrm{PH}$ in the coal liquefaction under $\mathrm{H}_{2}$ atmosphere. With the use of transition metals like $\mathrm{Ni}$, Co and Mo as catalysts, coal conversion increased markedly [21]. A detailed study of the Ni-W sulfide system by Voorhoeve et al. [22] showed that the interaction between nickel and the $\mathrm{WS}_{2}$ matrix has an important effect on catalytic activity.

Catalysts that are used typically for hydrotreatment are oxides of Ni, Co, Mo or combinations of these oxides on a supported catalyst. These catalysts are highly active in their sulfided form and therefore they are sulfided before the hydrotreatment. It has been shown that the thermodynamically stable forms of Nickel sulfide $\left(\mathrm{Ni}_{3} \mathrm{~S}_{2}\right)$ and Cobalt sulfide $\left(\mathrm{Co}_{9} \mathrm{~S}_{8}\right)$ do not possess appreciable activity. However, a combination of Ni or Co with Mo has a high activity for the hydrotreatment reactions (Pratt et al., 1980). 


\subsection{Coal Liquefaction Processes}

Solvent Refined Coal (SRC) process, the Exxon Donor Solvent (EDS) process and the H-Coal processes are the three main coal liquefaction techniques that were proven successful because of the high amounts of desirable fuel products produced. Descriptions of these processes are given below:

\section{Solvent Refine Coal (SRC) Process:}

In this process, coal is mixed with the solvent and $\mathrm{H}_{2}$ gas, heated in a preheater and pumped to a dissolver operating at $700-740 \mathrm{~K}$. The mixture is then sent to a separator where the gases are separated from the liquid slurry. Most of the raw hydrogen gas is recycled into the process after hydrogen sulfide scrubbing. The slurry is then filtered to separate unconverted coal in the form a solid residue. The SRC solution obtained as a filtrate is then vacuum distilled to separate ash-free SRC solids and solvent, which is further separated as naphtha and process recovered solvent.

The main product of SRC is used as a fuel for industrial boilers. The main disadvantage of the process is the mechanical problems with the filters and screens that result in an inefficient solid-liquid separation. Improved filter press operation techniques or new solid-liquid separation techniques will solve this problem. The flow scheme of this process is shown in Figure 2.14

\section{Exxon Donor Solvent (EDS) Process:}

In this process, shown in Figure 2.15, the liquefaction is carried out at 700-744 K and 10.3-13.8 MPa. The products are then distilled to separate hydrocarbon gases, 
naphtha, distillates and vacuum bottoms. The heavy bottoms slurry is then separated to form an ash residue of coal mineral matter and Fuel gas in a Flexicoking process.

Make up

Hydrogen

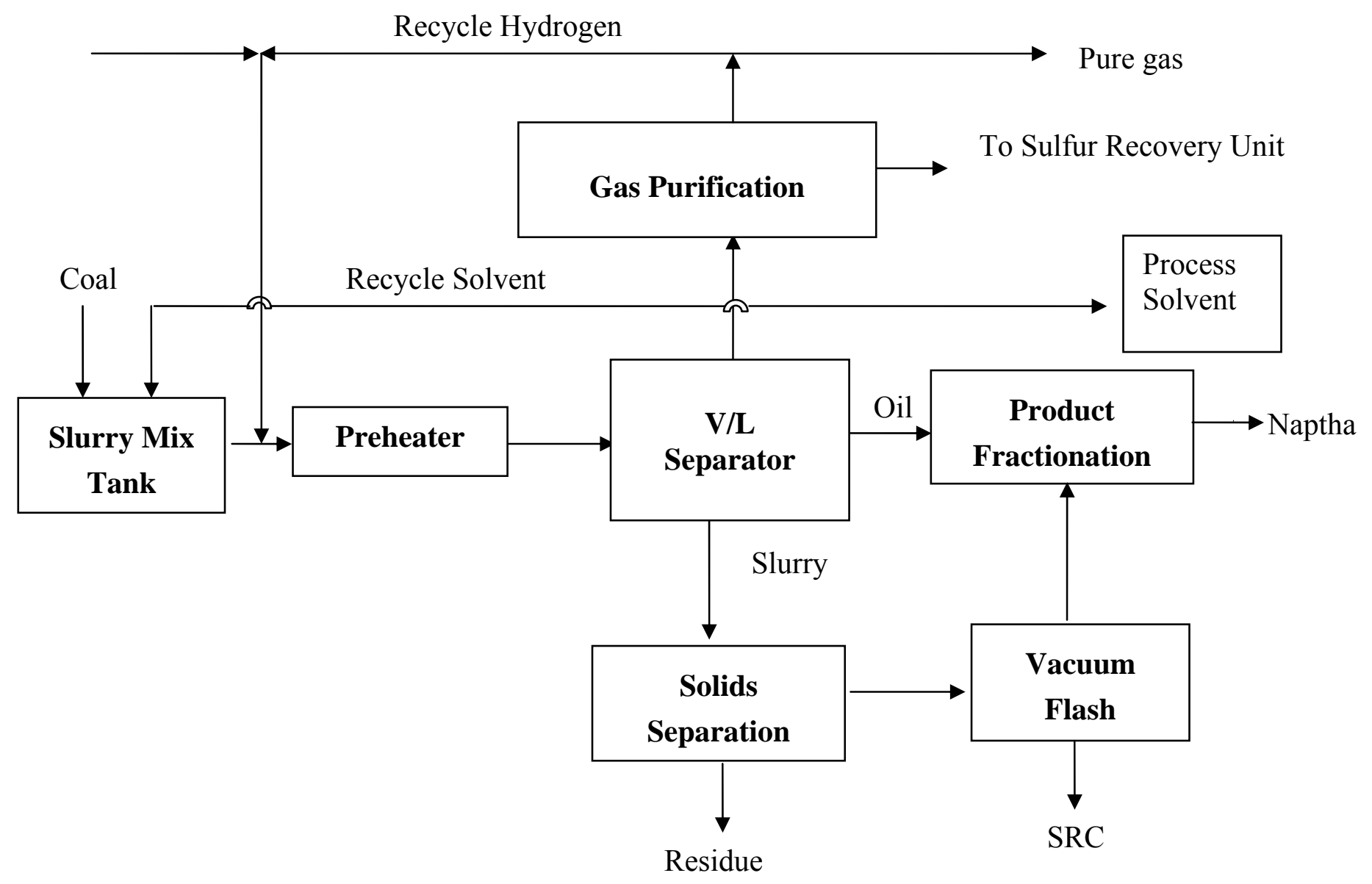

Figure 2. 14 Flow Scheme of SRC Process [21]

The gases are collected and sent to a steam-reforming unit to separate $\mathrm{H}_{2}$ gas. The liquid fuel is separated from the distillation unit as liquid products. The recovered solvent is hydrogenated and used in the process. 
In this process, the catalyst is not in direct contact with coal and hence the deactivation of the catalyst is prevented. The process incorporates a Flexicoking step that converts the residual mixture to more useful products. Also, the mechanical problems encountered in the SRC process are eliminated in this process by the use of vacuum distillation and the Flexicoking process. The main disadvantage of the process is the potential corrosion problems that may be encountered with lower rank coals containing high calcium. They form calcium carbonate during the reaction that deposits on the walls of the reactors.

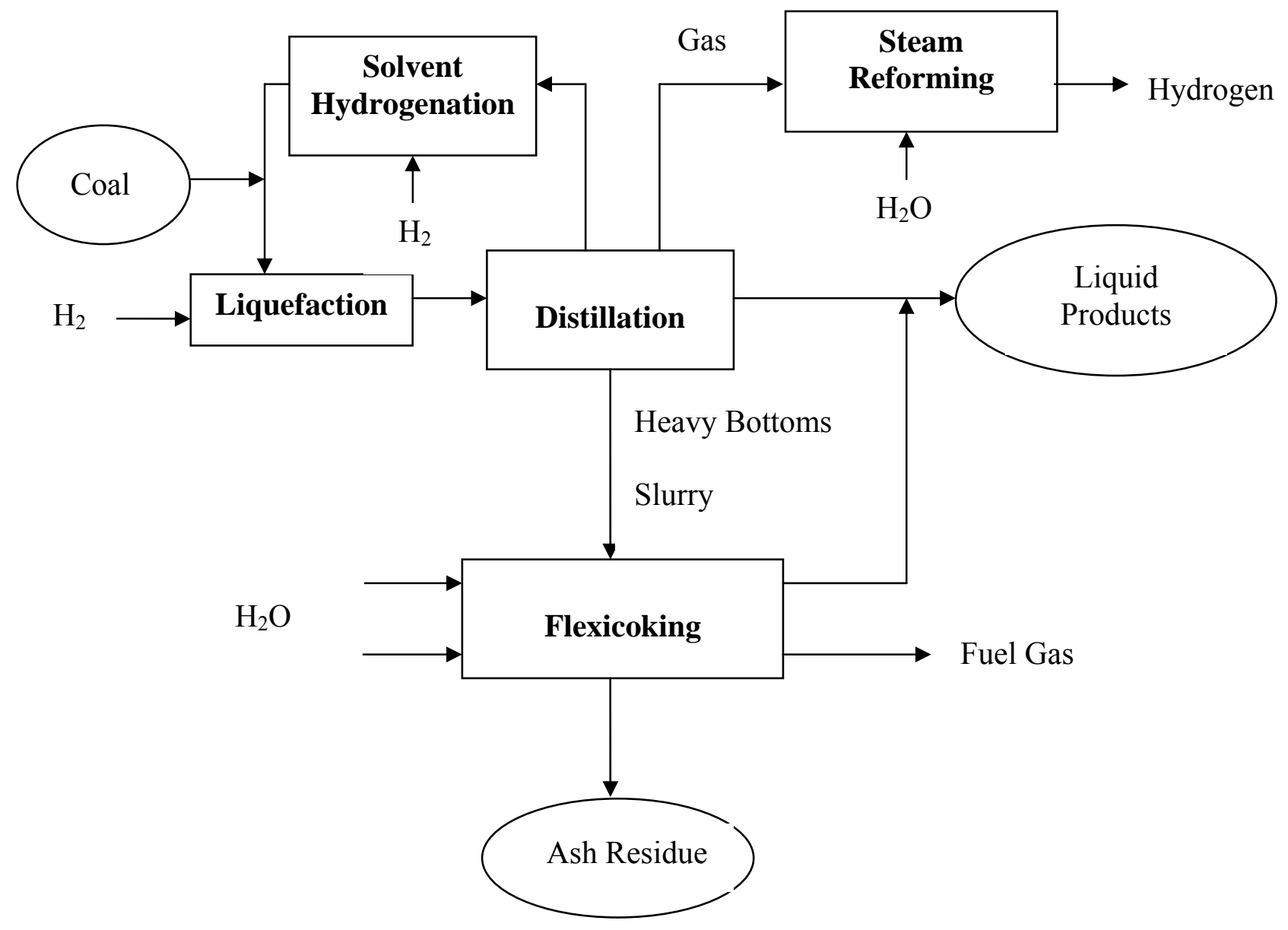

Figure 2. 15 Flow Scheme of EDS Process [22] 


\section{$\underline{\text { H- Coal Process: }}$}

In this process, shown in Figure 2.16, coal is first mixed with the solvent and then with compressed hydrogen. The mixture is then pumped to $20 \mathrm{MPa}$ and preheated to 644 $\mathrm{K}$ before it is fed to the reactor. The ebullated-bed reactor used in the process contains an internal tube for thorough recirculation of the mixture through the catalytic bed. The gas stream is scrubbed to separate the impurities such as ammonia, hydrogen sulfide etc. and the stream rich in $\mathrm{H}_{2}$ gas is recycled to the process. The liquid-solid product from the reactor is sent to a flash-separator where it is separated into lighter hydrocarbon liquids and the bottoms. These lighter hydrocarbon liquids combined with the condensate obtained directly from the reactor are collected in an atmospheric still. The bottoms are sent to a solid-liquid separator to separate the residue. The filtrate from this is then vacuum distilled to yield heavy distillates and residual fuel. The atmospheric still gives light and heavy distillate fractions.

The corrosion problems encountered in the EDS process are eliminated in this process as high-moisture and high-calcium containing coals showed no significant amount of deposition on the reactor walls. This process has an advantage of being used to produce fuel oil or syncrude by varying the severity of the process conditions. The hydrocyclones used for entrained solids separations give only two-thirds separation and hence the solid-liquid separation in this process is not so effective. 


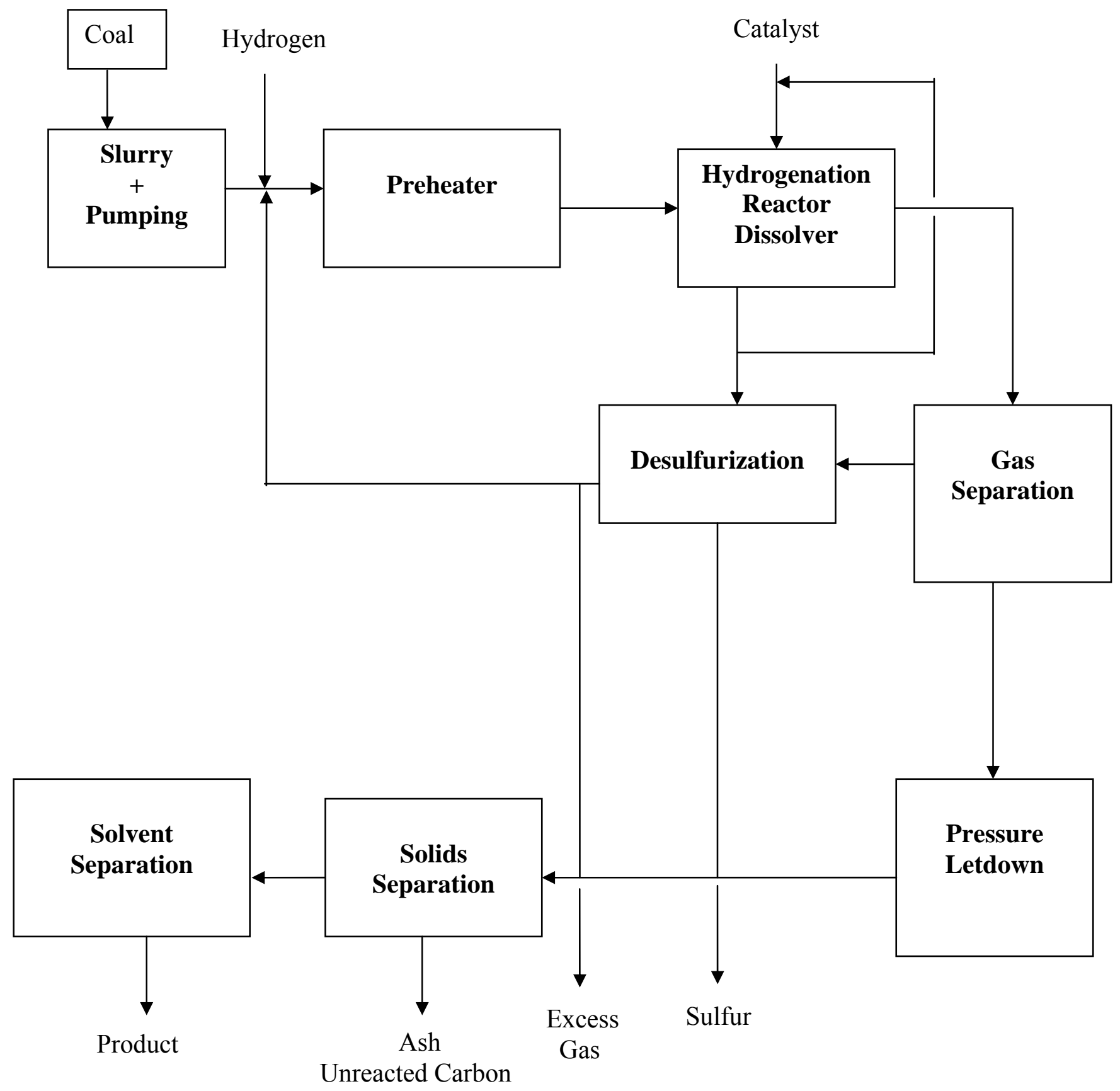

Figure 2. 16 Flow Scheme of H-Coal Process [23] 
Table 2.5 shows the comparison of the three major Liquefaction processes. It compares the operating conditions, recycle system, type of reactors and the catalysts of all the three processes.

Table 2. 5 Comparisons of Coal Liquefaction Processes [23]

\begin{tabular}{|c|c|c|c|}
\hline & SRC & EDS & H-Coal \\
\hline OPERATING CONDITIONS & & & \\
\hline Pressure, $\mathrm{MPa}$ & 10.3 & 10.3 & 12.3 \\
\hline Temperature, $\mathrm{K}$ & 724 & 722 & 726 \\
\hline Residence time, min & 40 & 40 & $30-70$ \\
\hline RECYCLE SYSTEM & $\begin{array}{c}\text { Recycle of } \\
\text { process solvent }\end{array}$ & $\begin{array}{l}\text { Recycle of } \\
\text { hydrogenated } \\
\text { solvent }\end{array}$ & $\begin{array}{l}\text { Recycle of heavy } \\
\text { distillate }\end{array}$ \\
\hline REACTOR & $\begin{array}{l}\text { Upflow } \\
\text { column reactor }\end{array}$ & $\begin{array}{l}\text { Upflow, plug } \\
\text { flow tubular } \\
\text { reactor }\end{array}$ & $\begin{array}{l}\text { Ebullated-bed } \\
\text { catalytic reactor }\end{array}$ \\
\hline CATALYST & - & $\begin{array}{l}\text { Ni-Mo for solvent } \\
\text { hydrogenation }\end{array}$ & Co-Mo or Ni-Mo \\
\hline
\end{tabular}

\subsection{Carbon Product Precursors}

\subsubsection{Pitch}

Pitch is a complex material comprised of thousands of components, mainly polyaromatic hydrocarbons and their hyrdrocyclic analogs. It is a solid at room 
temperature, but softens to a fluid at higher temperatures. Pitch can be coal and/or petroleum derived. Petroleum pitch is a residue from heat-treatment and distillation of petroleum fractions. One type of petroleum pitch can be produced as a byproduct in the catalytic cracking of crude oil. The heavy residues obtained are subjected to thermal treatment, distillation, and vacuum or steam stripping, or oxidation to produce pitch. The method of treatment determines the type of pitch produced. Pitch may also be produced as the solid substance formed by the distillation of coal-tar from recovery coke ovens. Coal is initially carbonized to produce three substances: coke, coal tar and flammable gas. Coal-tar, the condensable portion, is then distilled to remove the heavy creosote and anthracene oils. The residue after the distillation of coal tar is called coal-tar pitch.

The types of pitches known are

1. Isotropic pitch

2. Anisotropic pitch

3. Mesophase pitch

Isotropic pitches contain fine-grained structure and anisotropic pitches contain crystalline structure with large domain sizes. Mesophase is a state that contains characteristics between traditional solid and liquid phases. In this state, the molecules exhibit some amount of orientational order unlike the molecules in a typical liquid phase. Mesophase pitch hence can be defined as a complicated mixture of aromatic hydrocarbons that contains anisotropic liquid-crystalline molecules. 
Some uses of Pitch are:

1. Pitch is mainly used as a binder material to hold the coke particles together in carbon anodes, which are used in the production of aluminum by the smelting industry.

2. Pitch can be used as an impregnating material in electrode production. Pitches used for impregnation have lower softening points than the ones used for binding. The purpose of this impregnation is three-fold: to increase the wear resistance of the base material, and to increase the density and mechanical strength of the final product.

3. Pitch can be used for graphite production. By varying the impregnating and binder materials and the heat treatment conditions, a wide range of graphite materials can be produced.

4. Pitch can be used as a precursor for the production of carbon fibers. In the production of commercial carbon fibers, the pitch material is first extruded into filaments and then carbonized to convert the filaments into carbon.

5. Pitch can also be used in the production of carbon foam by controlled heating in a non-oxidizing atmosphere. These foamed materials have many useful properties such as low density and desired thermal conduction or insulation. They find applications in aerospace and other commercial industries.

6. Pitch is used in the manufacture of refractory brick material that is resistant to molten iron and slag. Pitch acts as a binder material in holding the mixtures of refractory oxides and their respective hydroxides. 
7. Pitch is used in the manufacture of anodes for Lithium Ion battery. Metal that forms an alloy with the lithium are used for the anodes in the Lithium Ion batteries. When carbon material such as pitch is added to the metals, lithium storage capacity can be increased.

\subsubsection{Coke}

Coke is a hard porous substance that is principally pure carbon derived by heating coal or heavy oil to drive off the volatile matter. Like pitch, coke is also petroleum and/or coal derived. Petroleum coke is a by-product of the oil refining process. The coke normally is derived from the heavy oil portion that contains more carbon and little hydrogen. There are two different types of coking processes followed: Delayed Coking and Fluid Coking.

Delayed Coking is the most widely used coking process in the petroleum industry. It uses heavy residual oil as a feedstock. During this process heavy residual oil is introduced into a furnace, heated to about $480^{\circ} \mathrm{C}$ and pumped into coking drums. Cracking and polymerization take place in the coke drum. The coking process initiates the formation of coke and causes it to solidify on the drum wall. This coke is further upgraded to produce specialty cokes and other valuable products. Three different carbon forms are produced using this process. They are:

1. Needle coke

2. Sponge coke

3. Shot coke 
Needle coke refers to acicular morphology of coke that forms needle like structures. Sponge coke is the amorphous and/or isotropic form of coke that is visibly porous. Shot coke is the abnormal form of coke that forms in small balls of few millimeters in diameter. Descriptions of delayed coke carbon forms are shown in Table

\section{6}

Table 2. 6 Carbon forms of Delayed Coke

\begin{tabular}{|c|l|}
\hline Type of Coke & \multicolumn{1}{|c|}{ Description } \\
\hline Needle Coke & $\begin{array}{l}\text { Ribbon like parallel ordered anisotropic } \\
\text { domains that can also occur as folded } \\
\text { structures }\end{array}$ \\
\hline Lenticular/ granular & $\begin{array}{l}\text { Lenticular anisotropic domains of various } \\
\text { sizes that are not aligned parallel to the } \\
\text { particle surface }\end{array}$ \\
\hline Mixed Layer & $\begin{array}{l}\text { Ribbon and lenticular anisotropic } \\
\text { domains of various sizes in curved and } \\
\text { irregular layered arrangements }\end{array}$ \\
\hline Sponge & $\begin{array}{l}\text { Porous microstructure with walls that are } \\
\text { generally anisotropic but with pores and } \\
\text { walls that vary in size }\end{array}$ \\
\hline
\end{tabular}

In the Fluid Coking process, a fluidized bed of hot coke particles is maintained at $500^{\circ} \mathrm{C}$. The hot coker feeds are sprayed into this hot fluidized bed, where they are cracked. During this process, the hot vapors deposit on the coke particles as thin liquid film layers. These particles grow in size by layers and are periodically removed. Descriptions of Fluid coke carbon forms can be seen in Table 2.7 
Pitch Coke is produced from the destructive distillation of coal tar pitch. Coal tar pitch is obtained as a residue during the thermal distillation of coal. It is inherently low in mineral impurities and ash as it is condensed from the vapor phase in the coke oven (as explained before). So the resulting coke from this coal tar pitch is also low in mineral impurities. Also, the Pitch-coke is low in sulfur content and is highly graphitizable.

Table 2. 7 Carbon forms of Fluid Coke

\begin{tabular}{|c|l|}
\hline Type of Coke & \multicolumn{1}{|c|}{ Description } \\
\hline Layered & $\begin{array}{l}\text { Anisotropic carbon domains aligned in } \\
\text { concentric layers parallel to the particle } \\
\text { surface similar to onion- like coke }\end{array}$ \\
\hline Non-Layered & $\begin{array}{l}\text { Anisotropic domains are not aligned to the } \\
\text { particle surface }\end{array}$ \\
\hline Aggregates & Fragments of anisotropic domains \\
\hline
\end{tabular}

The properties of coke depend on the coal feedstock and the method of coking. The microscopic texture of the coke, i.e., the optical behavior of coke in polarized light, helps in determining the end uses of coke. Many properties such as electrical resistivity, graphitizability, etc, depend on the microscopic structure. As explained in the case of pitches, isotropic cokes contain fine grained structure and anisotropic cokes contain an oriented crystalline structure. Isotropic cokes are used to produce nuclear grade graphite and anisotropic cokes are used to produce graphite electrodes and anodes.

Metallurgical Coke can be produced by carbonization of coal. It is the solid residue that is left when the coal is heated to high temperatures in the absence of air. Such 
coke is used in the steel industry for the reduction of iron ore. Cokes from coal contain 5 different carbon forms: isotropic, incipient anisotropic, circular anisotropic (granular), lenticular anisotropic (leaflet) and ribbon anisotropic (flow) 


\section{Chapter 3 EXPERIMENTAL PROCEDURE}

In this chapter, the experimental procedure is discussed in detail. The discussion includes the chemicals and gases, the experimental apparatus, the method of performing the hydrotreatment reactions and the extraction of the products. The procedures followed to characterize the final products i.e., evaluating the properties such as softening point, ash content, coking value and optical texture, are also presented.

\subsection{Liquefaction Reaction Overview}

The effectiveness of two coal-derived liquids and two catalysts in the hydrotreatment of a bituminous coal is investigated while holding the reaction conditions identical for all the runs. The temperature chosen is $400^{\circ} \mathrm{C}$, and the pressure is $500 \mathrm{psig}$ (cold) of hydrogen or nitrogen (depending on the specific reaction). The reaction time of one hour and a solvent to coal ratio of $5 / 1$ is maintained for all the runs. After the reaction is complete, the products are extracted using Tetrahydrofuran (THF) and refluxed overnight (for about 12-16 hours). This solution is first centrifuged and then filtered to separate the unconverted coal. The extract (THF soluble fraction) is roto-evaporated to remove THF from the hydrotreated coal fraction. This fraction is then vacuum distilled to recover the recycle solvent (the overheads) and the pitch (distillation bottoms product). This pitch is tested as a possible precursor for carbon products. A process flow diagram for the overall procedure is shown in Figure 3.1. 
Raw or

Catalytically

Hydrogenated

solvent

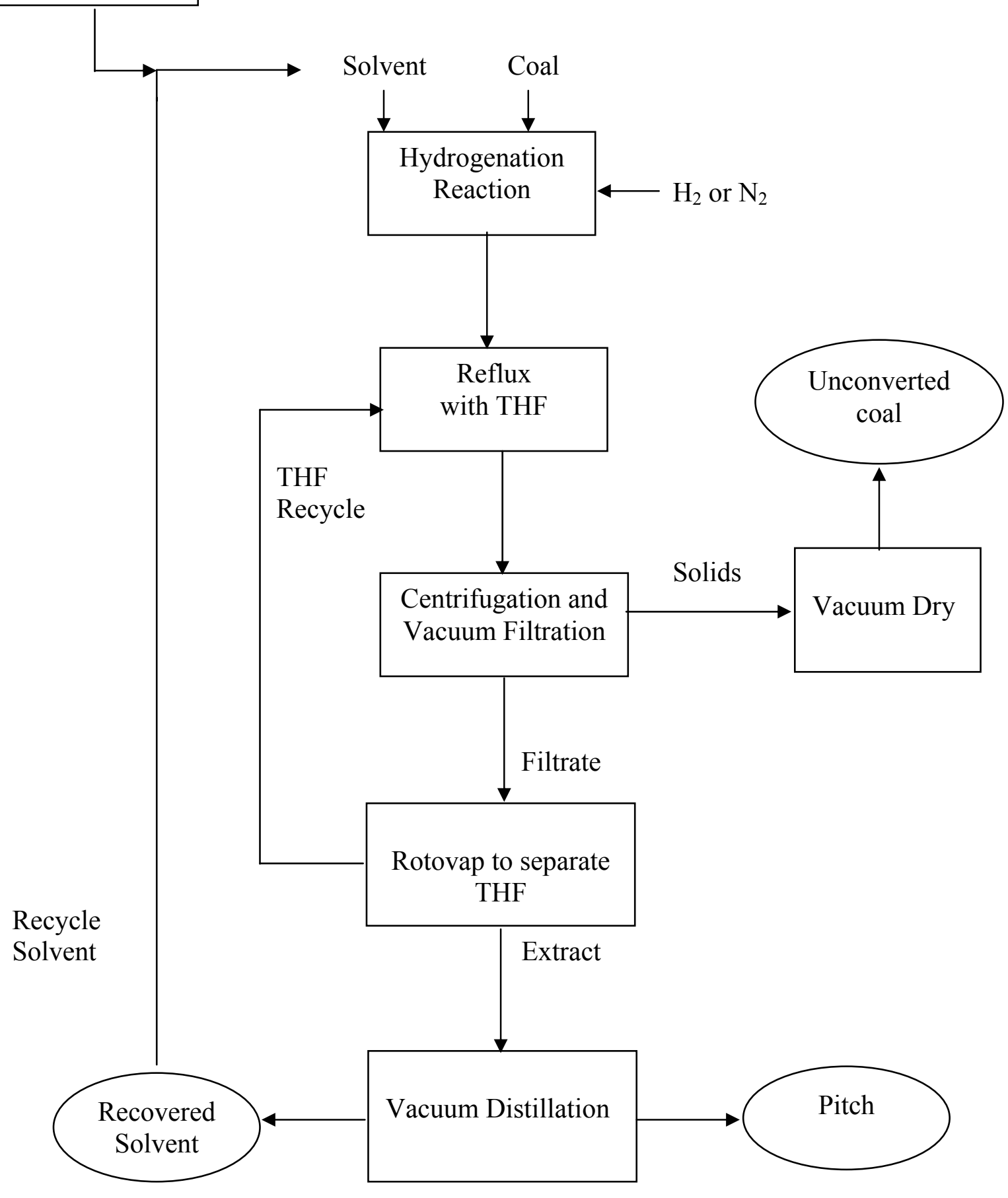

Figure 3. 1 Process Flow Sheet showing the procedure followed for hydrotreatment experiments 


\subsection{Materials}

Details about the materials used in the research are listed below:

Catalyst: $\mathrm{A} \mathrm{NiO} / \mathrm{MoO}_{3}$ catalyst supported on alumina is used in solvent hydrogenation. This is obtained from Criterion Catalyst and Technologies Corporation.

Coal: Marfork (Cedar grove seam) coal is used in the present work. The coal is dried under vacuum at a temperature of $90^{\circ} \mathrm{C}$ with a slow purge of nitrogen. The analysis of the coal is shown in Table 3.1. This coal was selected because it exhibits good yield and is easy to work with.

\section{Solvents:}

- Two coal-derived solvents were used as hydrogen donor solvents in the coal hydrotreatment reaction. They are Heavy Creosote Oil (HCO) and Carbon Black Base (CBB). These solvents are coal tar distillates and were so named because each sample was obtained at a different time from a different production run. They were supplied by Koppers Industries, Pittsburgh, PA. The elemental analysis of both samples is shown in Table 3.2

- Tetrahydrofuran (THF) was used as an extraction solvent during the work up of the products. It was obtained from Fisher Scientific, Pittsburgh, PA and is 98\% pure. ( MSDS sheets for THF are included in the Appendix B)

- Tetralin (1,2,3,4 Tetrahydronaphthalene) was used as a model hydrogen donor solvent. It is obtained at $97 \%$ purity from Aldrich Chemical Company, USA. (MSDS sheets for Tetralin are included in the Appendix B)

- Carbon disulfide $\left(\mathrm{CS}_{2}\right)$ was used in NMR analysis. It is of Spectranalyser grade with $99.9 \%$ purity and was obtained from Fisher Scientific Company. 
- Tetramethyl Silane was used in NMR analysis. It is of NMR grade with $99.9 \%$ purity and was obtained from Alfa Aeser Company.

Gases: Nitrogen and Hydrogen were used as the gaseous atmosphere for the experiments. These are obtained with $99 \%$ purity from Air Gas of West Virginia, Morgantown, WV.

Table 3. 1 Characteristics of Marfork Coal

\begin{tabular}{|c|c|}
\hline Carbon, \% & 81.05 \\
\hline Sulfur, \% & 0.85 \\
\hline Hydrogen, \% & 4.82 \\
\hline Nitrogen, \% & 1.25 \\
\hline Oxygen, \% & 12.03 \\
\hline Volatile matter, \% & 34.5 \\
\hline Ash, \% & 6 \\
\hline Inert content, \% & 26.2 \\
\hline $\mathrm{SiO}_{2}$ & 52.31 \\
\hline $\mathrm{Al}_{2} \mathrm{O}_{3}$ & 32.65 \\
$\mathrm{Fe}_{2} \mathrm{O}_{3}$ & 6.51 \\
$\mathrm{CaO}^{2}$ & 1.46 \\
\hline $\mathrm{Reflectance}$ & 1 \\
\hline
\end{tabular}


Table 3. 2 Elemental Analysis of as-received, coal-derived solvents

\begin{tabular}{|c|c|c|}
\hline Element & $\begin{array}{c}\text { Heavy Creosote Oil } \\
\text { (HCO) }\end{array}$ & $\begin{array}{c}\text { Carbon Black Base } \\
\text { (CBB) }\end{array}$ \\
\hline $\mathbf{C}$ & 92.3 & 91.6 \\
\hline $\mathbf{H}$ & 5.8 & 5.7 \\
\hline $\mathbf{N}$ & 2.8 & 1.1 \\
\hline $\mathbf{S}$ & 0.4 & 0.5 \\
\hline O (by difference) & - & 1.15 \\
\hline
\end{tabular}

\subsection{Solvent Hydrogenation}

In this research, the solvents are tested both as-received and in their hydrogenated forms as hydrogen donor solvents in the coal hydrotreatment reaction. One important aim of this research is to determine the effectiveness of two different catalysts in the solvent hydrogenation reaction. The two catalysts are: Mineral matter from coal and $\mathrm{NiO} / \mathrm{MiO}_{3}$ on alumina.

The unconverted coal from the coal hydrotreatment reaction contains most of the mineral matter associated with coal. This is termed as mineral matter (MM). This can act as a good catalyst in the hydrogenation reactions. In the fist step, Heavy Creosote Oil is hydrogenated using the unconverted coal as the catalyst. Details of this process are given in Section 3.3.1. The second catalyst $\mathrm{NiO} / \mathrm{MiO}_{3}$ was tested on the other solvent Carbon Black Base. Details of this process are shown in Section 3.3.2. 


\subsubsection{Using Mineral matter (MM) obtained from coal as a catalyst}

Solvent hydrogenation using this unconverted coal as a catalyst is carried out in the tubing bomb reactors. The procedure followed is quite similar to the hydrotreatment reaction of coal and is discussed in detail in Section 3.4. The solvent used in this study is HCO. The mineral matter (unconverted coal) is obtained from the hydrotreatment reaction of Marfork coal with the solvent HCO. The solvent and mineral matter from coal are added in the ratio of 10/1 into the reactor. The reactor is first pressure purged and then

pressurized to 500 psi (cold) with $\mathrm{H}_{2}$. The hydrogenation is then carried out by charging it into the sand bath at $450^{\circ} \mathrm{C}$. The products are extracted using Tetrahydrofuran (THF) and the mineral matter is separated using centrifugation followed by vacuum filtration. THF is separated from the hydrogenated solvent by roto-evaporation. This hydrogenated solvent is then tested with the coal to determine its effectiveness for converting coal into THF soluble products.

\subsubsection{Using $\mathrm{NiO} / \mathrm{MiO}_{3}$ supported on alumia as a catalyst}

Solvent hydrogenation using $\mathrm{NiO} / \mathrm{MoO}_{3}$ as a catalyst is carried out in a 5 gallon stirred tank reactor. The catalyst is contained in an annular basket made of $316 \mathrm{SS}$, which is placed inside the reactor. The catalyst basket consists of a screen that holds the catalyst particles. The solvent flows freely through this screen due to the motion of the agitator. A temperature controller sets the temperature and a motor connected to the Magnadrive controls the impeller speed of the agitator. The catalyst is a mixture of oxides containing $13 \mathrm{wt} \% \mathrm{Mo}$ and $3 \mathrm{wt} \% \mathrm{Ni}$. The catalyst is first sulfided in the reactor at a temperature of $210^{\circ} \mathrm{C}$ for one hour using dimethyl sulfoxide (DMSO). Once the 
sulfiding reaction is complete, the residual gases are vented from the reactor and the reactor is purged with nitrogen twice while hot.

The solvent $\mathrm{CBB}$ is first flushed through the reactor to remove any residual DMSO and then the reactor is filled with the solvent. The impeller speed is set at 1000 rpm. Hydrogenation is then carried out at $350^{\circ} \mathrm{C}$ for 1 hour using 500 psi of $\mathrm{H}_{2}$ (cold). The residual gases are vented once again and the contents are collected into one-gallon tins.

\subsection{Experimental Procedure}

\subsubsection{Reactor Preparation}

Hydrotreatment reactions on the coal are performed in $50 \mathrm{cc}$ tubing bomb microreactors (TBMR). The overall view of the reactor is shown in Figure 3.2. Two such microreactors are used for each hydrogenation run and hence each such run is performed in duplicate. The reactors are thoroughly cleaned before each use. The caps and the inside of the reactors are scoured using a cylindrical wire brush. Air is then blown down the reactor stem and the body to remove any particulates present in them. Finally a small amount of THF is run down through the stem and openings of the reactor. The reactor is then wiped using a filter paper and dried for about 10 min. in a drying oven. A small amount of copper anti-seize lubricant is applied to the threads before the end caps are tightened. The lubricant prevents the caps from seizing to the reactor body at high temperature and thus helps in the subsequent removal of the Swagelok caps. The reactor is placed in a vise and the Swagelok cap is tightened until hand tight. An extra quarter 


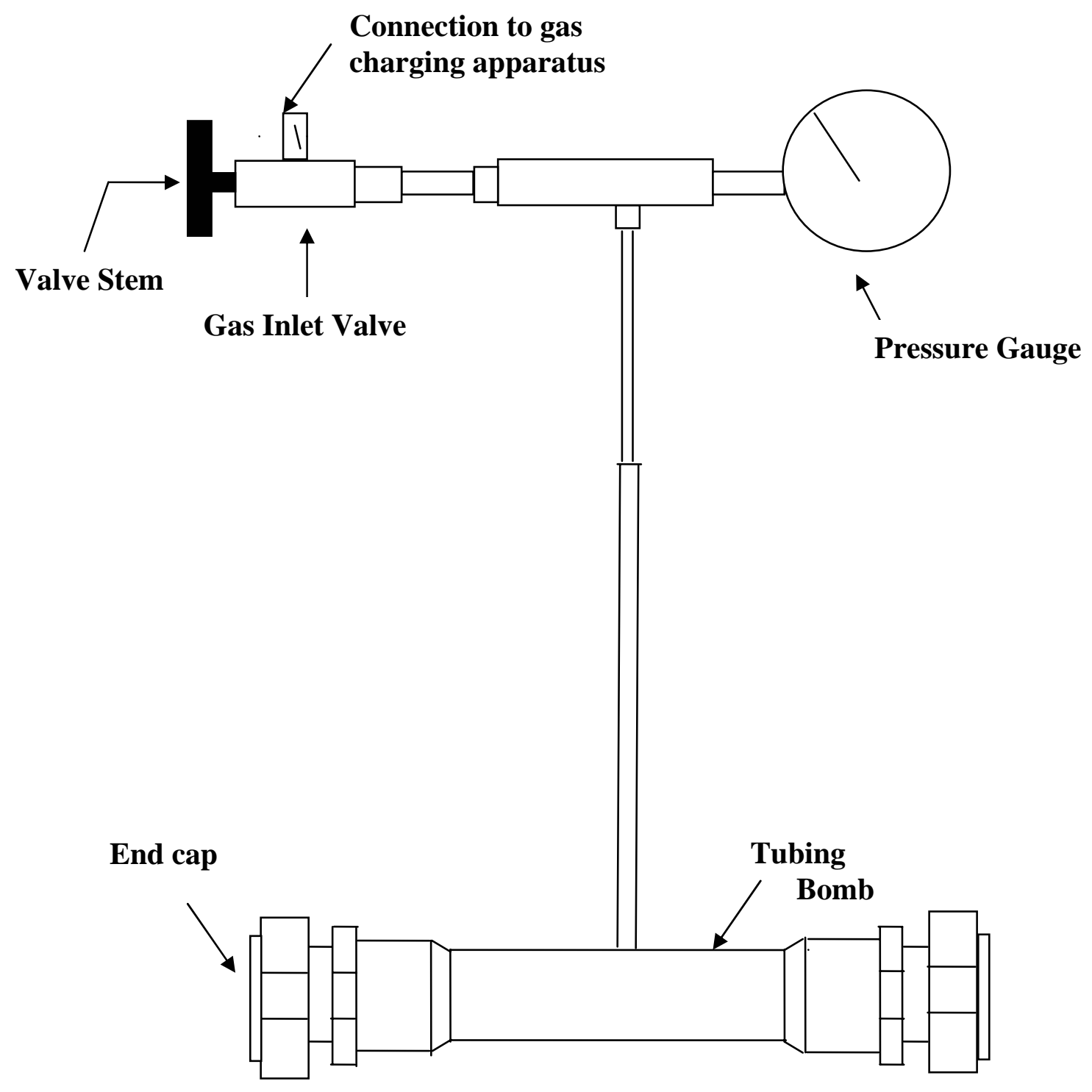

Figure 3. 2 Overall view of the $50 \mathrm{ml}$ tubing bomb microreactor 
turn is added using a wrench to seal the cap. Before charging the reactor, a leak test is done on the reactor using a nitrogen or hydrogen pressure (depending on the specific run). The reactors are pressurized to 1000 psi initially with hydrogen or nitrogen and checked for leaks by dipping them in water. Bubbles indicate the presence of a leak in the reactor. The purge valve is then slowly opened to allow the reactor to reach atmospheric pressure. If the reactor shows any leaks, the leak is either fixed or the reactor is replaced by another one.

After the leak test, one of the caps is removed and the reactants are charged into the reactor. Coal-derived solvent is added first. As the solvents are quite viscous, their mass is measured by difference. The amount of coal to be added is determined (based on solvent to coal ratio of 5/1), weighed on an analytical balance and added to the reactor. Typical amounts of solvent and coal added are 20 grams and 4 grams respectively. Ball bearings are also weighed and added to the reactor. These balls help in stirring the reactor contents when the reaction is in progress. Finally the second cap is tightened and the reactor is again checked for leaks.

\subsubsection{Reactor Purging and Gas Charging}

The hydrogenation reactions are run under either a nitrogen or hydrogen atmosphere. The presence of oxygen during the reaction is undesirable as its reaction with coal promotes cross-linking and forms large insoluble coal fragments. A gas delivery system equipped with a pressure gauge is attached to the reactor stem by a quick-connect fitting. This system is shown in Figure 3.2. It consists of a valve for gas venting purposes. This valve is connected with an adapter. The adapter is connected to 
the hydrogen cylinder tubing and the valve is kept partially open. The hydrogen cylinder valve is then opened to allow the gas flow into the reactor. The reactor is then depressurized to vent the gas present in it. This pressure purging is done three to four times to ensure near complete removal of oxygen. After pressure purging, the reactor is finally pressurized to the desired cold reaction pressure. The reactors are once again checked for leaks by dipping them in water. If no leaks are detected, the reactor preparation is complete.

\subsubsection{Agitation Mechanism}

An agitation mechanism (shown in Figure 3.3) is provided for the reactor system. A variable speed controller calibrated for different rotations per minute is used for the reactor agitation. A shaft and a holder arm are attached to this agitation mechanism. Two reactors can be supported on this holder at a time. The reactors are clamped to this arm using a holding clamp.

\subsubsection{Reaction Procedure}

The sand bath is first preheated to a temperature about $25^{\circ} \mathrm{C}$ greater than the reaction temperature. This compensates for the initial temperature drop when the reactors are charged in the sand bath reactor. The reactors are placed securely in the holder using the clamps. The preheated, fluidized sand bath is raised using a winch-and-pulley system until the reactors are completely immersed in the sand. The shaking mechanism is turned on and the speed is adjusted so that the reactors are vertically agitated at approximately $400 \mathrm{rpm}$. A drop in the temperature is noticed and when the temperature reaches a 


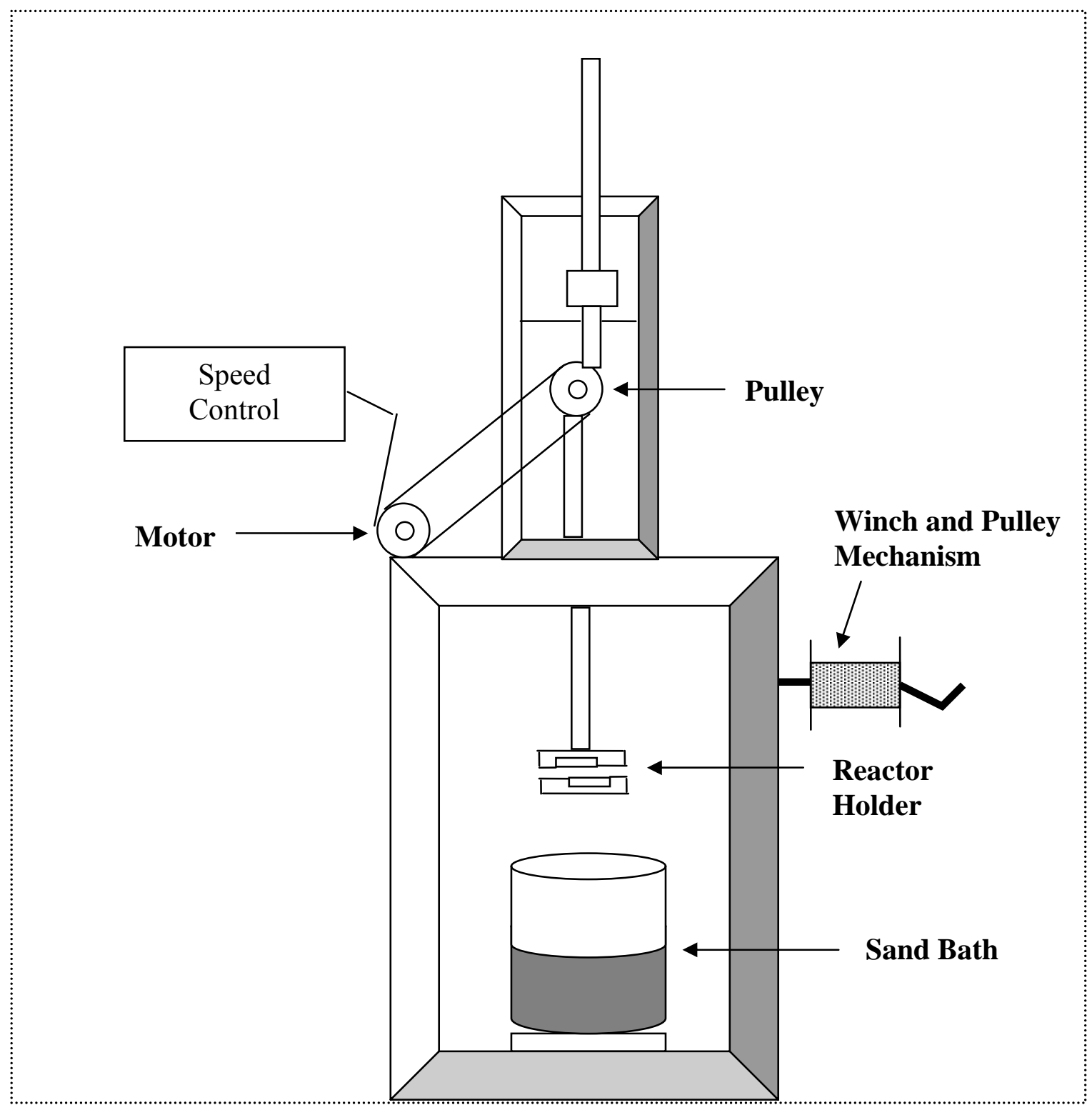

Figure 3. 3 Sand Bath Reactor with Agitation Mechanism 
Constant value during the reaction, the sand bath is set at the reaction temperature. Once the reaction time is complete, the agitator is turned off and the sand bath is lowered. The reactors are taken out from the holder and quickly quenched in a cold-water bath. The gas inlet valve is slowly opened to allow the reactor to reach atmospheric pressure by venting all the gaseous species into the hood. The gases are not collected in these experiments.

\subsubsection{Product Collection}

The products of all the reactions, after venting the residual gases, are viscous fluids interlaced with some solid particles of the unconverted coal. The contents of the reactor are emptied into a $500 \mathrm{ml}$ flat-bottomed flask. This is accomplished by first loosening the end caps of the reactor using a wrench. The contents of the reactor are allowed to drip into the flask, which has been fitted with a funnel (see Figure 3.4).

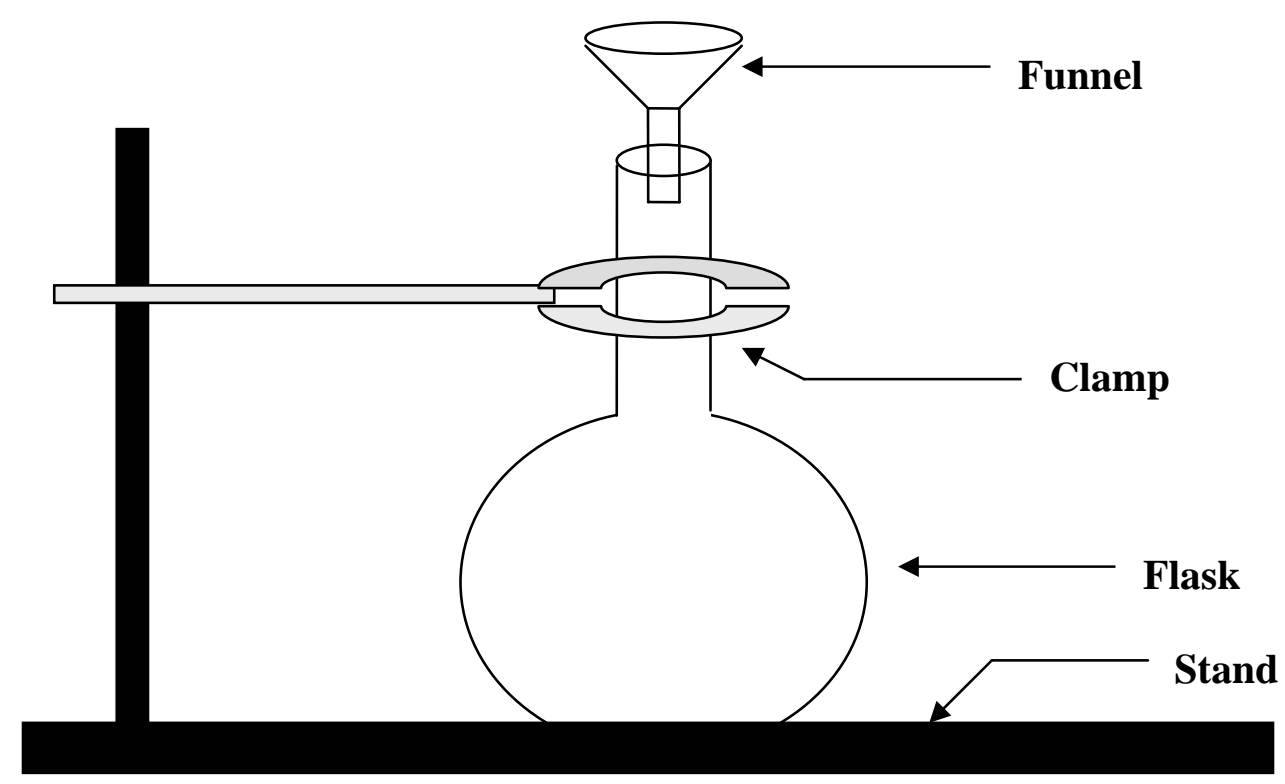

Figure 3. 4 Products collection into a flask 
A heat gun is aimed at the reactor body to help promote this process. The reactor is then turned upside down over the funnel and the other cap is also removed. The unconverted coal particles stick to the reactor and tend to remain inside the reactor. THF is used to wash (both the body and stem) these particles into the flask. The gas inlet valve is opened and THF is used to flush any matter from the stem and valve. This process is repeated several times to ensure that all the reaction mass is washed from the reactor.

\subsubsection{Separation of Unconverted Coal}

The flask containing the product mass and THF is refluxed overnight to maximize the solubilization of the products. For this purpose, the flask is placed in a heating mantle connected to a variac that helps set the temperature of the solution to $75^{\circ} \mathrm{C}$ (see Figure 3.5). The flask is connected to a water-cooled condenser. The contents of the flask are allowed to reflux overnight (usually 12-16 hours) to ensure exhaustive extraction of the soluble reaction products in THF.

The flask is then cooled to room temperature and the contents are transferred into a pre-weighed glass bottle. The glass bottle is fitted with a lid and the solids are separated from the solution by centrifugation in two stages. Initially, the contents are centrifuged for 15 minutes at $1400 \mathrm{rpm}$. The liquid portion of the centrifuged product is decanted into a Buchner-type filtering funnel that is operating under vacuum suction. The filtering funnel is fitted with a preweighed filter paper. The solid product in the glass bottle is washed with more THF and stirred so that the soluble species present in the midst of the solid particles is washed off. This is centrifuged again for about 30 min at $1400 \mathrm{rpm}$. 


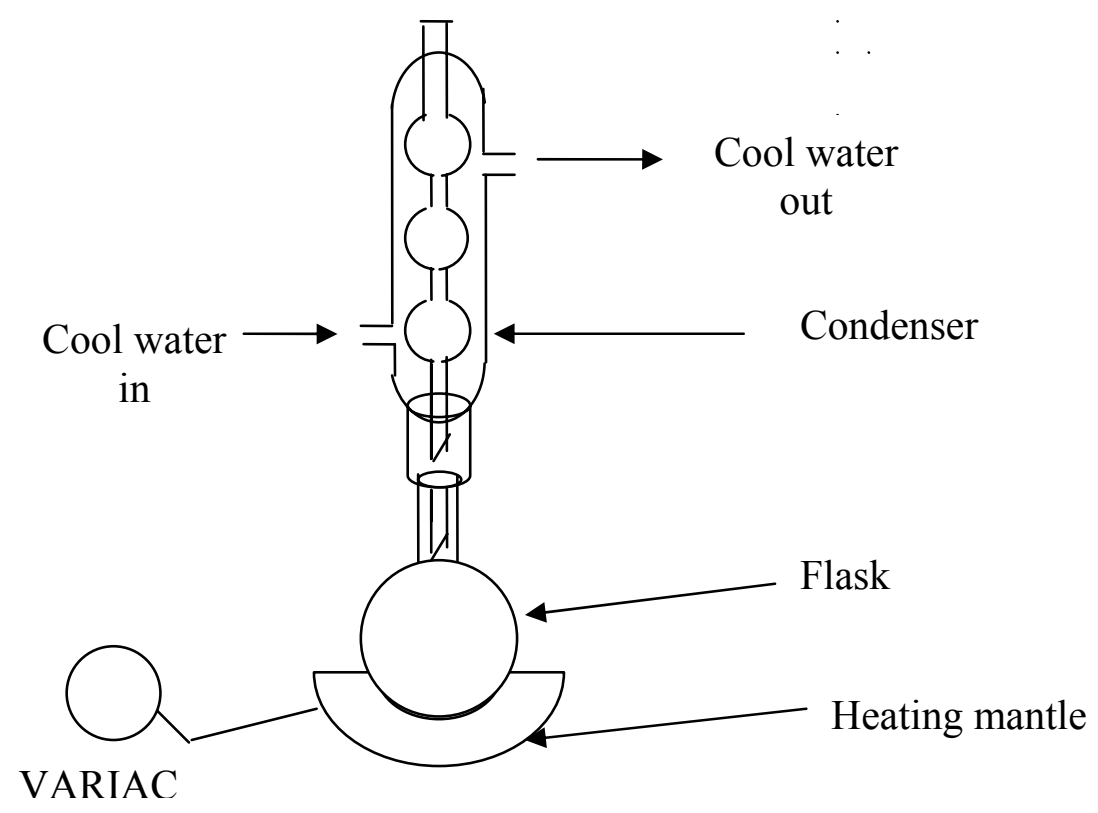

Figure 3.5 Reflux condensing Apparatus

The THF insoluble fraction accounts for the amount of unconverted coal. This residue present in the bottle and that collected on the filter paper are dried overnight in a vacuum oven at $80^{\circ} \mathrm{C}$ and $25-30 \mathrm{~mm} \mathrm{Hg}$. The amount of this THF insoluble product is weighed. The overall conversion and the coal-alone conversion are calculated using Equations 3-1 and 3-2 respectively. All the THF insoluble matter is assumed to come from the coal only and not from the added solvent, but some of the solvent may end up as a conversion product in THF solubles.

$\%$ Overall Conversion $=\frac{[(\text { Mass of Raw Coal }+ \text { Mass of Solvent })-(\text { Mass of THF Insolubles })]}{\text { Mass of Raw Coal }+ \text { Mass of Solvent }} \times 100 \quad 3-1$

$\%$ Coal - alone Conversion $(\mathrm{daf})=\frac{[(\text { Mass of Dry Coal })-(\text { Mass of THF Insolubles })]}{\text { Mass of Coal }(\text { daf })} \times 100$ 


\subsubsection{Products Isolation}

The filtrate is transferred into a pre-weighed $250 \mathrm{ml}$ round bottomed flask. The THF from this fraction is separated by rotary evaporation. The resulting hydrogenation products are further separated using vacuum distillation. The experimental setup for vacuum distillation is shown in Figure 3.6. The flask containing the product mixture is placed on a heating mantle and connected to the distillation apparatus.

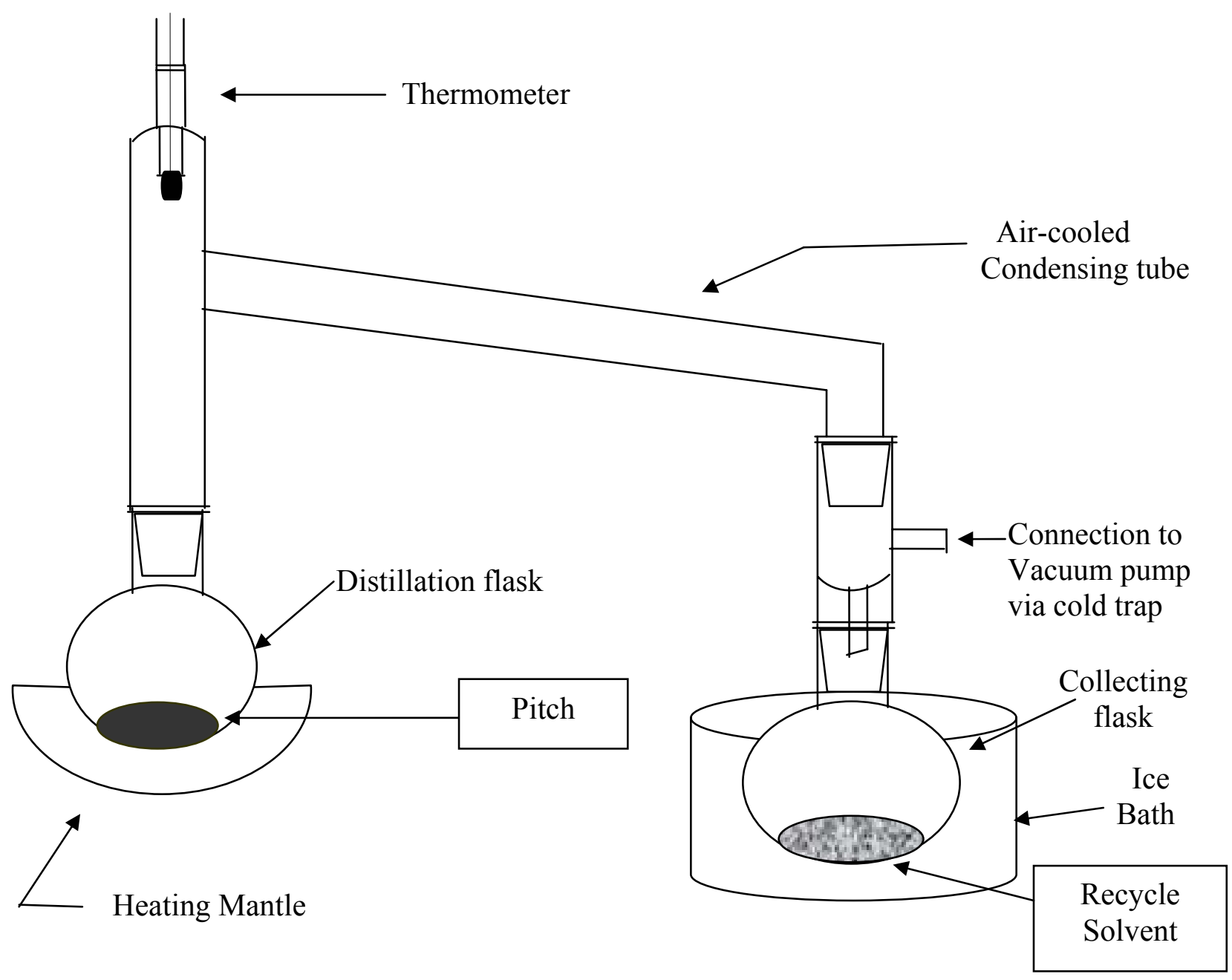

Figure 3. 6 Vacuum Distillation Apparatus for the collection of light products and the isolation of the heavy products 
The distillation apparatus consists of a distillation head, a condensing tube and a fitting, which connects to a vacuum pump. When the heat is turned on, the lower boiling solvent will begin to evaporate. This then condenses in the condensing tube and is collected in the flask. Distillation is carried till $80 \%-85 \%$ of the solvent is recovered. In all cases this is achieved when the temperature of the bottoms residue reaches around $200^{\circ} \mathrm{C}-220^{\circ} \mathrm{C}$. The distillation process takes approximately about $15-20$ minutes. The amounts of the residue from the vacuum distillation (pitch) and the distillate (recycle solvent) are measured.

A cold trap is used between the distillation unit and the vacuum pump to collect any vapors leaving the system. The cold trap contains a dry ice trap placed in a dry ice and acetone bath. The vapors are condensed in the collector tube and removed after each run. If these vapors enter the pump, the pump oil is contaminated and the efficiency of the pump will be reduced.

\subsection{Characterization of Hydrotreatment Products}

Certain standard analyses are used to evaluate the properties of the coal extract pitches (i.e. high-boiling distillate bottom product) collected from the hydrogenation reactions as possible precursors for carbon materials. These evaluation tests include softening point, coke yield, ash content, optical examination of the cokes produced from its pitch, and elemental analysis.

\subsubsection{Softening Point}

The softening point is a measure of the ability of the sample to flow at a given 
temperature. The softening point also gives an indication of possible applications such as binder pitch, impregnation pitch, and pitch for fiber spinning.

The softening point of the pitch product is determined by the dropping cell method using ASTM D3104. A Mettler FP80HT central processor and a Mettler FP83HT dropping cell are used for this purpose. The sample holder is filled with a molten sample which is allowed to cool in the sample holder. The sample holder is then placed into the dropping cell and an automatic programmer is used to set the heating rate and temperature range. A heating rate of $2^{\circ} \mathrm{C} / \mathrm{min}$ and a temperature range of about $70-200^{\circ} \mathrm{C}$ are typically used. The softening point, in ${ }^{\circ} \mathrm{C}$, is then determined as the temperature at which the sample, suspended in a cylindrical cup with a $1 / 4$ inch hole in the bottom, flows downward for a distance of 0.8 inches to break a light beam passing below the sample holder.

\subsubsection{Coking Value}

Coking Value gives an indication of the pitch's relative coke forming tendency and gives the amount of non- volatile matter present in the sample.

The coking value is determined using the West Virginia University (WVU) method. The sample is placed in a pre-weighed porcelain crucible, which is then immersed in a bed of coke breeze inside a larger crucible. The coke breeze prevents oxygen from entering the sample during coking. The sample is then introduced into Fisher Scientific Isotemp Programmable Furnace Model 497 where it is heated to $600^{\circ} \mathrm{C}$ at a rate of $5^{\circ} \mathrm{C} / \mathrm{min}$ in the first two hours and then cooled at a rate of $10{ }^{\circ} \mathrm{C} / \mathrm{min}$ until it reaches room 
temperature. The long heating time allows the characteristic domains of the sample to develop more fully. The crucible is then taken out, weighed again and the amount of residue left after the heating is determined. The coking value is calculated using Equation 3-3.

$$
\text { Coking Value, } \%=\left(\frac{\text { Mass of Residue After Heating }}{\text { Mass of Original Sample }}\right) \times 100 \quad 3-3
$$

\subsubsection{Ash Content}

Ash is the material remaining after the carbon of a sample is completely burned in air. It is the inorganic oxides of the mineral matter, which were present in the original coal.

The ash content determination is carried out in a Fisher Scientific Isotemp Programmable Furnace Model 497 and the method followed is specified by ASTM D2415 [3]. The sample is placed in a pre-weighed, partially covered crucible. It is heated in the furnace first at a rate of $5{ }^{\circ} \mathrm{C} / \mathrm{min}$ until the furnace reaches $500{ }^{\circ} \mathrm{C}$ in air and then at a rate of $3{ }^{\circ} \mathrm{C} / \mathrm{min}$ until the temperature reaches $750{ }^{\circ} \mathrm{C}$. It is held at $750{ }^{\circ} \mathrm{C}$ for three hours. The sample is cooled at a rate of $10{ }^{\circ} \mathrm{C} / \mathrm{min}$ to ambient temperature. The crucible is weighed again to determine the amount of ash remaining.

Ash content is calculated from Equation 3-4.

$$
\text { Ash Content, } \%=\left(\frac{\text { Mass of Residual Ash }}{\text { Mass of Original Sample }}\right) \times 100 \quad 3-4
$$




\subsubsection{Optical Texture}

The optical texture of the coke sample suggests its possible end uses. The texture of a coke can be either isotropic or anisotropic. Elongated domains indicate anisotropic nature and the absence of such domains indicates istropic nature. It also reveals any graphitization properties of the sample.

The optical texture of the sample is determined by means of a polarized-light optical microscope (Zeiss Axiostop, West Germany). The coke sample produced previously is embedded in epoxy resin and its cross section is polished on a Buchler Ltd. Metallurgical Apparatus with different textured abrasives. The sample is then observed under the Zeiss polarized-light microscope and optical texture is determined. A camera mounted on the polarized-light microscope is used to photograph the optical textures.

\subsubsection{Elemental Analysis}

Elemental analysis is performed on coal, mineral matter, pitches, solvents, hydrogenated solvents and recycled solvents. An elemental carbon balance can then be performed for different hydrotreatment reactions.

A Flash EA 1112 series elemental analyzer from Thermo Quest is used for the analysis (see Figure 3.7). It consists of two sections: the analytical section and the control section. The analytical section is comprised of two furnaces, a thermal conductivity detector, separation columns, adsorption filters, specific reactors required by each configuration, and an auto-sampler. The control section consists of the pneumatic and the electronic compartments. The status of the instrument is monitored through a 
synoptic panel, located on the front of the main unit. The instrument is fully controlled by a computer through a dedicated software program.

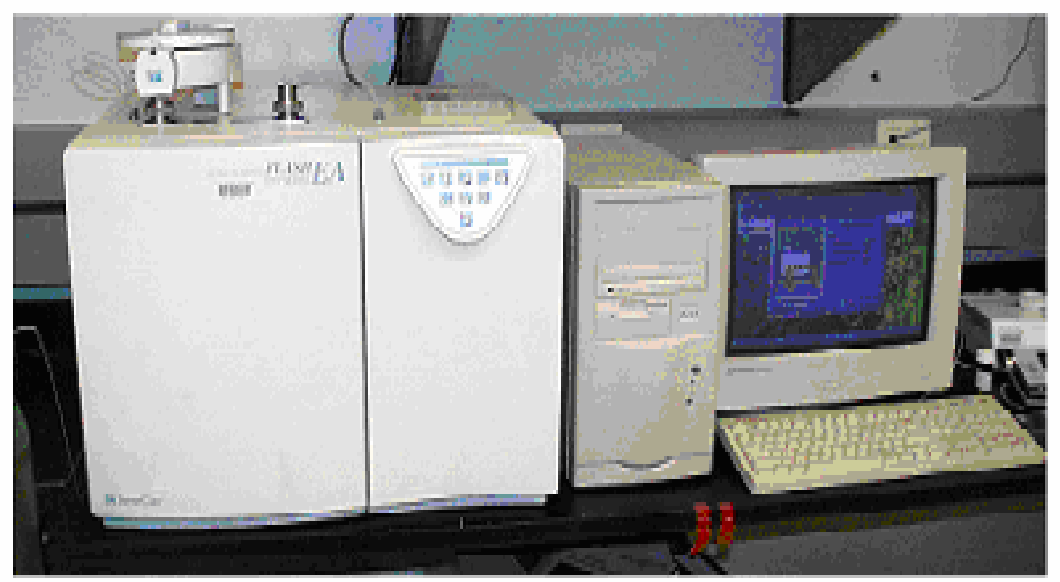

Figure 3. 7 Elemental Analyzer -Flash EA 1112 Series

A small amount of sample (1-3 mg) is carefully weighed and placed in a small pre-weighed aluminium foil container. A small amount of Vanadium pentoxide (3-5 $\mathrm{mg}$ ), which serves as an oxidizing agent and helps in complete combustion of the sample is added to this tin container. The tin container is closed and in the process all the air present in the container evacuated and its mass (container + sample) is recorded. The sample is then introduced into the autosampler from where it is dropped into the combustion reactor. The sample is converted into carbon dioxide, water, nitrogen oxides, and sulfur oxides. In the next step, these gases are then passed into a gas chromatographic column, where they are separated and detected by a thermal conductivity detector to give the percentages of nitrogen, carbon, hydrogen, and sulfur in 
the original sample. Percentage oxygen is usually determined by difference. The unit is frequently calibrated by means of a standard of known chemical composition.

\subsubsection{Nuclear Magnetic Resonance (NMR)}

Fresh, recovered and hydrogenated solvents are analyzed to determine the ratio of aromatic to aliphatic hydrogen content using an NMR Spectrometer. Basic Proton NMR is conducted using a Varian EM-360 NMR spectrometer (see Figure 3.8). This instrument helps in the determination of the structural composition of liquids and soluble

chemical compounds, e.g. the aromatic to aliphatic hydrogen ratio of solvent mixtures in this case.

\section{Description:}

In the continuous NMR spectrometers, the sample to be analyzed is placed in a magnetic field and irradiated by a radio frequency signal. The spectrum is then generated by sweeping a small change in the magnetic field over the sample. The instrument used in this case can be divided into two units: the Magnet assembly and the EFT-60 Spectrometer. The magnet assembly is housed in a separate unit. The magnet provides field strength of $14.092 \mathrm{KG}$ and a corresponding field frequency of $60 \mathrm{MHz}$ is used. This EFT-60 Spectrometer is manufactured by Anasazi. The data acquisition system and data interpretation are handled by a dedicated software program, also provided by Anasazi Instruments. The EFT-60 spectrometer uses the magnet from the Varian EM-360 spectrometer and the software program to obtain proton NMR spectra. 


\section{Sample Preparation:}

The samples are prepared in long, thin glass tubes. The sample to be tested is first introduced in the tube (about 4-6 drops) and dissolved in a solvent (Carbon Disulfide $\left(\mathrm{CS}_{2}\right)$ in this case) up to three quarters full. A very small amount of Tetramethyl Silane (TMS) is added to this $\mathrm{CS}_{2}$ dissolved sample. TMS helps zeroing the instrument during the analysis. Once the sample is prepared, the glass tube is sealed properly by coating with a thin epoxy layer. It is then inserted in the magnet and the spectrum is initiated.

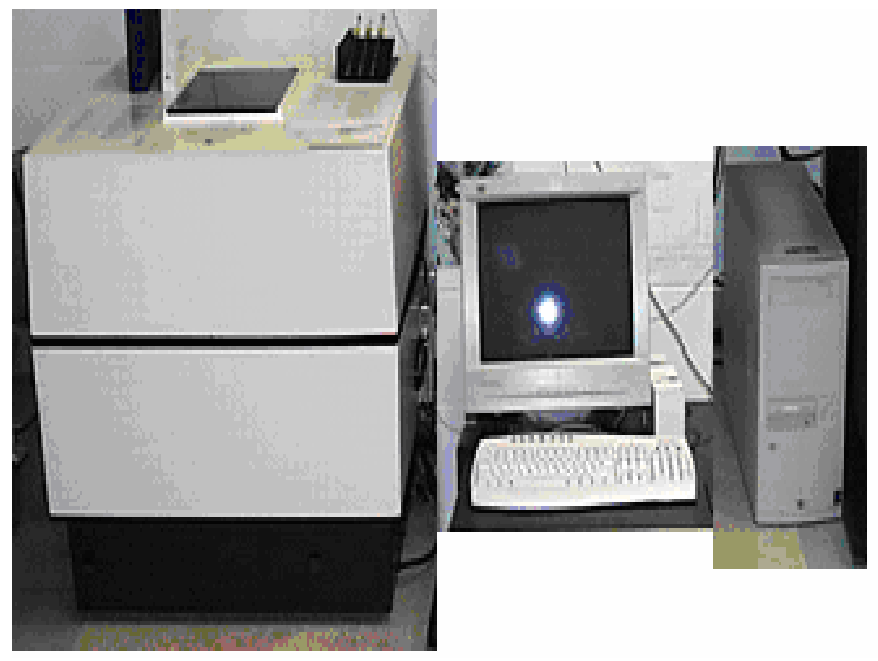

Figure 3. 8 Nuclear Magnetic Resonance (NMR) Spectrometer 


\section{Chapter 4 RESULTS AND DISCUSSION}

In this chapter, the results of coal conversion using mild hydrotreatment, performed with the two as- received coal-derived solvents HCO (Heavy Creosote Oil) and CBB (Carbon Black Base), their hydrogenated forms, and the recovered forms are discussed. The five main goals of this research are:

1. To determine the effectiveness of the two solvents in the coal hydrotreatment reaction.

2. To determine the effectiveness of the hydrotreatment reaction residue (unconverted coal) and $\mathrm{NiO} / \mathrm{MiO}_{3}$ as catalysts in the solvent hydrogenation.

3. To determine the effectiveness of the hydrogenated forms of both the solvents in the coal hydrotreatment reaction.

4. To study the effectiveness of recycled solvent as a hydrogen donor solvent in the coal hydrotreatment reaction.

5. To assess the converted coal product for use as a pitch or coke feedstock.

Reaction conditions are kept identical for all the coal liquefaction runs and are listed below.

\section{Reaction Conditions}

- Temperature $\quad-400^{\circ} \mathrm{C}$

- Pressure $\left(\mathrm{N}_{2}\right.$ or $\left.\mathrm{H}_{2}\right) \quad$ - 500 psig (cold)

- Solvent-to-Coal ratio - 5/1

- Reaction time $\quad-1$ hour 
The reasons for using the above conditions are as follows:

- When three different temperatures of $350^{\circ} \mathrm{C}, 400^{\circ} \mathrm{C}$ and $450^{\circ} \mathrm{C}$ were used in the coal hydrotreatment, the temperature of $400^{\circ} \mathrm{C}$ was found to be optimum with highest conversion (results will be shown later in this chapter).

- The high solvent-to-coal ratio has the advantage of producing more recovered solvent, which can be further used to study the effectiveness of these recycled solvents as potential hydrogen donor solvents for the coal hydrotreatment reactions.

Solvents are then characterized on their ability to convert coal into THF solubles. The effectiveness is measured in terms of overall conversion and coal-alone conversion given by Equations 3.1 and 3.2 respectively. The main difference between these two calculations is that the overall conversion takes into account the coal and the solvent, while the coal-alone basis takes into account only the conversion of the coal.

The effect of temperature on solvent CBB (fresh and hydrogenated) was studied by varying the reaction base-case temperature of $400^{\circ} \mathrm{C}$ by $\pm 50^{\circ} \mathrm{C}$. The effect of the reaction atmosphere was also studied by conducting the same hydrotreatment reaction in both $\mathrm{N}_{2}$ and $\mathrm{H}_{2}$ atmospheres, keeping all other reaction conditions identical. Also, the effectiveness of the recovered hydrogenated CBB solvent for use as a hydrogenation solvent in hydrotreatment of coal is discussed. Finally, ash content, coke yield, softening point and optical texture of the recovered hydrogenation pitch products from all the reactions are discussed. 


\subsection{Solvent Hydrogenation}

The pressure profiles of solvent hydrogenation of Carbon Black Base (CBB) and Heavy Creosote Oil (HCO) are shown in Figures 4.1 and 4.2 respectively. The solvent $\mathrm{CBB}$ was hydrogenated at $350^{\circ} \mathrm{C}$ and 500 psig (cold) pressure using $\mathrm{NiO} / \mathrm{MiO}_{3}$ as the catalyst. The solvent $\mathrm{HCO}$ was hydrogenated at $400^{\circ} \mathrm{C}$ and $500 \mathrm{psig}$ (cold) pressure using the unconverted coal residue as the catalyst. The unconverted coal used as the catalyst was obtained from the hydrotreatment reaction of coal with the same solvent HCO. As can be seen from Figures 4.1 and 4.2, there is a difference in initial and final cold pressures of hydrogen (i.e. the first and last data points in the figure) indicating the consumption of hydrogen by the solvent during the process. The drop in pressure is much more significant for the solvent $\mathrm{CBB}$ than that for $\mathrm{HCO}$ even though $\mathrm{HCO}$ was hydrogenated at a slightly higher temperature than the solvent $\mathrm{CBB}$. The less significant decrease in hydrogen pressure for the case of $\mathrm{HCO}$ indicates that either the unconverted coal is not an effective catalyst in solvent hydrogenation reaction or $\mathrm{HCO}$ is not as amenable to hydrogenation as CBB. This was further confirmed when the hydrogenated HCO solvent gave only a slight increase in coal conversion during the hydrotreatment reactions. The amount of hydrogen that is consumed in the solvent hydrotreatment process can be calculated using the ideal gas equation. The number of moles of moles of hydrogen consumed is first calculated using the Ideal Gas equation (Equation 4.1) using the difference in the initial and final pressures.

$$
\mathrm{n}_{1}-\mathrm{n}_{2}=\left(\mathrm{P}_{1}-\mathrm{P}_{2}\right) \mathrm{V} / \mathrm{R} \mathrm{T}
$$




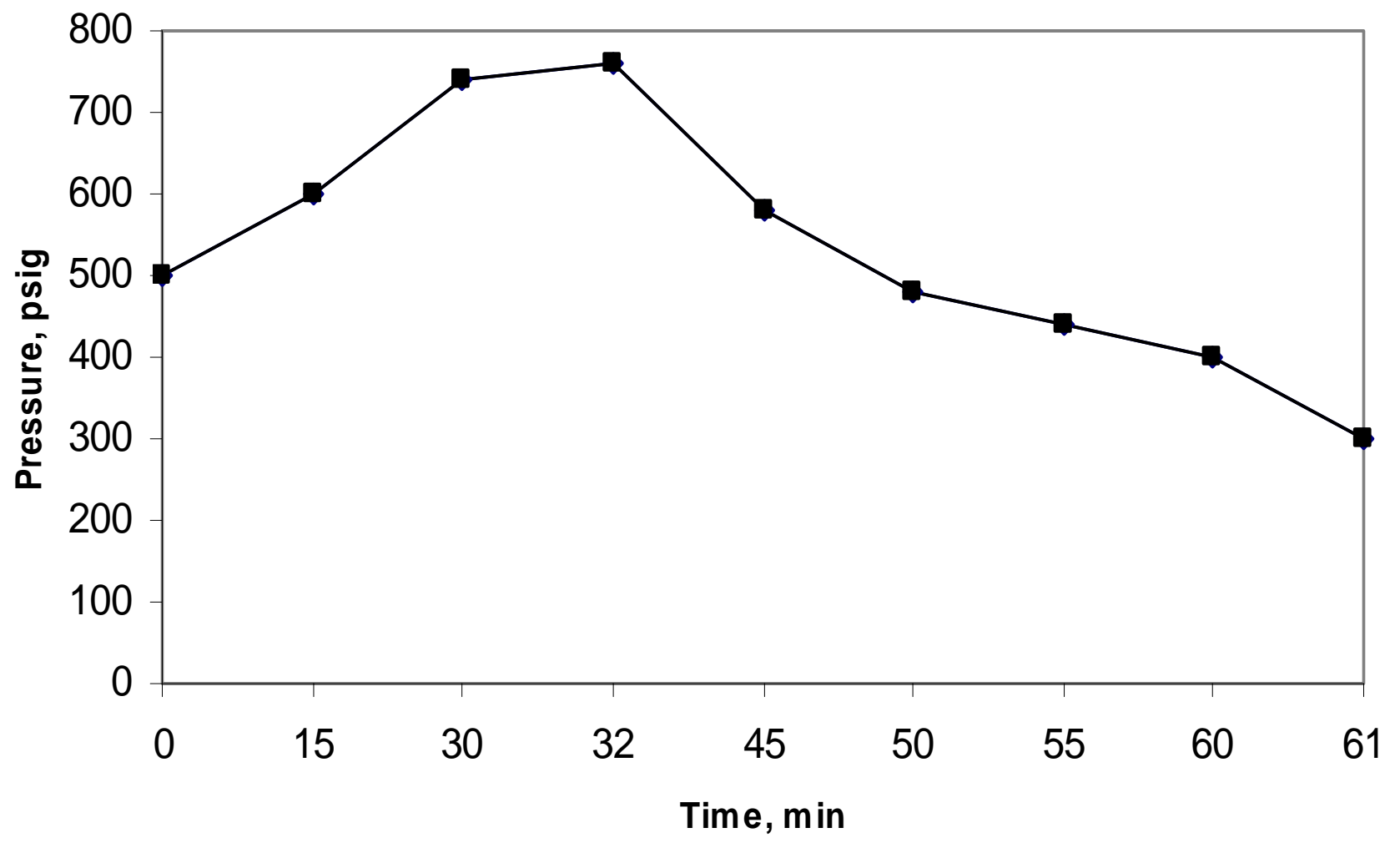

Figure 4. 1 Pressure profile for hydrogenation of $\mathrm{CBB}$ using $\mathrm{NiO} / \mathrm{MoO}_{3}$ as catalyst at 500 psig $\mathrm{H}_{2}$ (cold) and $350^{\circ} \mathrm{C}$ for 1 hour 


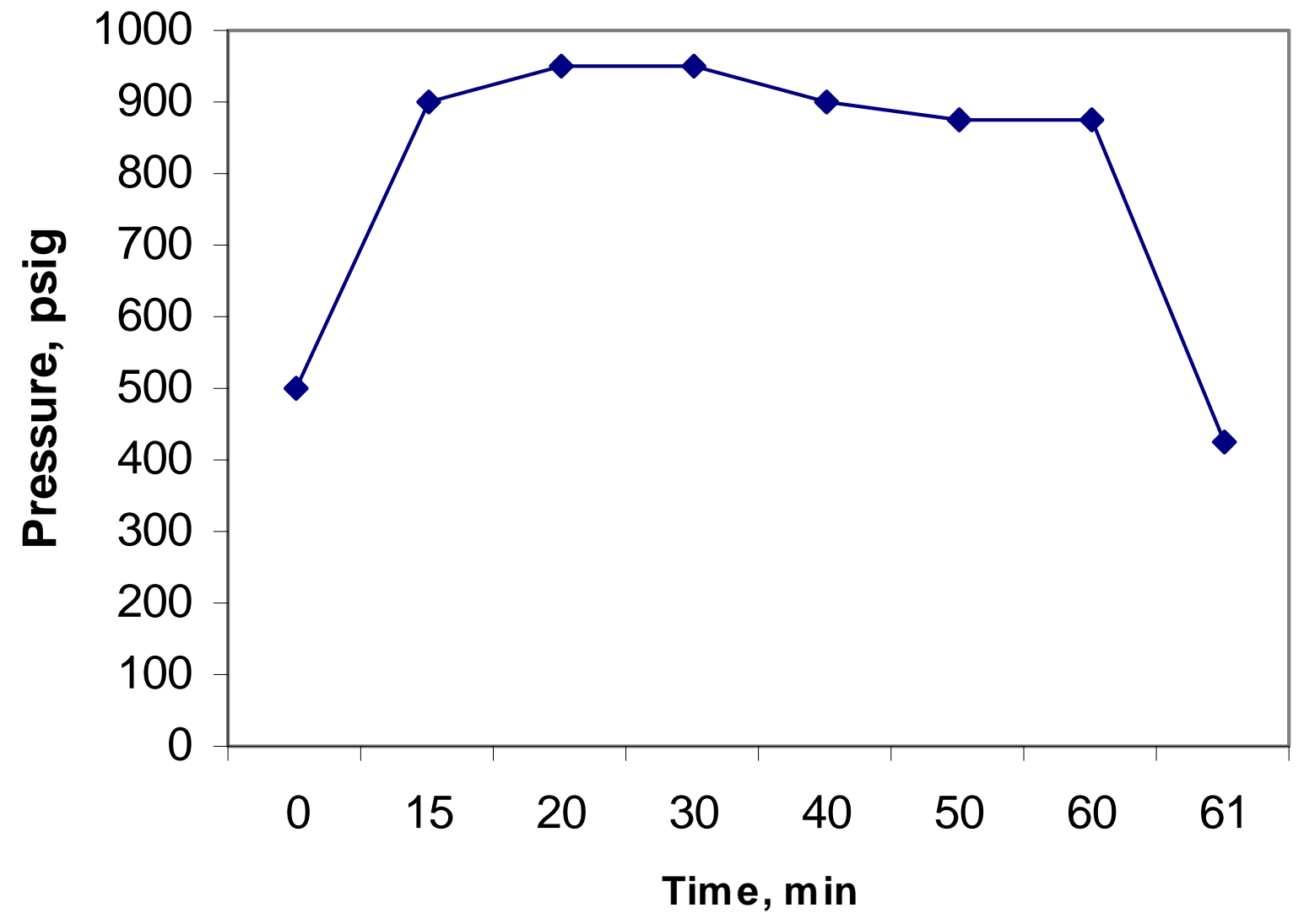

Figure 4. 2 Pressure profile for hydrogenation of $\mathrm{HCO}$ using unconverted coal as catalyst at 500 psig $\mathrm{H}_{2}$ (cold) and $400^{\circ} \mathrm{C}$ for 1 hour 
The calculated number of moles of hydrogen is further used to calculate the wt $\%$ of hydrogen consumed. The wt \% of hydrogen consumed in each case is shown in Table 4.1. It can be seen that the wt $\%$ hydrogen consumed in case of $\mathrm{CBB}$ is much more than in $\mathrm{HCO}$.

Table 4. 1 Solvent hydrogenation conditions and results

\begin{tabular}{|c|c|c|c|}
\hline Solvent & Temperature $\mathbf{~}^{\mathbf{0}} \mathrm{C}$ ) & Pressure (psig) & $\begin{array}{c}\text { Wt. \% of Hydrogen } \\
\text { consumed }\end{array}$ \\
\hline HCO & $400^{\circ} \mathrm{C}$ & $500 \mathrm{psig}$ & 0.09 \\
\hline CBB & $350^{\circ} \mathrm{C}$ & $500 \mathrm{psig}$ & 0.14 \\
\hline
\end{tabular}

It should be noted that when the residue was used as a catalyst, the reaction mass only contained about $2-3 \%$ mineral matter. This may be too low to show significant catalytic effect.

\subsection{Solvent Testing}

\subsubsection{Fresh Solvents}

The first goal of the research is to determine the effectiveness of the two as-received coal-derived solvents $\mathrm{HCO}$ and $\mathrm{CBB}$ in the coal hydrotreatment process. For this reason, coal hydrotreatment reactions were conducted using these solvents at $400^{\circ} \mathrm{C}$ and 500 psig (cold) of $\mathrm{N}_{2}$. Figure 4.3 shows these results. The coal-alone conversions for $\mathrm{HCO}$ and $\mathrm{CBB}$ are $33.75 \pm 2.84 \%$ and $47.83 \pm 2.23 \%$ respectively. The overall conversions for $\mathrm{HCO}$ and $\mathrm{CBB}$ are $88.56 \pm 0.17 \%$ and $90.76 \pm 0.17 \%$ respectively. The graph further shows the coal-alone and overall conversions of $68.42 \pm 0.63 \%$ and 


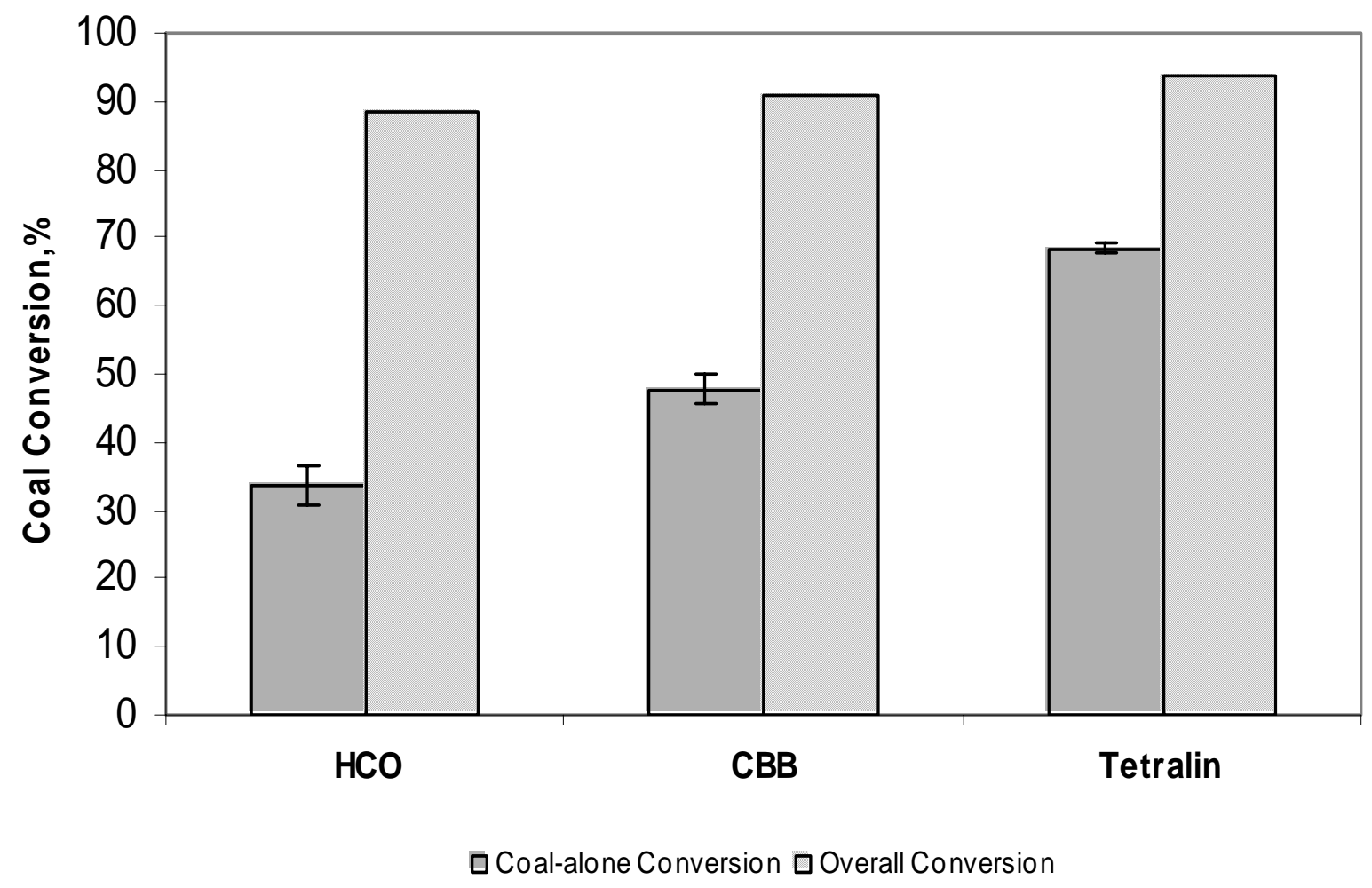

Figure 4. 3 Percent of Coal Conversion with fresh as-received solvents at $400^{\circ} \mathrm{C}$ and 500 psig $\mathrm{N}_{2}$ (cold) 
$93.94 \pm 0.07 \%$ respectively with pure solvent Tetralin in $\mathrm{N}_{2}$ atmosphere. Tetralin is the model solvent for hydrotreatment reactions that gives very high conversions.

The important thing is to be noted here is that the overall conversion takes into account both the coal and the solvent. A large part of the THF solubles come from the solvent which is completely soluble in THF. For this reason, coal-alone conversion can be taken as a more reliable measure than the overall conversion. Based on the coal-alone conversions, Figure 4.3 shows that as-received $\mathrm{CBB}$ is a more effective solvent for coal hydrotreatment reactions than as-received HCO. The result was further confirmed in a hydrogen atmosphere (500 psig) when the solvent CBB gave a much better conversion than solvent HCO (results are shown later in Section 4.3).

\subsubsection{Solvent Pretreatment}

Figure 4.4 shows the conversion results of the as-received solvent $\mathrm{HCO}$ and the hydrogenated HCO. The solvent in this case is hydrogenated using unconverted coal as a catalyst. The coal-alone conversions for fresh $\mathrm{HCO}$ and hydrogenated $\mathrm{HCO}(\mathrm{H}-\mathrm{HCO})$ in $\mathrm{N}_{2}$ atmosphere are $33.75 \pm 2.84 \%$ and $38.71 \pm 2.22 \%$ respectively. The conversion with Fresh $\mathrm{HCO}$ in $\mathrm{H}_{2}$ atmosphere is $51.75 \pm 2.6 \%$ and is shown in the same graph. The results show that the conversion to THF solubles increased when the hydrogenated solvent was used. However, the conversion was much better when the fresh HCO is used

in the $\mathrm{H}_{2}$ atmosphere. This shows that $\mathrm{H}-\mathrm{HCO}$ is not a good hydrogen-donor solvent in the hydrotreatment of coal. 


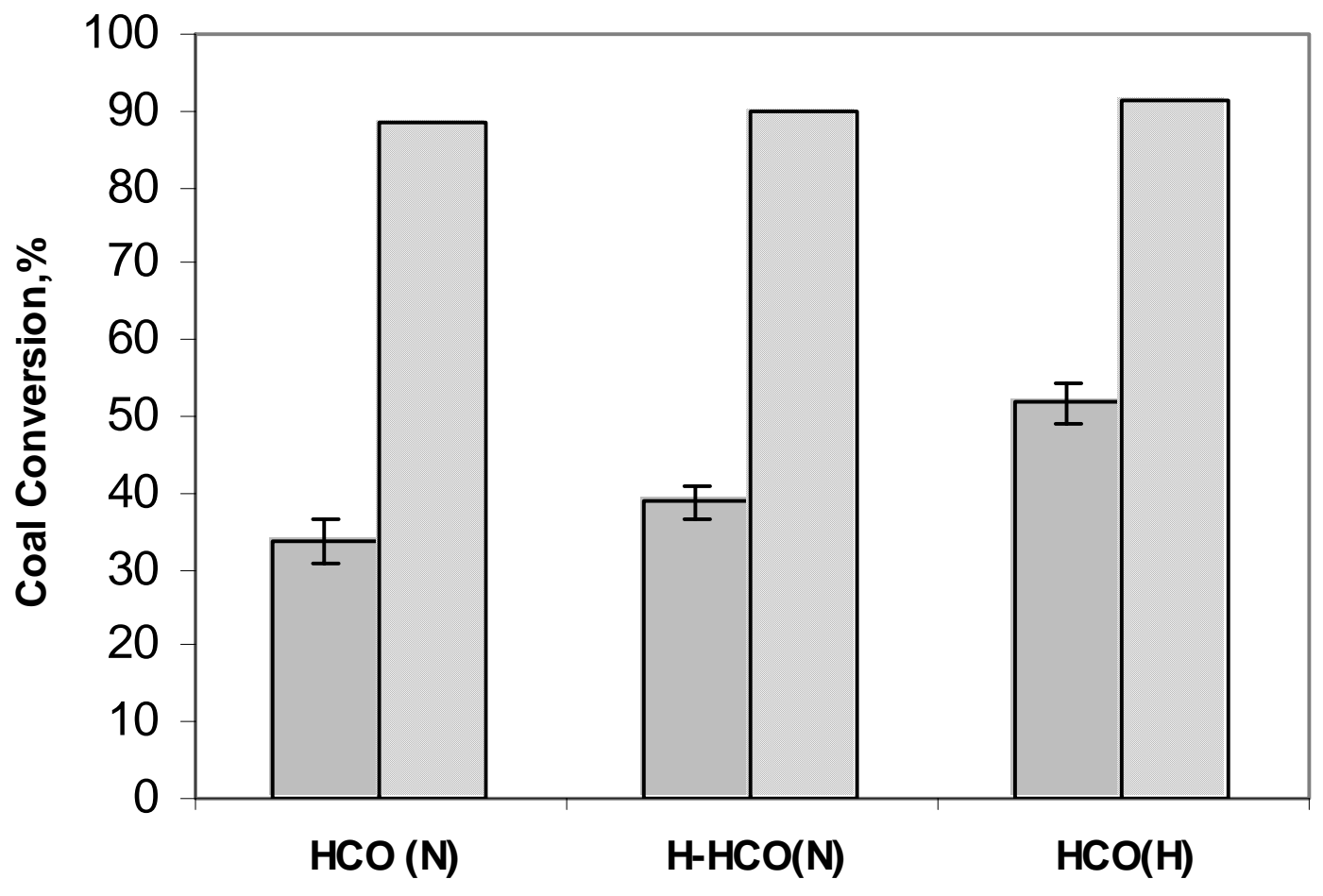

$\square$ Coal-alone Conversion $\square$ Overall Conversion

$$
\text { N-Nitrogen } \quad \text { H-Hydrogen }
$$

Figure 4. 4 Percent of Coal Conversion with fresh $\mathrm{HCO}$ and $\mathrm{H}-\mathrm{HCO}$ at $400^{\circ} \mathrm{C}$ and 500 psig $\mathrm{N}_{2}$ or $\mathrm{H}_{2}$ (cold) 
Figure 4.5 shows the conversion results of the hydrotreatment reaction conversion with the solvent $\mathrm{CBB}$ and hydrogenated $\mathrm{CBB}(\mathrm{H}-\mathrm{CBB})$ in $\mathrm{N}_{2}$ atmosphere. The solvent in this case is hydrogenated using $\mathrm{NiO} / \mathrm{MoO}_{3}$ as a catalyst. The graph further shows the conversion of $\mathrm{CBB}$ in $\mathrm{H}_{2}$ for the identical reaction conditions. The coal-alone conversions for fresh $\mathrm{CBB}$ and $\mathrm{H}-\mathrm{CBB}$ in $\mathrm{N}_{2}$ atmosphere are $47.83 \pm 2.23 \%$ and $60.99 \pm$ $0.47 \%$ respectively. The conversion for fresh (as-received) $\mathrm{CBB}$ in $\mathrm{H}_{2}$ atmosphere was $57.22 \pm 0.75 \%$. The results in this case show that the conversion to THF solubles increased when the hydrogenated solvent is used in the presence of nitrogen. This shows that $\mathrm{H}-\mathrm{CBB}$ is a very effective solvent in the coal hydrotreatment reactions.

It can be further be seen that the conversion with $\mathrm{H}-\mathrm{CBB}$ in $\mathrm{N}_{2}$ is slightly greater than the conversion with the fresh $\mathrm{CBB}$ in hydrogen atmosphere (unlike HCO). Use of hydrogenated solvent, in this case, gives the advantage of eliminating hydrogen in the coal-reaction step of the main process. So, handling hydrogen at extreme process conditions can be avoided with an added advantage of better conversion.

\subsubsection{Blends of Fresh and Hydrogenated Solvents}

Several reactions were performed with the blends of fresh and hydrogenated solvent to determine the minimum amount of hydrogenated solvent that brings a significant increase in the conversion. Figure 4.6 shows the coal-alone and overall conversions of blends of fresh and hydrogenated $\mathrm{CBB}$ for reaction in $\mathrm{N}_{2}$. Coal-alone conversions with blends of $25 \%, 50 \%$, and $75 \%$ hydrogenated solvent in raw solvent are $51.39 \pm 1.26 \%, 52.26 \pm 1.11 \%$ and $58.08 \pm 1.07 \%$ respectively. The overall 


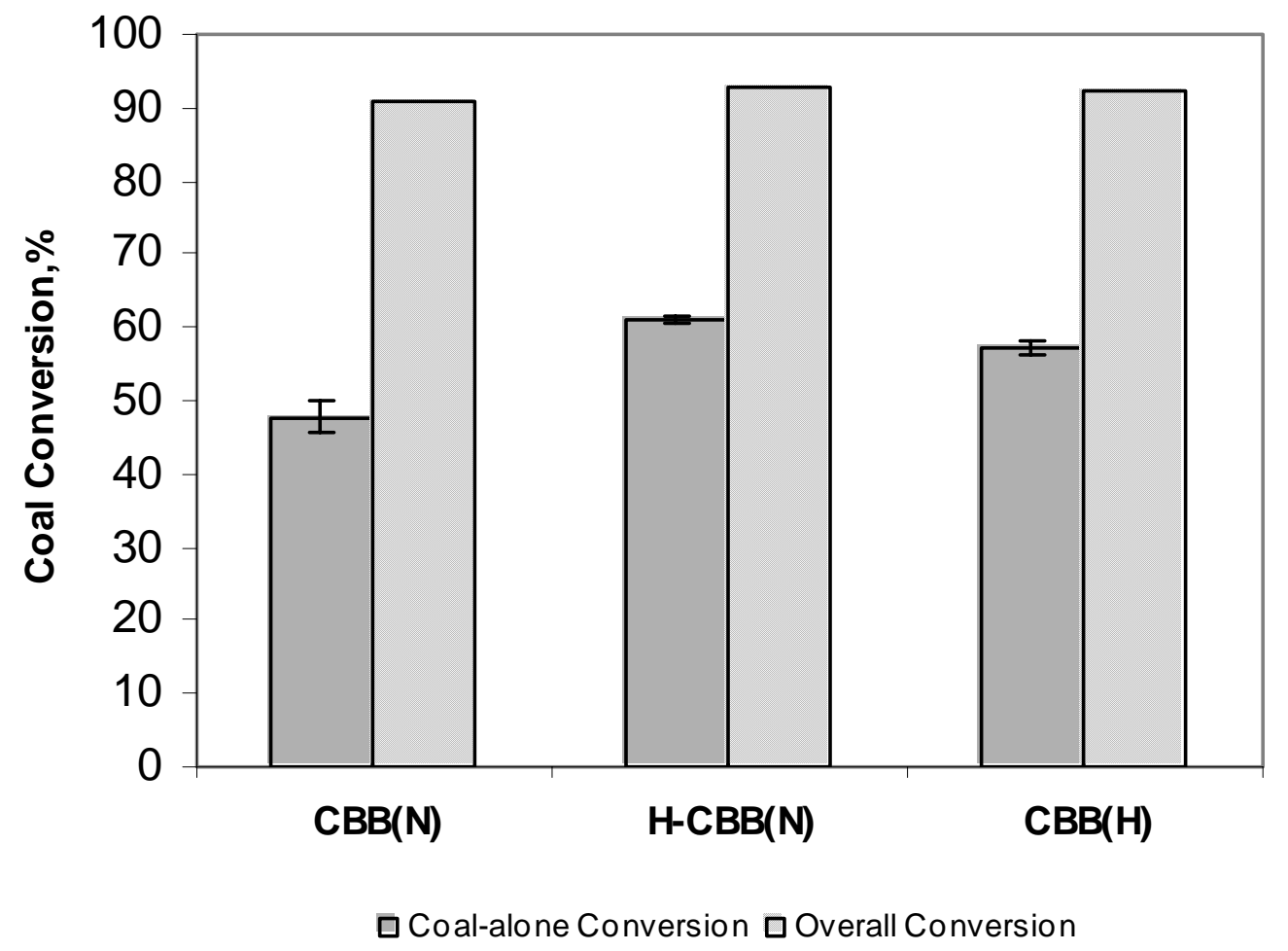

N-Nitrogen $\quad$ H-Hydrogen

Figure 4. 5 Percent of Coal Conversion with fresh $\mathrm{CBB}$ and $\mathrm{H}-\mathrm{CBB}$ at $400^{\circ} \mathrm{C}$ and 500 psig $\mathrm{N}_{2}$ or $\mathrm{H}_{2}$ (cold) 


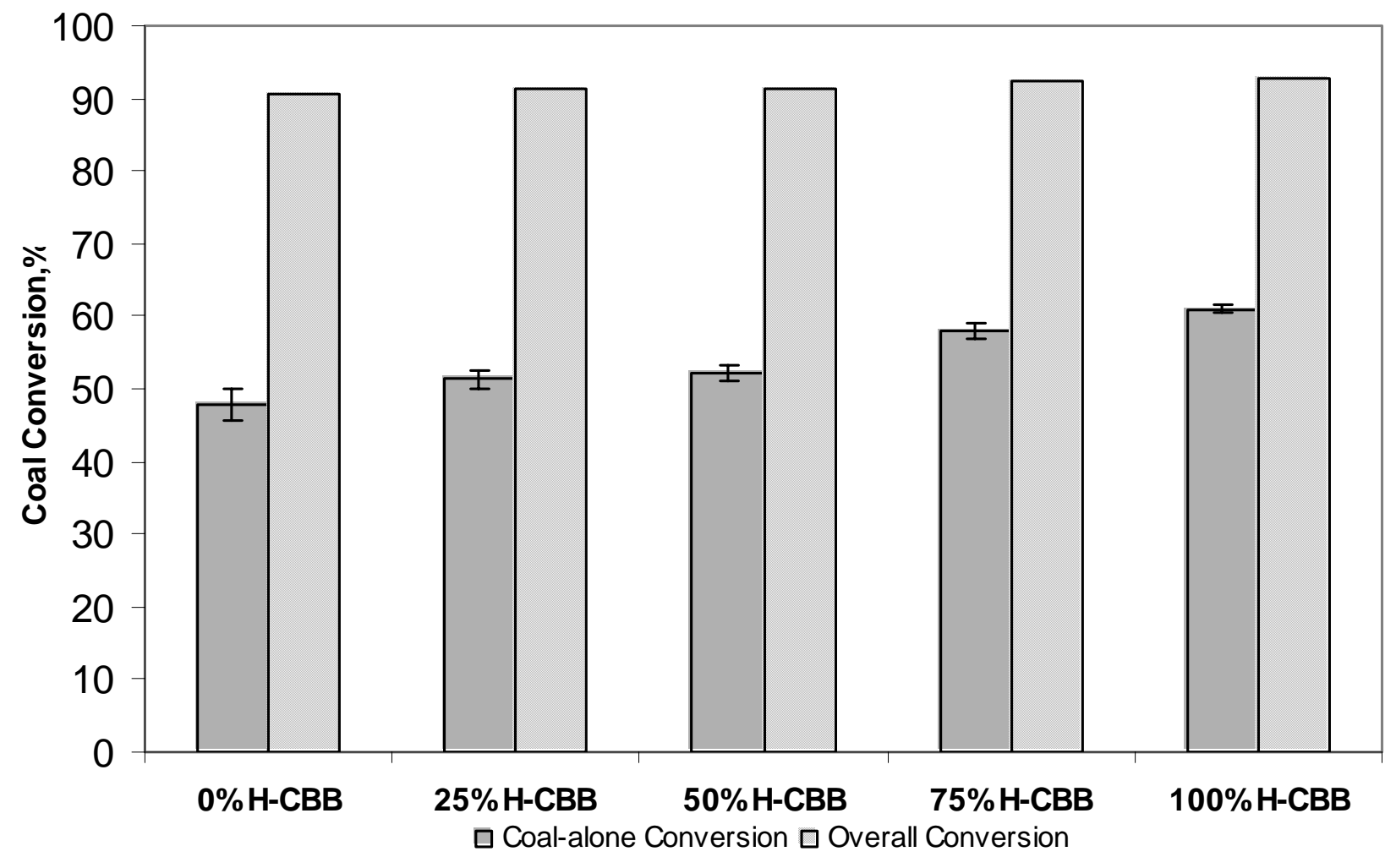

Figure 4. 6 Percent of Coal Conversion with blends of fresh CBB and H-CBB at $400^{\circ} \mathrm{C}$ and 500 psig $\mathrm{N}_{2}$ (cold) 
conversions with blends of $25 \%, 50 \%$ and $75 \%$ hydrogenated solvent in raw solvent are $91.31 \pm 0.48 \%, 91.45 \pm 0.12 \%$ and $92.35 \pm 0.11 \%$. The coal-alone conversions with 25 $\%$ and $50 \%$ hydrogenated $\mathrm{CBB}$ were found to be approximately equal and only slightly better than the conversion with the fresh CBB (47.8\%) and the coal-alone conversion with $75 \%$ hydrogenated solvent is only slightly less (approximately $2 \%$ ) and comparable to that with $100 \%$ hydrogenated solvent.

Figure 4.7 shows the relationship between percent-hydrogenated CBB used in the blend and the percent coal-alone conversion to THF solubles. It was found that the addition of hydrogenated CBB increased the percent conversion, but the effect is more pronounced when the solvent contains more than $50 \%$ hydrogenated CBB.

\subsubsection{Recovered Solvent and Successive Hydrotreatment reactions}

Hydrotreatment reactions were performed with the recovered solvents from the coal hydrotreatment reaction of coal with $\mathrm{H}-\mathrm{CBB}$ in a $\mathrm{N}_{2}$ atmosphere to assess their performance as hydrogen donor solvents. The coal-alone conversion with recovered H$\mathrm{CBB}$ was $43.02 \pm 1.56 \%$. When this value is compared with that of the fresh $\mathrm{H}-\mathrm{CBB}$, it is seen that the recovered solvent does not perform as well as the fresh H-CBB. Successive hydrotreatment reactions were also run to see if the addition of fresh H-CBB to the recovered brings a considerable increase in the coal-alone conversion.

Pass 1 is the reaction performed with the recovered $\mathrm{H}-\mathrm{CBB}$ with the make-up fresh $\mathrm{H}-\mathrm{CBB}$. Pass 2 is the reaction performed with the recovered solvent from pass 1 with fresh make-up H-CBB. The blends of fresh and recovered solvents used in each case 


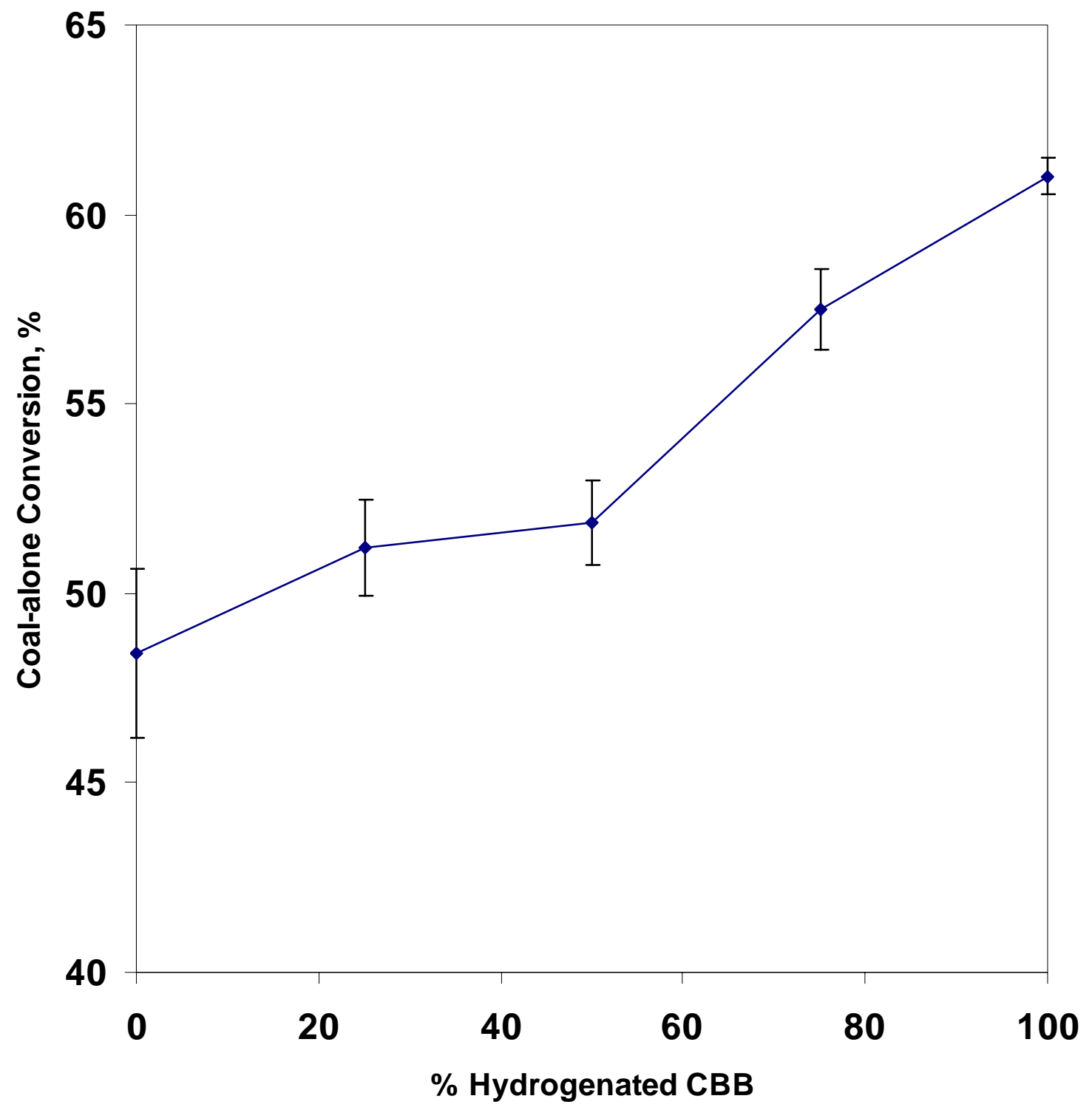

Figure 4. 7 Relationship between percent hydrogenated CBB and percent coalalone conversion at $400^{\circ} \mathrm{C}$ and 500 psig $\mathrm{N}_{2}$ (cold) 
are shown in Table 4.2. Figure 4.8 shows these results in comparison with the fresh $\mathrm{H}$ CBB. From Figure 4.8, it can be seen that the coal-alone conversions with pass 1 and pass 2 reactions were $48.74 \pm 0.94 \%$ and $51.00 \pm 1.27 \%$ respectively. It can be seen that the coal-alone conversion decreases with pass 1 and pass 2 when compared with the fresh $\mathrm{H}-\mathrm{CBB}$

\section{Table 4. 2 Amount of Fresh and Recovered Solvents used in the successive hydrotreatment reactions}

\begin{tabular}{|c|c|c|}
\hline Reaction type & Recovered solvent (\%) & Fresh H-CBB (\%) \\
\hline Pass 1 & 80 & 20 \\
\hline Pass 2 & 70 & 30 \\
\hline
\end{tabular}

The slight increase in conversion from pass 1 to pass 2 solvent is probably due to the amount of fresh make-up H-CBB used. The amount of fresh make-up H-CBB used in pass 2 was increased from $20 \%$ to $30 \%$. This is because the separation of lights (recovered solvent) becomes more difficult from recovered to pass 2 . Hence, the increase in the conversion from recovered $\mathrm{H}-\mathrm{CBB}$ to pass 2 reactions can be attributed to the increase in percent of fresh make-up $\mathrm{H}-\mathrm{CBB}$ added. It is suspected that if the solvent continued to be recycled, results as obtained for Pass 2 would most likely be observed. 


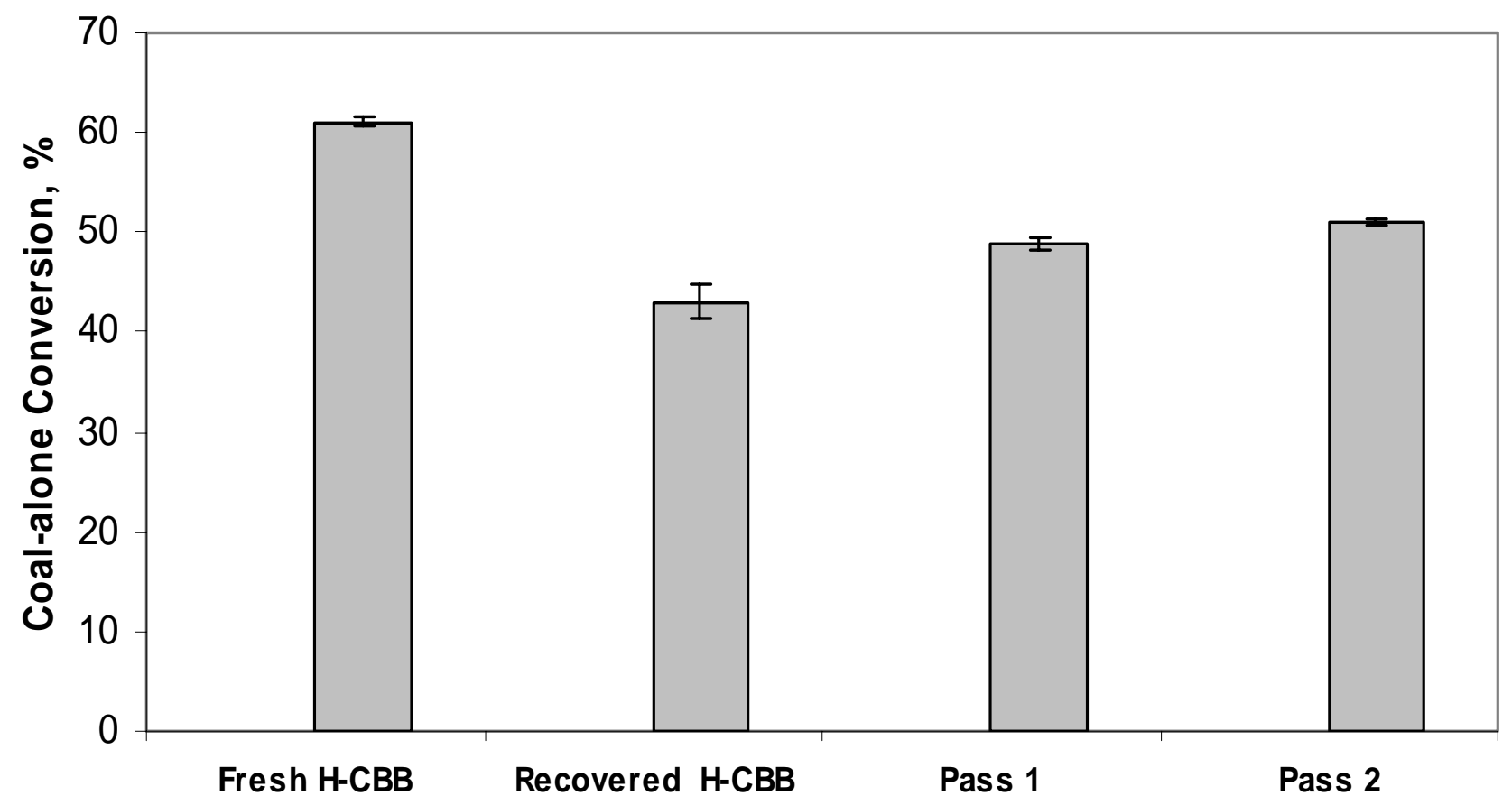

Figure 4. 8 Percent of coal-alone conversion with recovered H- CBB and with successive hydrotreatment reactions at $400^{\circ} \mathrm{C}$ and $500 \mathrm{psig} \mathrm{N}_{2}$ (cold) 


\subsection{Effect of Reaction Atmosphere}

The effect of the gaseous reaction atmosphere was studied on both the solvents $\mathrm{HCO}$ and $\mathrm{CBB}$ in two different reaction atmospheres, viz. Nitrogen and Hydrogen. Figure 4.9 shows the coal-alone conversions of hydrotreatment reactions of coal with fresh solvents $\mathrm{HCO}$ and $\mathrm{CBB}$ at $400^{\circ} \mathrm{C}$ and 500 psig $\mathrm{N}_{2}$ and $\mathrm{H}_{2}$ (cold). The coal-alone conversions for $\mathrm{HCO}$ and $\mathrm{CBB}$ in 500 psig in $\mathrm{N}_{2}$ are $33.75 \pm 2.84 \%$ and $47.83 \pm 2.23 \%$ respectively. The coal-alone conversions for $\mathrm{HCO}$ and $\mathrm{CBB}$ in $500 \mathrm{psig} \mathrm{H}_{2}$ are $51.75 \pm$ $2.6 \%$ and $57.22 \pm 0.75 \%$ respectively. It can be seen that the coal conversions in hydrogen are much higher than their corresponding conversion values in nitrogen for both the fresh solvents. The reason for this is because of hydrogen consumption from the gas phase and is further illustrated clearly in section 4.4 using the hydrotreatment reaction pressure profiles.

\subsection{Hydrotreatment Reactions Pressure Profiles}

The study of the pressure profiles for the coal hydrotreatment reactions gives a good insight into the reaction chemistry. For this purpose, the pressure of the hydrotreatment reactions was monitored during the course of the reaction and also after quenching. Figure 4.10 and Figure 4.11 show the pressure profiles for fresh solvents $\mathrm{HCO}$ and $\mathrm{CBB}$ in $\mathrm{N}_{2}$ and $\mathrm{H}_{2}$ atmospheres respectively. It can be seen that due to rapid heating, the pressure increases during the course of the reaction. The maximum pressure attained for both the solvents in each case did not differ greatly. 


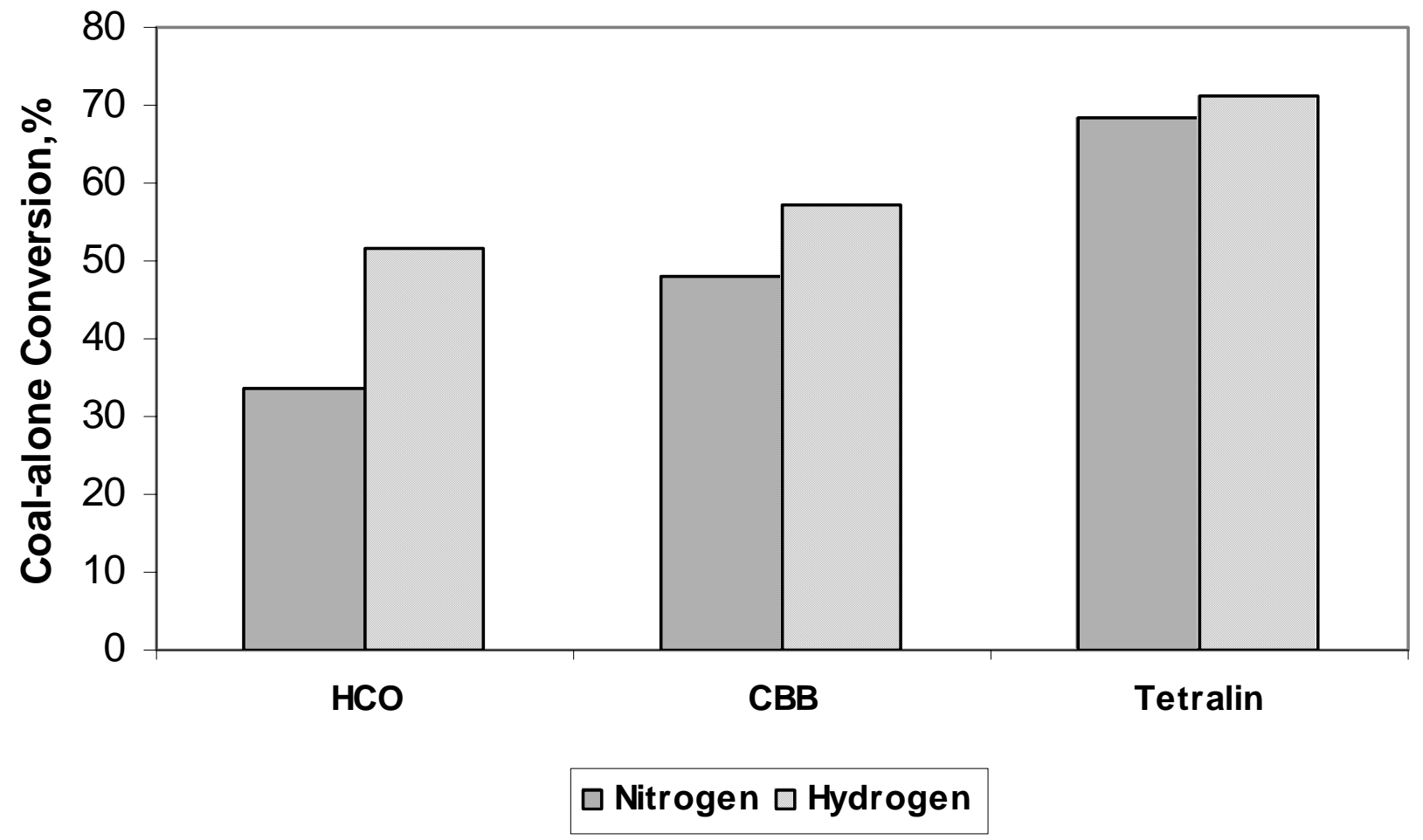

Figure 4. 9 Percent of coal-alone conversion with fresh $\mathrm{HCO}$ and $\mathrm{CBB}$ at $400^{\circ} \mathrm{C}$ and 500 psig $\mathrm{N}_{2}$ or $\mathrm{H}_{2}$ (cold) 


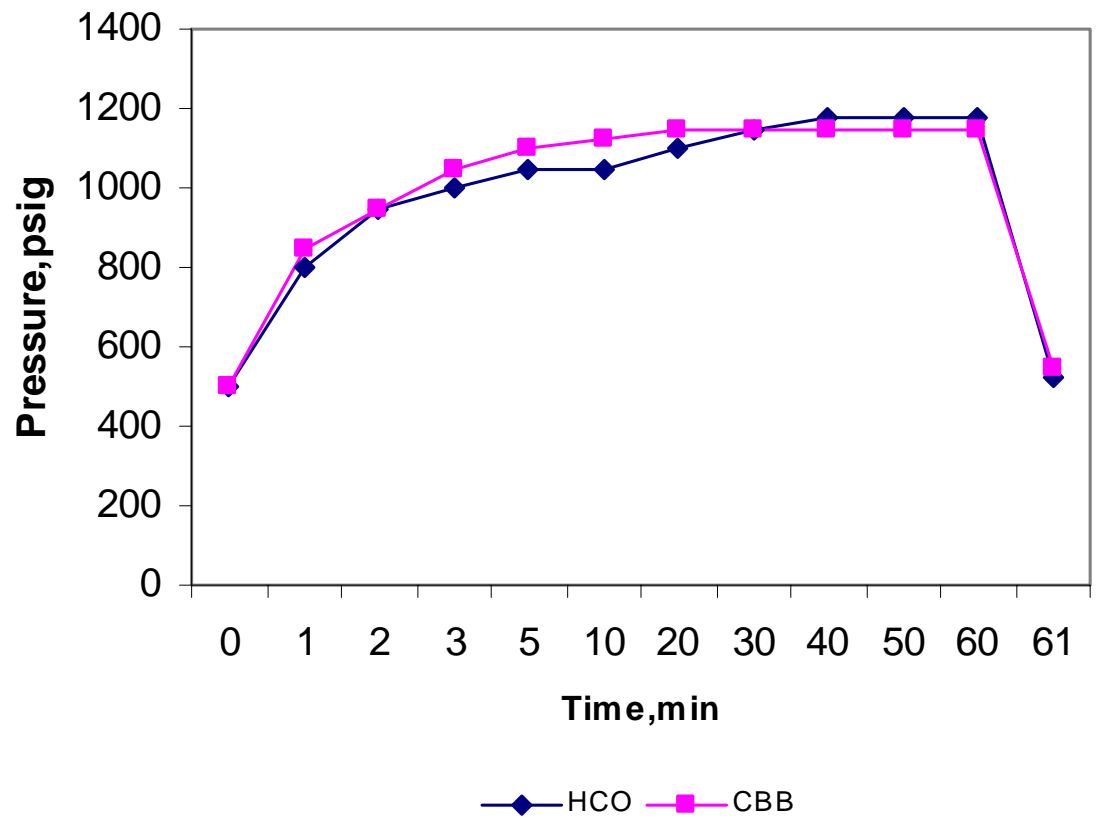

Figure 4. 10 Pressure profile for hydrotreatment reaction with fresh $\mathrm{HCO}$ and CBB at $400^{\circ} \mathrm{C} 500$ psig $\mathrm{N}_{2}$ (cold)

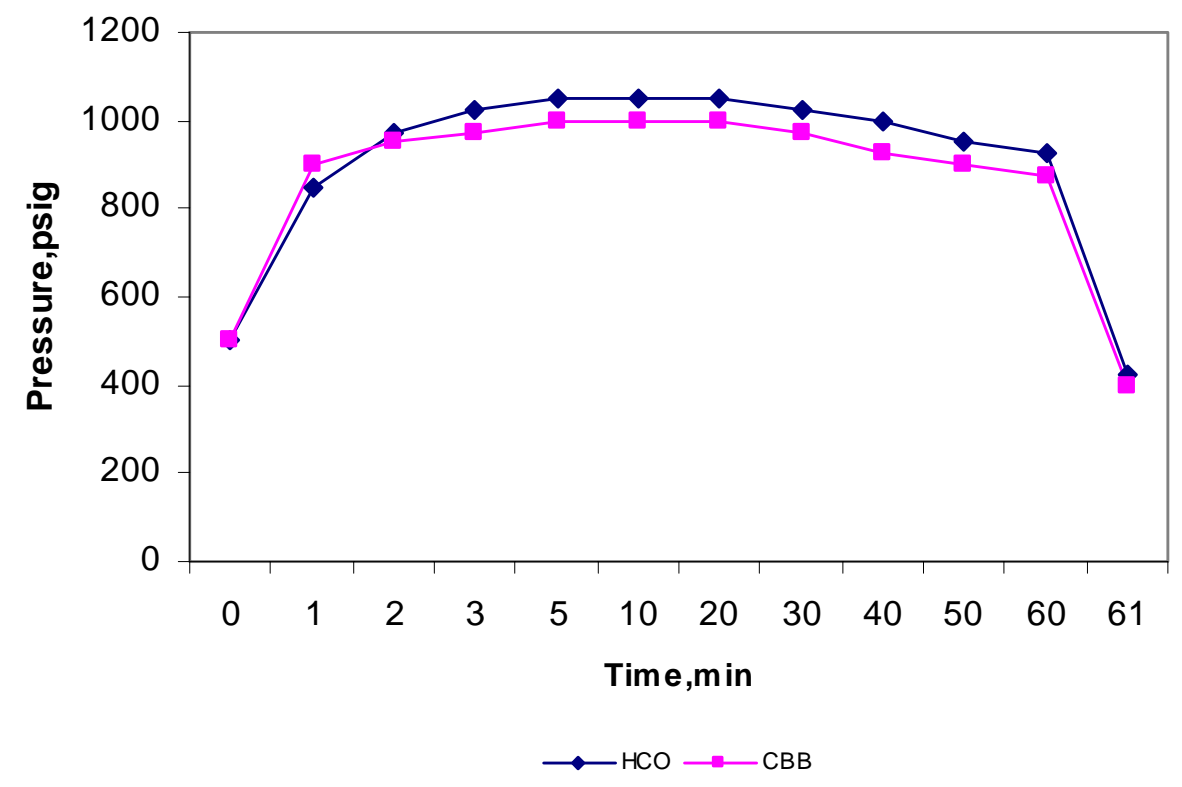

Figure 4. 11 Pressure profile for hydrotreatment reaction with fresh $\mathrm{HCO}$ and $\mathrm{CBB}$ at $400^{\circ} \mathrm{C} 500 \mathrm{psig}_{2}$ (cold) 
For the $\mathrm{N}_{2}$ atmosphere, the pressure reaches a maximum value and remains at that pressure for the remainder of the reaction. In the case of the $\mathrm{H}_{2}$ atmosphere, the pressure reaches a maximum value and then decreases with time. This shows that the hydrogen is being consumed. Also, the final cold pressure of hydrogen after quenching (the last data point in the figures) is less than the initial cold pressure, once again indicating hydrogen consumption. (It should be noted that both the initial and final cold pressures are measured at room temperature.) This is not observed in the case of the inert atmosphere of $\mathrm{N}_{2}$, where there will not be any gas consumption. In fact a reverse trend of an increase in the final cold pressure was observed. This additional increase in pressure accounts for the production of non-condensible product gases produced during the hydrotreatment reactions.

\subsection{Effect of Reaction Temperature and Pressure}

\subsubsection{Reaction Temperature}

The effect of the hydrotreatment, temperature was studied using the fresh CBB solvent. Three different temperatures of $350^{\circ} \mathrm{C}, 400^{\circ} \mathrm{C}$ and $450^{\circ} \mathrm{C}$ were selected. Temperatures below $350^{\circ} \mathrm{C}$ are avoided because at these temperatures the solvent cannot accomplish a good digestion of coal. And at temperatures above $450^{\circ} \mathrm{C}$, the retrogressive reactions like polymerization and repolymerization tend to dominate and a good conversion cannot be achieved. 
The other reaction conditions such as solvent/ coal ratio of 5/1, pressure of 500 psig (cold) and reaction time of 1 hour were maintained the same for all the reactions. Figure 4.12 shows the coal-alone conversions for fresh $\mathrm{CBB}$ and $\mathrm{H}-\mathrm{CBB}$ in $\mathrm{N}_{2}$ atmosphere for the three chosen temperatures. The coal-alone conversions are $23.08 \pm$ $1.73 \%$ at $350^{\circ} \mathrm{C}, 47.83 \pm 2.23 \%$ at $400^{\circ} \mathrm{C}$ and $24.04 \pm 2.7 \%$ at $450^{\circ} \mathrm{C}$. This indicates that the temperatures $350^{\circ} \mathrm{C}$ and $450^{\circ} \mathrm{C}$ could not give better conversion results because of poor digestion and retrogressive reactions respectively. The same trend of higher conversion at $400^{\circ} \mathrm{C}$ than at $350^{\circ} \mathrm{C}$ and $450^{\circ} \mathrm{C}$ were observed with the solvent $\mathrm{H}-\mathrm{CBB}$ but with enhanced conversions at all the three temperatures.

Figure 4.13 shows the coal-alone conversions for $\mathrm{CBB}$ in $\mathrm{H}_{2}$ atmosphere. The coal-alone conversions at $350^{\circ} \mathrm{C}, 400^{\circ} \mathrm{C}$ and $450^{\circ} \mathrm{C}$ are $25.64 \pm 1.59 \%, 57.22 \pm 0.75 \%$ and $47.21 \pm 1.33 \%$ respectively. The results indicate that the presence of hydrogen gas is critical for this solvent to obtain much better conversions at $400^{\circ} \mathrm{C}$ and $450^{\circ} \mathrm{C}$. However, the conversion did not improve much at $350^{\circ} \mathrm{C}$. The conversions once again follow the same trend of poor conversions at $350^{\circ} \mathrm{C}$ and $450^{\circ} \mathrm{C}$ compared to those at $400^{\circ} \mathrm{C}$. Hence $400^{\circ} \mathrm{C}$ appears to be the optimum temperature for the coal hydrotreatment reactions using these particular solvents. It should be noted that all these runs were performed for a time of one hour. It may be that at $350^{\circ} \mathrm{C}$ and $450^{\circ} \mathrm{C}$, a higher conversion could be obtained if the reactions were run for different time periods. This was not done in the present study. 


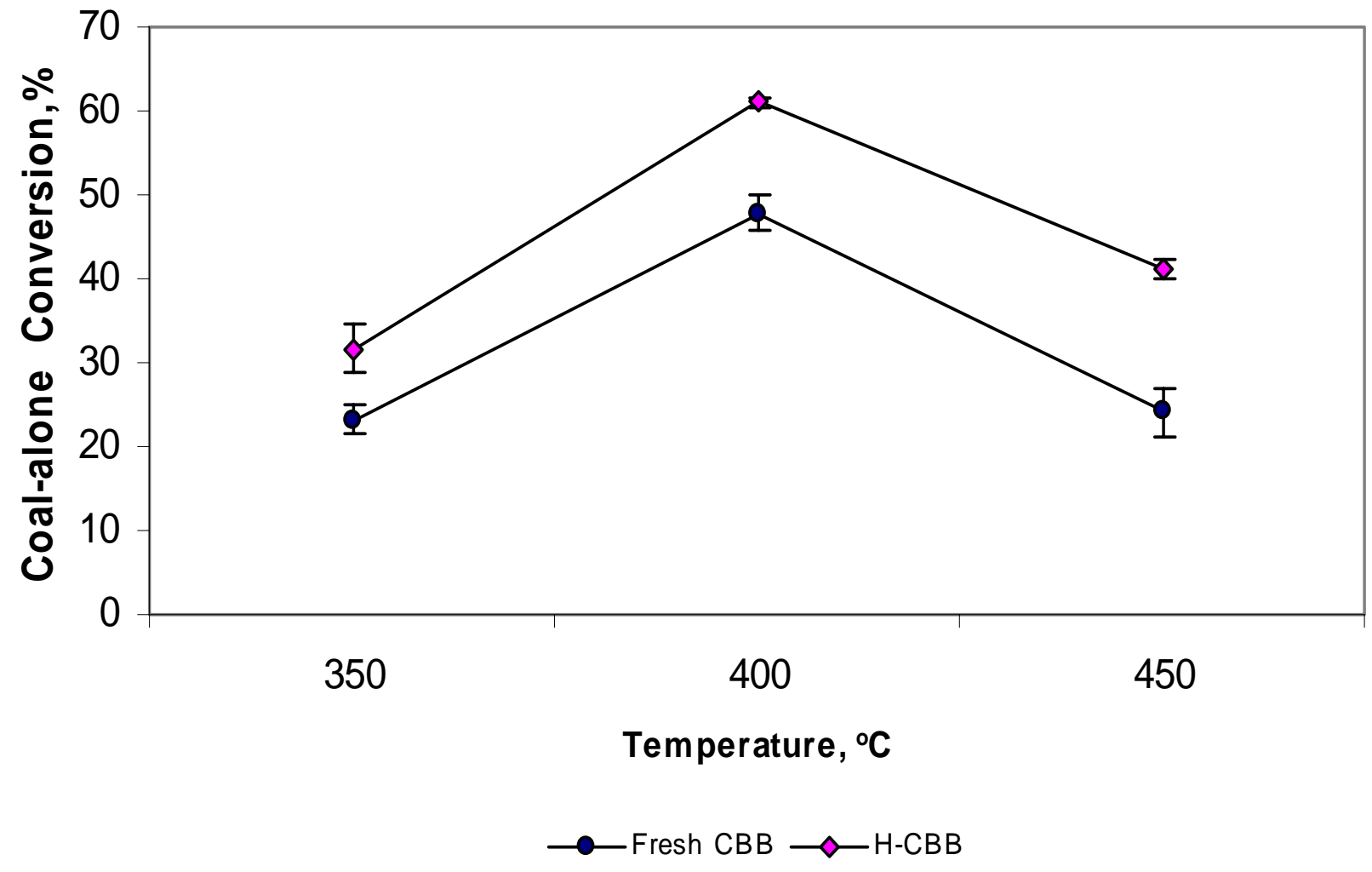

Figure 4. 12 Percent of coal-alone conversion with fresh CBB and $\mathrm{H}-\mathrm{CBB}$ at different temperatures and $500 \mathrm{psig} \mathrm{N}_{2}$ (cold) (Reaction time: 1 hour; Solvent/coal: 5/1) 


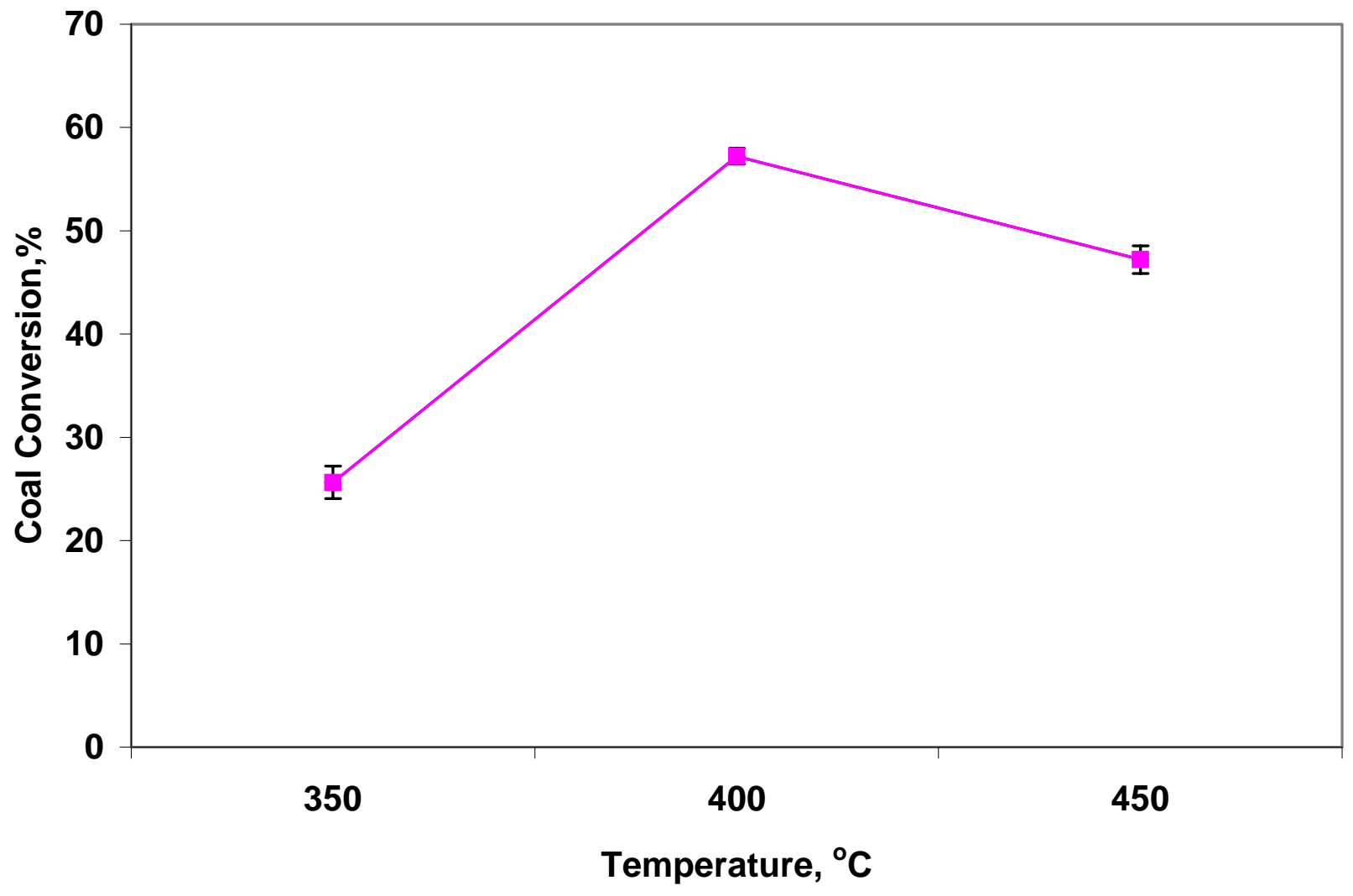

Figure 4. 13 Percent of coal-alone conversion with fresh CBB at different temperatures and 500 psig $\mathrm{H}_{2}$ (cold) (Reaction time: 1 hour; Solvent/coal: 5/1) 


\subsubsection{Reaction Pressure}

The pressure profiles for the hydrotreatment reactions at different temperatures in $\mathrm{N}_{2}$ and $\mathrm{H}_{2}$ atmospheres are shown in Figures 4.14 and 4.15 respectively. It should be noted that the final cold pressure, in the case of $\mathrm{H}_{2}$ atmosphere, is less than the initial cold pressure indicating hydrogen consumption during the reaction. Figures 4.14 and 4.15 show that, regardless of the reaction atmosphere, the maximum pressure attained during the reaction increases with the increase in temperature. In $\mathrm{N}_{2}$ atmosphere, increase in temperature also indicates an increase in the production of non-condensibles. In the case of $\mathrm{H}_{2}$ atmosphere, the difference between the final and initial cold pressure increases from $350^{\circ} \mathrm{C}$ to $400{ }^{\circ} \mathrm{C}$ and decreases from $400^{\circ} \mathrm{C}$ to $450{ }^{\circ} \mathrm{C}$. This is consistent with the fact of increased conversion values from $350^{\circ} \mathrm{C}$ to $400^{\circ} \mathrm{C}$ and decreased conversion values from $400^{\circ} \mathrm{C}$ to $450^{\circ} \mathrm{C}$.

\subsection{Mass Balance}

A mass balance was done on all the coal hydrotreatment reactions to account for the losses during the process and also to check the validity of the conversion data. The amount of coal and solvent charged are noted and are considered as inputs in the mass balance calculations. The outputs include the amount of THF insolubles separated, pitch produced and the solvent recovered during the distillation. Table 4.3 shows the overall mass balances with fresh solvents $\mathrm{HCO}$ and $\mathrm{CBB}$ at $400^{\circ} \mathrm{C}$ and 500 psig $\mathrm{N}_{2}$ and $\mathrm{H}_{2}$ (cold). The reactions were performed in duplicate and the two are shown for every reaction. It 


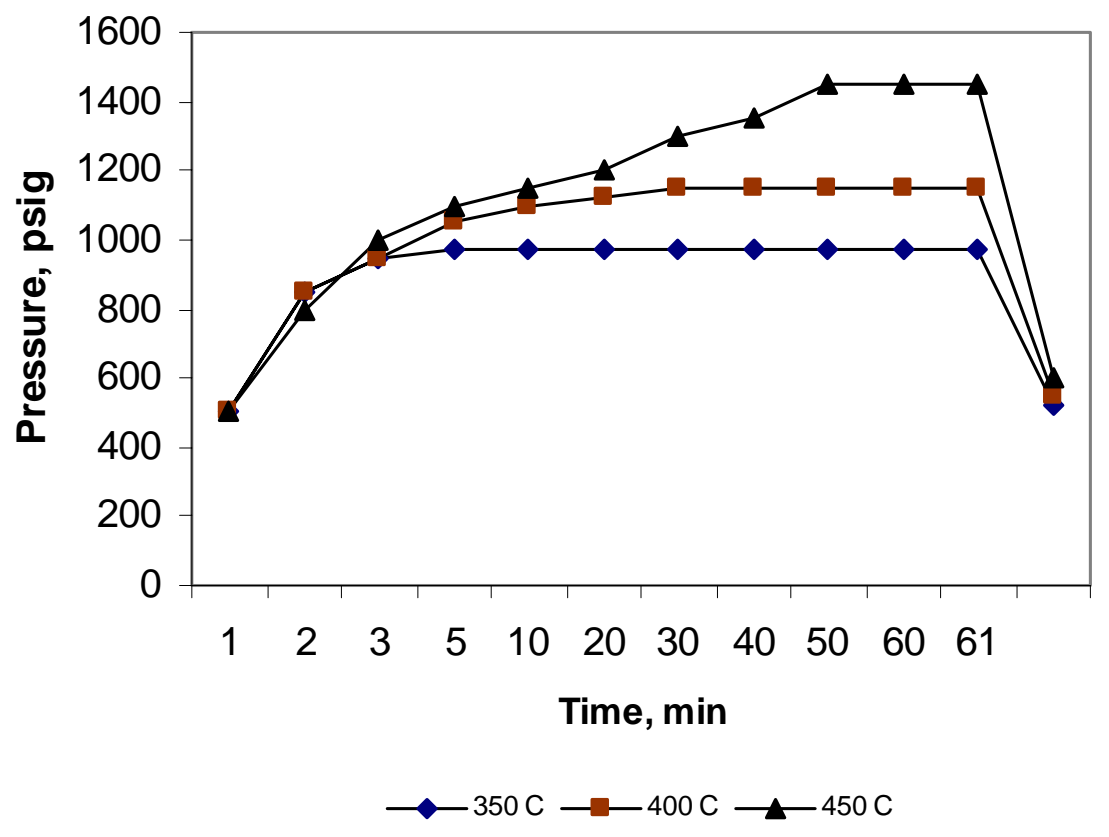

Figure 4. 14 Pressure profile for hydrotreatment reaction with fresh CBB at different temperatures and 500 psig $\mathbf{N}_{2}$ (cold)

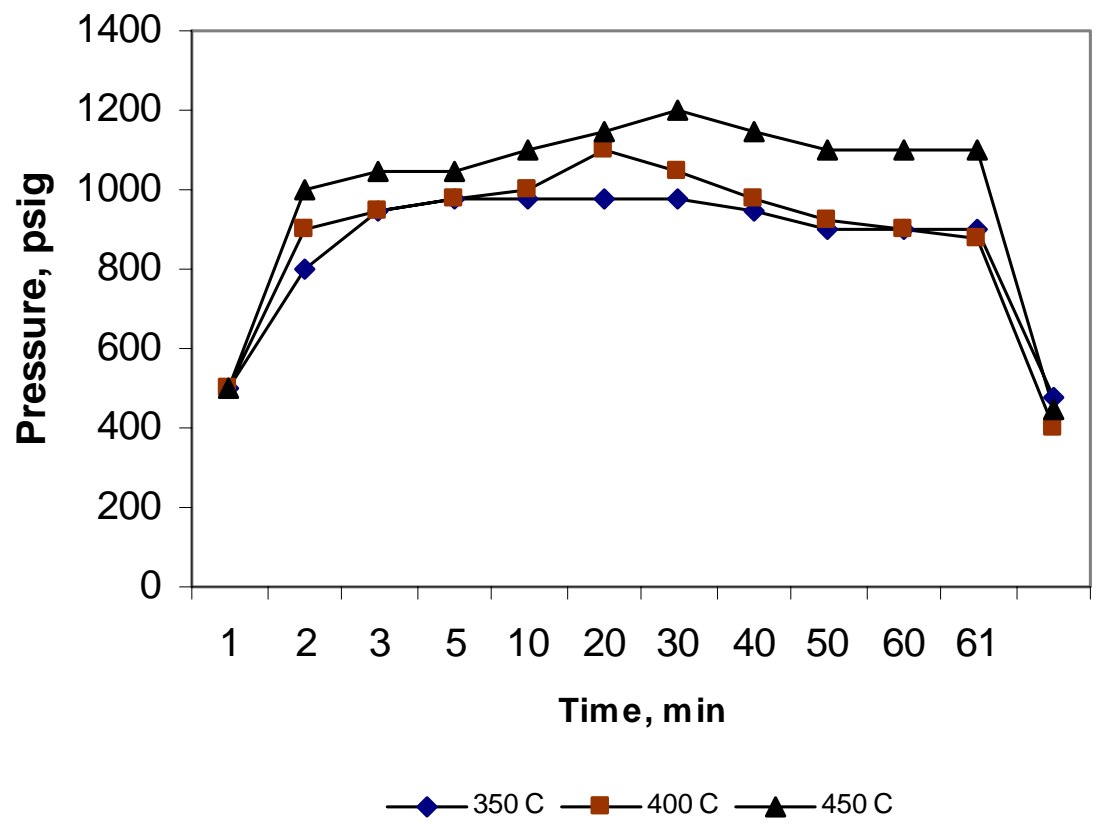

Figure 4. 15 Pressure profile for hydrotreatment reaction with fresh CBB at different temperatures and 500 psig $\mathrm{H}_{2}$ (cold) 
should be noted that the non-condensable gases produced during the reaction are not recovered and are not included in the mass balance. The results in all the cases show that the output is less than the corresponding input indicating losses.

The net loss of mass can occur during the reaction and/or during the product separation stages. The various reasons for mass loss are as follows:

1. The product gases that are produced during the reaction are not recovered, but vented into the hood and hence not accounted in the mass balance. This step could account for a mass loss ranging from $2 \%$ to $5 \%$, i.e., most of the mass loss.

2. In the filtration step, some of the coal-derived solvent or products get trapped in the THF insolubles. Even after several washings, there always seemed to be some amount of products being trapped. When the THF insolubles are vacuum dried, the product is vaporized and removed completely. This amount of product was not accounted for in the mass balance.

3. During the roto-evaporation, some of the light components of the product may be condensed along with THF and separated. The mass loss in this stage is almost negligible $(<0.5 \%)$ as the product might not contain many low boiling components with boiling points comparable to that of THF.

4. The vacuum distillation accounts for the majority of the losses, as during the initial stages, the light components of the product mass do not condense in the collecting flask and are collected in the cold trap that is set up to protect the pump. This was further confirmed when a faintly colored liquid was found in the cold trap at the end of the distillation process. However, the amount of product that remains in the distillation adapters is accounted for by weighing them before 
and after the distillation. This amount of product is added to the recovered solvent.

Table 4. 3 Overall Mass Balances of hydrotreatment reactions with fresh solvents

\begin{tabular}{|c|c|c|c|c|c|c|c|c|c|}
\hline Solvent & $\begin{array}{c}\text { Reaction } \\
\text { Atmosphere }\end{array}$ & $\begin{array}{c}\text { INPUT } \\
\text { Coal } \\
\mathbf{( g )}\end{array}$ & $\begin{array}{c}\text { INPUT } \\
\text { Solvent } \\
\mathbf{( g )}\end{array}$ & $\begin{array}{c}\text { Total } \\
\text { mass } \\
\mathbf{I n} \\
\mathbf{( g )}\end{array}$ & $\begin{array}{c}\text { OUTPUT } \\
\text { THF } \\
\text { insolubles } \\
\mathbf{( g )}\end{array}$ & $\begin{array}{c}\text { OUTPUT } \\
\text { Pitch } \\
\mathbf{( g )}\end{array}$ & $\begin{array}{c}\text { OUTPUT } \\
\text { Recovered } \\
\text { Solvent } \\
\text { (g) }\end{array}$ & $\begin{array}{c}\text { Total } \\
\text { mass } \\
\text { Out } \\
\text { (g) }\end{array}$ & $\begin{array}{c}\text { Losses } \\
\mathbf{( \% )}\end{array}$ \\
\hline HCO & $\mathrm{N}_{2}$ & 4.0013 & 20.01 & 24.0113 & 2.7058 & 2.9567 & 16.82 & 22.4825 & 6.80 \\
\hline HCO & $\mathrm{N}_{2}$ & 4.0047 & 20.00 & 24.0047 & 2.7442 & 2.7812 & 17.01 & 22.5354 & 6.52 \\
\hline CBB & $\mathrm{N}_{2}$ & 4.0023 & 20.01 & 24.0123 & 2.176 & 3.2960 & 17.07 & 23.206 & 6.52 \\
\hline CBB & $\mathrm{N}_{2}$ & 4.0039 & 20.03 & 24.0339 & 2.2352 & 3.3574 & 16.93 & 22.5226 & 6.71 \\
\hline HCO & $\mathrm{H}_{2}$ & 4.0025 & 20.00 & 24.0025 & 2.0769 & 3.3032 & 17.05 & 22.4301 & 7.01 \\
\hline HCO & $\mathrm{H}_{2}$ & 4.0010 & 20.04 & 24.0410 & 2.1233 & 3.1998 & 17.12 & 22.4431 & 7.12 \\
\hline CBB & $\mathrm{H}_{2}$ & 4.0041 & 20.02 & 24.02541 & 1.8581 & 3.6622 & 16.97 & 22.4903 & 6.82 \\
\hline CBB & $\mathrm{H}_{2}$ & 4.0084 & 20.01 & 20.0184 & 1.8884 & 3.3420 & 17.20 & 22.426 & 7.08 \\
\hline
\end{tabular}

As can be seen from Table 4.3, the average mass loss due to the fresh solvents both in $\mathrm{N}_{2}$ and $\mathrm{H}_{2}$ atmospheres are almost the same ranging from $6 \%$ - 7.5\%. Table 4.4 shows the overall mass balances for the hydrogenated solvents. The average mass losses in this case are slightly more than those with the corresponding fresh solvents. This can be attributed to the fact that the hydrogenatd solvents are lighter than the fresh solvents and produce more light non-condensibles during the reaction, which are not recovered in the products separation. 
Table 4. 4 Overall Mass Balances of hydrotreatment reactions with hydrogenated solvents

\begin{tabular}{|c|c|c|c|l|c|c|c|c|}
\hline Solvent & $\begin{array}{c}\text { INPUT } \\
\text { Coal } \\
\text { (g) }\end{array}$ & $\begin{array}{c}\text { INPUT } \\
\text { Solvent } \\
\text { (g) }\end{array}$ & $\begin{array}{c}\text { Total } \\
\text { mass } \\
\text { In } \\
\mathbf{( g )}\end{array}$ & $\begin{array}{l}\text { OUTPUT } \\
\text { THF } \\
\text { insolubles } \\
\text { (g) }\end{array}$ & $\begin{array}{c}\text { OUTPUT } \\
\text { Pitch } \\
\text { (g) }\end{array}$ & $\begin{array}{c}\text { OUTPUT } \\
\text { Recovered } \\
\text { Solvent } \\
\text { (g) }\end{array}$ & $\begin{array}{c}\text { Total } \\
\text { mass } \\
\text { Out } \\
\text { (g) }\end{array}$ & $\begin{array}{c}\text { Losses } \\
\text { (\%) }\end{array}$ \\
\hline H-HCO & 4.0027 & 20.00 & 24.0027 & 2.5743 & 2.2631 & 17.34 & 22.1774 & 8.23 \\
\hline H-HCO & 3.2002 & 15.10 & 18.3002 & 2.0341 & 1.7736 & 13.02 & 16.8277 & 8.75 \\
\hline H-CBB & 4.0015 & 20.00 & 24.0015 & 1.8591 & 3.3653 & 16.85 & 22.0744 & 8.73 \\
\hline H-CBB & 4.0023 & 20.02 & 24.0025 & 1.7279 & 3.0365 & 17.23 & 21.9944 & 9.22 \\
\hline
\end{tabular}

Table 4.5 shows the overall mass balances for recovered and successive hydrotreatment reaction runs. Increased mass loss more than that for the fresh $\mathrm{H}-\mathrm{CBB}$ is noted in all cases. This is because the recovered solvents are lighter than their corresponding fresh solvents. Table $\mathbf{4 . 6}$ shows overall mass balances for hydrotreatment reactions with the solvents $\mathrm{CBB}$ and $\mathrm{H}-\mathrm{CBB}$ at different temperatures $\left(350^{\circ} \mathrm{C}\right.$ and $450^{\circ} \mathrm{C}$ ). The net mass loss with fresh solvent at $350^{\circ} \mathrm{C}$ in both hydrogen and nitrogen atmospheres is almost identical and comparable to those at $400^{\circ} \mathrm{C}$. The increase in mass loss at $450^{\circ} \mathrm{C}$ can once again be attributed to the fact that more product gases are produced at higher temperatures, and these are not recovered or counted in the mass balance. 
Table 4. 5 Overall Mass Balances with recovered solvents and successive hydrotreatment reactions

\begin{tabular}{|c|c|c|c|c|c|c|c|c|}
\hline Solvent & $\begin{array}{c}\text { INPUT } \\
\text { Coal } \\
\text { (g) }\end{array}$ & $\begin{array}{c}\text { INPUT } \\
\text { Solvent } \\
\text { (g) }\end{array}$ & $\begin{array}{c}\text { Total } \\
\text { mass in }\end{array}$ & $\begin{array}{c}\text { OUTPUT } \\
\text { THF } \\
\text { insolubles } \\
\text { (g) }\end{array}$ & $\begin{array}{c}\text { OUTPUT } \\
\text { Pitch } \\
\mathbf{( g )}\end{array}$ & $\begin{array}{c}\text { OUTPUT } \\
\text { Recovered } \\
\text { Solvent } \\
\text { (g) }\end{array}$ & $\begin{array}{c}\text { Total } \\
\text { mass } \\
\text { out }\end{array}$ & $\begin{array}{c}\text { Losses } \\
\mathbf{( \% )}\end{array}$ \\
\hline $\begin{array}{c}\text { Recovered } \\
\text { H-CBB }\end{array}$ & 4.0002 & 20.00 & 24.0002 & 2.4083 & 3.3569 & 16.02 & 21.7852 & 9.23 \\
\hline $\begin{array}{c}\text { Recovered } \\
\text { H-CBB }\end{array}$ & 4.0011 & 20.01 & 24.0111 & 2.3902 & 3.4356 & 16.13 & 21.9558 & 8.56 \\
\hline Pass 1 & 4.0004 & 20.02 & 24.0204 & 2.2018 & 3.5407 & 16.22 & 21.9625 & 9.37 \\
\hline Pass 1 & 4.0003 & 20.00 & 24.0003 & 2.1771 & 3.6451 & 16.03 & 21.8522 & 9.83 \\
\hline Pass 2 & 4.0022 & 20.02 & 24.0222 & 2.0744 & 4.6196 & 15.23 & 21.924 & 9.57 \\
\hline Pass 2 & 4.0015 & 20.02 & 24.0215 & 2.1252 & 4.6686 & 15.03 & 21.8238 & 10.07 \\
\hline
\end{tabular}

Table 4. 6 Overall Mass Balances of hydrotreatment reactions at different temperatures

\begin{tabular}{|c|c|c|c|c|c|c|c|c|}
\hline Solvent & $\begin{array}{c}\text { Reaction } \\
\text { atmosphere }\end{array}$ & $\begin{array}{c}\text { Reaction } \\
\text { Temperature } \\
\left({ }^{\circ} \mathbf{C}\right)\end{array}$ & $\begin{array}{c}\text { INPUT } \\
\text { Coal (g) }\end{array}$ & $\begin{array}{c}\text { INPUT } \\
\text { Solvent } \\
\mathbf{( g )}\end{array}$ & $\begin{array}{c}\text { OUTPUT } \\
\text { THF } \\
\text { insolubles } \\
\mathbf{( g )}\end{array}$ & $\begin{array}{c}\text { OUTPUT } \\
\text { Pitch } \\
\mathbf{( g )}\end{array}$ & $\begin{array}{c}\text { OUTPUT } \\
\text { Recovered } \\
\text { Solvent } \\
\text { (g) }\end{array}$ & $\begin{array}{c}\text { Losses } \\
\mathbf{( \% )}\end{array}$ \\
\hline $\mathrm{CBB}$ & $\mathrm{N}_{2}$ & $350^{\circ} \mathrm{C}$ & 4.0047 & 20.01 & 3.1588 & 2.5575 & 16.85 & 6.23 \\
\hline $\mathrm{CBB}$ & $\mathrm{N}_{2}$ & $350^{\circ} \mathrm{C}$ & 4.0082 & 20.02 & 3.1220 & 2.4484 & 17.23 & 6.87 \\
\hline $\mathrm{CBB}$ & $\mathrm{H}_{2}$ & $350^{\circ} \mathrm{C}$ & 4.0050 & 20.02 & 3.0639 & 2.2355 & 16.87 & 8.37 \\
\hline $\mathrm{CBB}$ & $\mathrm{H}_{2}$ & $350^{\circ} \mathrm{C}$ & 4.0072 & 20.00 & 3.0410 & 2.0346 & 17.00 & 8.75 \\
\hline $\mathrm{CBB}$ & $\mathrm{N}_{2}$ & $450^{\circ} \mathrm{C}$ & 4.0092 & 20.02 & 3.1190 & 2.0615 & 16.82 & 9.22 \\
\hline $\mathrm{CBB}$ & $\mathrm{N}_{2}$ & $450^{\circ} \mathrm{C}$ & 4.0107 & 20.02 & 3.1002 & 2.1256 & 16.73 & 9.45 \\
\hline $\mathrm{CBB}$ & $\mathrm{H}_{2}$ & $450^{\circ} \mathrm{C}$ & 4.0040 & 20.02 & 2.2324 & 2.99734 & 16.76 & 9.37 \\
\hline $\mathrm{CBB}$ & $\mathrm{H}_{2}$ & $450^{\circ} \mathrm{C}$ & 4.0073 & 20.02 & 2.2551 & 2.7519 & 16.83 & 10.03 \\
\hline
\end{tabular}




\subsection{Ash Content}

Ash contents of THF insolubles and pitch fraction were determined for all the hydrotreatment reactions using ASTM D2415 method. Ash content is a measure of inorganic oxides of the mineral matter which was present in the original coal. THF insolubles contain essentially all the mineral matter present in the coal and other unconverted organic matter of the coal. Thus the THF insolubles contain more ash than the pitch samples as most of the mineral matter gets concentrated in the THF insolubles. Low ash content is a desirable characteristic of the pitch since the mineral matter is considered as an impurity and restricts the use of pitch as a carbon product precursor. The ash content of the fresh, hydrogenated and recovered solvents was found to be negligible. Tables 4.7, 4.8, 4.9 and 4.10 show the ash contents of THF insolubles and pitches and the relative errors in their measurement.

Table 4. 7 Ash contents of THF Insolubles and pitches with fresh and hydrogenated solvents

\begin{tabular}{|c|c|c|c|c|c|}
\hline Solvent & $\begin{array}{c}\text { Reaction } \\
\text { Atmosphere }\end{array}$ & $\begin{array}{c}\text { Ash \% in } \\
\text { THF } \\
\text { insolubles }\end{array}$ & $\begin{array}{c}\text { \%Relative } \\
\text { error }\end{array}$ & $\begin{array}{c}\text { Ash \% in } \\
\text { Pitch }\end{array}$ & $\begin{array}{c}\text { \% Relative } \\
\text { error }\end{array}$ \\
\hline HCO & $\mathrm{N}_{2}$ & 10.74 & 1.07 & 0.11 & 6.32 \\
\hline HCO & $\mathrm{H}_{2}$ & 12.26 & 1.14 & 0.25 & 7.21 \\
\hline H-HCO & $\mathrm{N}_{2}$ & 11.34 & 1.86 & 0.12 & 5.22 \\
\hline CBB & $\mathrm{N}_{2}$ & 12.54 & 1.62 & 0.21 & 6.79 \\
\hline CBB & $\mathrm{H}_{2}$ & 13.99 & 1.79 & 0.24 & 7.32 \\
\hline H-CBB & $\mathrm{N}_{2}$ & 14.89 & 2.34 & 0.13 & 7.37 \\
\hline
\end{tabular}


Table 4. 8 Ash contents of THF Insolubles and pitches with combinations of fresh and hydrogenated solvents

\begin{tabular}{|l|c|c|c|c|c|}
\hline Solvent & $\begin{array}{c}\text { Reaction } \\
\text { Atmosphere }\end{array}$ & $\begin{array}{c}\text { Ash \% in } \\
\text { THF } \\
\text { insolubles }\end{array}$ & $\begin{array}{c}\text { \%Relative } \\
\text { error }\end{array}$ & $\begin{array}{c}\text { Ash \% } \\
\text { in } \\
\text { Pitch }\end{array}$ & $\begin{array}{c}\text { \% Relative } \\
\text { error }\end{array}$ \\
\hline $\begin{array}{l}\mathbf{2 5 \%} \text { H-CBB + } \\
\mathbf{7 5 \%} \text { CBB }\end{array}$ & $\mathrm{N}_{2}$ & 12.69 & .02 & 0.12 & 7.22 \\
\hline $\begin{array}{l}\mathbf{5 0 \%} \text { H-CBB }+ \\
\mathbf{5 0} \% \mathbf{C B B}\end{array}$ & $\mathrm{N}_{2}$ & 13.76 & 1.33 & 0.17 & 6.37 \\
\hline $\begin{array}{l}\mathbf{7 5 \%} \text { H-CBB + } \\
\mathbf{2 5 \%} \mathbf{C B B}\end{array}$ & $\mathrm{N}_{2}$ & 14.92 & 1.472 & 021 & 7.87 \\
\hline
\end{tabular}

Table 4. 9 Ash contents of THF Insolubles and pitches with hydrotreatment reactions at different temperatures

\begin{tabular}{|c|c|c|c|c|c|c|}
\hline Solvent & $\begin{array}{c}\text { Reaction } \\
\text { Atmosphere }\end{array}$ & $\begin{array}{c}\text { Reaction } \\
\text { Temperature }\end{array}$ & $\begin{array}{c}\text { Ash \% in } \\
\text { THF } \\
\text { insolubles }\end{array}$ & $\begin{array}{c}\text { \%Relative } \\
\text { error }\end{array}$ & $\begin{array}{c}\text { Ash \% } \\
\text { in } \\
\text { Pitch }\end{array}$ & $\begin{array}{c}\text { \% } \\
\text { Relative } \\
\text { error }\end{array}$ \\
\hline CBB & $\mathrm{N}_{2}$ & $350^{\circ} \mathrm{C}$ & 8.97 & 2.05 & 0.02 & 4.87 \\
\hline CBB & $\mathrm{N}_{2}$ & $450^{\circ} \mathrm{C}$ & 10.29 & 1.38 & 0.13 & 5.38 \\
\hline CBB & $\mathrm{H}_{2}$ & $350^{\circ} \mathrm{C}$ & 8.46 & 2.15 & 0.05 & 6.32 \\
\hline CBB & $\mathrm{H}_{2}$ & $450^{\circ} \mathrm{C}$ & 12.85 & 1.96 & 0.07 & 4.56 \\
\hline H-CBB & $\mathrm{H}_{2}$ & $350^{\circ} \mathrm{C}$ & 8.72 & 1.89 & 0.09 & 6.83 \\
\hline H-CBB & $\mathrm{H}_{2}$ & $450^{\circ} \mathrm{C}$ & 11.56 & 1.52 & 0.12 & 7.22 \\
\hline
\end{tabular}


Table 4. 10 Ash contents of THF Insolubles and pitches with recovered and successive hydrotreatment reactions

\begin{tabular}{|c|c|c|c|c|c|}
\hline Solvent & $\begin{array}{c}\text { Reaction } \\
\text { Atmosphere }\end{array}$ & $\begin{array}{c}\text { Ash \% in } \\
\text { THF } \\
\text { insolubles }\end{array}$ & $\begin{array}{c}\text { \%Relative } \\
\text { error }\end{array}$ & $\begin{array}{c}\text { Ash \% in } \\
\text { Pitch }\end{array}$ & $\begin{array}{c}\text { \% Relative } \\
\text { error }\end{array}$ \\
\hline $\begin{array}{c}\text { Recovered } \\
\text { H-CBB }\end{array}$ & $\mathrm{N}_{2}$ & 12.84 & 1.47 & 0.05 & 7.85 \\
\hline Pass 1 & $\mathrm{N}_{2}$ & 13.07 & 1.33 & 0.11 & 7.32 \\
\hline Pass 2 & $\mathrm{N}_{2}$ & 13.43 & .1 .52 & 0.08 & 6.92 \\
\hline
\end{tabular}

These results indicate that the ash content of all the THF insoluble samples was in the range of $8-15 \%$, and that for the pitches is in the range of $0.02-0.25 \%$. The ash content of the THF insolubles is much more than the ash content of the pitches for each specific reaction because of the reason mentioned above. Also, the percentage relative error in determining the ash content values is much less for the THF insolubles as this fraction contains most of the ash, whereas the pitches contain very little ash and hence give high relative errors in the ash determinations. Further it can be seen that the ash content of the THF insolubles is slightly higher for the reactions that give higher conversions. This is because higher conversions, indicated by the smaller amount of THF insolubles, have less unconverted coal in the residue and hence the ash in this case gets concentrated in a relatively small amount of unconverted mass.

\subsection{Ash Balance}

The ash values determined for the raw coal, THF insolubles and pitches are used to perform an overall ash balance on each hydrotreatment reaction. The ash balances for all 
the hydrotreatment reactions are shown in Table 4.11. The fresh, hydrogenated and recovered solvents showed negligible ash contents and were not included in the calculations.

As seen earlier, mass loss is inevitable in the products separation. Due to mass loss of lighter components, the ash gets concentrated in a relatively low mass of the final pitch product during te vacuum distillation step. Hence, the calculated ash content of the pitch products is higher than the actual value and results in a positive mass balance. The positive balance is therefore a consequence of negative mass balance. For this reason, the results with the negative ash balance were discarded and not shown

\subsection{Coke Yield and Softening Point}

Coke yield and softening point are two important properties of pitches. Coke yield is a measure of the amount of non-volatile carbon present in the pitch sample. High coke yield is a desirable characteristic for the use of these pitches as carbon product precursors since the final yield of the carbon product can be maximized. The coke yield of all the pitches produced from the hydrotreatment reactions was calculated using the WVU coking method. The softening point is the temperature at which a substance changes from a hard material to a softer and more viscous material. It is a measure of the ability of the sample to flow at a given temperature. The softening point gives an idea about the possible applications of the pitch material. 
Table 4. 11 Ash Balances of hydrotreatment reaction runs

\begin{tabular}{|c|c|c|c|c|c|c|c|}
\hline Solvent & $\begin{array}{c}\text { Reaction } \\
\text { Atmosphere }\end{array}$ & $\begin{array}{c}\text { Reaction } \\
\text { temperature }\end{array}$ & $\begin{array}{c}\text { Ash in } \\
\text { Coal } \\
\text { (g) }\end{array}$ & $\begin{array}{c}\text { Ash Out } \\
\text { THF } \\
\text { insolubles } \\
\text { (g) }\end{array}$ & $\begin{array}{c}\text { Ash } \\
\text { Out } \\
\text { Pitch } \\
\text { (g) } \\
\end{array}$ & $\begin{array}{l}\text { Total } \\
\text { Ash } \\
\text { Out (g) }\end{array}$ & $\begin{array}{c}\text { (Out- } \\
\text { in) / in } \\
(\%)\end{array}$ \\
\hline HCO & $\mathrm{N}_{2}$ & $400^{\circ} \mathrm{C}$ & 0.2748 & 0.2892 & 0.0032 & 0.2924 & 6.01 \\
\hline HCO & $\mathrm{H}_{2}$ & $400^{\circ} \mathrm{C}$ & 0.2749 & 0.2779 & 0.0079 & 0.2858 & 3.97 \\
\hline H-HCO & $\mathrm{N}_{2}$ & $400^{\circ} \mathrm{C}$ & 0.2749 & 0.2919 & 0.0027 & 0.2946 & 6.68 \\
\hline CBB & $\mathrm{N}_{2}$ & $400^{\circ} \mathrm{C}$ & 0.2757 & 0.2814 & 0.0070 & 0.2884 & 4.61 \\
\hline CBB & $\mathrm{H}_{2}$ & $400^{\circ} \mathrm{C}$ & 0.2748 & 0.2814 & 0.0080 & 0.2898 & 5.31 \\
\hline H-CBB & $\mathrm{N}_{2}$ & $400^{\circ} \mathrm{C}$ & 0.2749 & 0.2768 & 0.0081 & 0.2849 & 3.61 \\
\hline $\begin{array}{l}25 \% \text { HCBB }+ \\
75 \% \text { СВВ }\end{array}$ & $\mathrm{N}_{2}$ & $400^{\circ} \mathrm{C}$ & 0.2749 & 0.2815 & 0.0032 & 0.2847 & 3.56 \\
\hline $\begin{array}{c}50 \% \text { HCBB }+ \\
50 \% \text { CBB }\end{array}$ & $\mathrm{N}_{2}$ & $400^{\circ} \mathrm{C}$ & 0.2749 & 0.2880 & 0.0072 & 0.2952 & 7.02 \\
\hline $\begin{array}{c}75 \% \text { HCBB }+ \\
25 \% \text { СВB }\end{array}$ & $\mathrm{N}_{2}$ & $400^{\circ} \mathrm{C}$ & 0.2749 & 0.2779 & 0.0077 & 0.2856 & 3.89 \\
\hline $\begin{array}{c}\text { Recovered } \\
\text { H-CBB }\end{array}$ & $\mathrm{N}_{2}$ & $400^{\circ} \mathrm{C}$ & 0.2748 & 0.3092 & 0.0016 & 0.3108 & 13.10 \\
\hline Pass 1 & $\mathrm{~N}_{2}$ & $400^{\circ} \mathrm{C}$ & 0.2748 & 0.2877 & 0.0038 & 0.2975 & 6.07 \\
\hline Pass 2 & $\mathrm{~N}_{2}$ & $400^{\circ} \mathrm{C}$ & 0.2749 & 0.3039 & 0.0029 & 0.3068 & 11.61 \\
\hline CBB & $\mathrm{N}_{2}$ & $350^{\circ} \mathrm{C}$ & 0.2751 & 0.2833 & 0.0010 & 0.2843 & 3.34 \\
\hline CBB & $\mathrm{N}_{2}$ & $450^{\circ} \mathrm{C}$ & 0.2755 & 0.3190 & 0.0026 & 0.3216 & 16.73 \\
\hline CBB & $\mathrm{H}_{2}$ & $350^{\circ} \mathrm{C}$ & 0.2751 & 0.2894 & 0.0011 & 0.2905 & 5.60 \\
\hline CBB & $\mathrm{H}_{2}$ & $450^{\circ} \mathrm{C}$ & 0.2750 & 0.2868 & 0.0021 & 0.2889 & 5.05 \\
\hline
\end{tabular}


In the vacuum distillation step, the THF soluble fraction is separated into pitch and recovered distillate solvent. This distillation, depending upon the severity of the conditions and amount of solvent recovered, affects the final coke yield and the softening point of the pitch. In previous work done at WVU, it was shown that the final properties of the pitch can be tailored by distilling various amounts of light distillate solvent. In the present research, in order to determine the effect of the reaction type i.e., the solvent, reaction atmosphere and reaction temperature on the final pitch material, all the distillation conditions were fixed during the distillation. The amount of solvent recovered was $80-85 \%$ and a vacuum of $30 \mathrm{~mm} \mathrm{Hg}$ was maintained constant for all the distillations. The final vapor temperature in the pot was kept in the range of $200^{\circ} \mathrm{C}$ to $220^{\circ} \mathrm{C}$. Table 4.12 shows the coke yield and softening point values of the pitch fraction for the coal hydrotreatment reactions with fresh solvents in $\mathrm{N}_{2}$ and $\mathrm{H}_{2}$.

Table 4. 12 Coke yield and softening points of the pitch fraction for coal hydrotreatment with fresh as received solvents in $\mathrm{N}_{2}$ and $\mathrm{H}_{2}$ reaction atmospheres at $400^{\circ} \mathrm{C}$

\begin{tabular}{|c|c|c|c|}
\hline Solvent & $\begin{array}{c}\text { Reaction } \\
\text { Atmosphere }\end{array}$ & Coke Yield, \% & $\begin{array}{c}\text { Softening Point } \\
\left({ }^{\circ} \mathbf{C}\right)\end{array}$ \\
\hline HCO & $\mathrm{N}_{2}$ & 54.52 & 154.8 \\
\hline CBB & $\mathrm{N}_{2}$ & 57.55 & 145.2 \\
\hline HCO & $\mathrm{H}_{2}$ & 61.13 & 157.7 \\
\hline CBB & $\mathrm{H}_{2}$ & 45.65 & 122.3 \\
\hline
\end{tabular}


It can be seen from the Table 4.12 that the coke yields for both the solvents is in the range of $50 \%-70 \%$ and the softening point is in the range of $120^{\circ} \mathrm{C}-160^{\circ} \mathrm{C}$. The coke yield is similar to the coke yield of the commercial pitches $(50 \%-60 \%)$. There is little or no dependence of the solvent type on the coke yield in $\mathrm{N}_{2}$ atmosphere whereas there is a difference in coke yield with the solvent type in $\mathrm{H}_{2}$ atmosphere. The softening point of $\mathrm{CBB}$ in $\mathrm{H}_{2}$ atmosphere is very low compared with the other solvents. The higher softening points of above $120^{\circ} \mathrm{C}$ are too high for their application as the binder pitches, but they can be used in applications that require high softening point and high coke yields.

Table 4.13 shows the coke yield and softening points of the pitch fraction for coal hydrotreatment with hydrogenated solvents in $\mathrm{N}_{2}$ atmosphere at $400^{\circ} \mathrm{C}$. The coke yields are once again in the desirable range for the binder pitches. The softening point of pitch with $\mathrm{H}-\mathrm{CBB}$ is very high when compared with that of the solvent $\mathrm{H}-\mathrm{HCO}$.

Table 4. 13 Coke yield and softening points of the pitch fraction for coal hydrotreatment with hydrogenated solvents in 500 psig $\mathrm{N}_{2}$ (cold) at $400^{\circ} \mathrm{C}$

\begin{tabular}{|c|c|c|}
\hline Solvent & Coke Yield, \% & Softening Point $\left({ }^{\circ} \mathbf{C}\right)$ \\
\hline H-HCO & 55.06 & 145.5 \\
\hline H-CBB & 68.98 & 171.3 \\
\hline
\end{tabular}

Table 4.14 shows the coke yield and softening points of the pitch fraction for coal hydrotreatment with recovered $\mathrm{H}-\mathrm{CBB}$ and the successive hydrotreatment reactions with 
make-up H-CBB in 500 psig $\mathrm{N}_{2}$ (cold) and $400^{\circ} \mathrm{C}$. The softening points were found to decrease with the use of the recovered solvent in the successive hydrotreatment reactions where additional $\mathrm{H}-\mathrm{CBB}$ was included as make up.

Table 4. 14 Coke yield and softening points of the pitch fraction for coal hydrotreatment with recovered solvents and with successive hydrotreatment reactions in 500 psig $\mathrm{N}_{2}$ (cold) at $400^{\circ} \mathrm{C}$

\begin{tabular}{|c|c|c|}
\hline Solvent & Coke Yield, \% & Softening Point $\left({ }^{\circ} \mathbf{C}\right)$ \\
\hline Recovered H-CBB & 65.59 & 160.7 \\
\hline Pass 1 & 49.57 & 155.2 \\
\hline Pass 2 & 47.95 & 135.8 \\
\hline
\end{tabular}

Figure 4.16 shows the dependence of the softening point on the reaction temperature for the solvents $\mathrm{CBB}$ and $\mathrm{H}-\mathrm{CBB}$ in $\mathrm{N}_{2}$ and/or $\mathrm{H}_{2}$ atmospheres. It is evident that there is a difference in the softening point with changes in the hydrotreatment temperature when all other conditions are kept constant during the vacuum distillation step. However the dependence is quite random with the solvent type and gaseous atmosphere. The hydrogenated solvents gave higher softening point pitches than the fresh solvents. Figure 4.17 shows the change of softening points (for the same vacuum distillation conditions as mentioned above) with the composition of blends of fresh and hydrogenated CBB, the highest and lowest softening points being produced with $\mathrm{H}-\mathrm{CBB}$ and fresh $\mathrm{CBB}$ respectively. The blends of $25 \%, 50 \%$ and $75 \% \mathrm{H}-\mathrm{CBB} / \mathrm{CBB}$ showed relatively constant softening points, where the coal-alone conversions were comparable. 


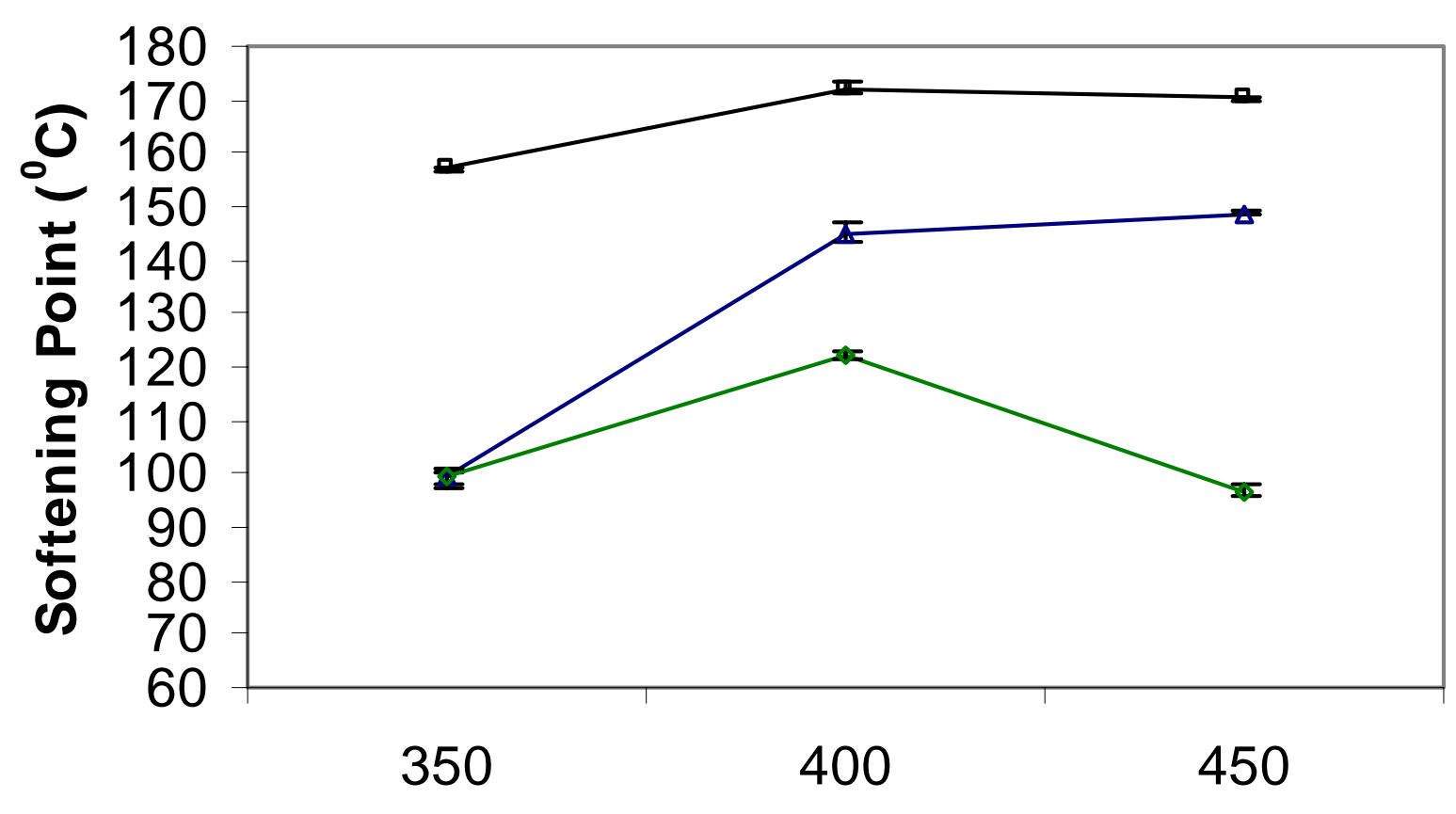

Hydrotreatment Temperature $\left({ }^{\circ} \mathrm{C}\right)$ $\rightarrow \mathrm{CBB}(\mathrm{N}) \rightarrow \mathrm{CBB}(\mathrm{H}) \rightarrow \mathrm{H}-\mathrm{CBB}(\mathrm{N})$

\section{N-Nitrogen H-Hydrogen}

Figure 4. 16 Dependence of Softening points of the pitch on the coal hydrotreatment temperature for fresh and hydrogenated solvents in $\mathbf{N}_{2}$ and/or $\mathrm{H}_{2}$ atmospheres 


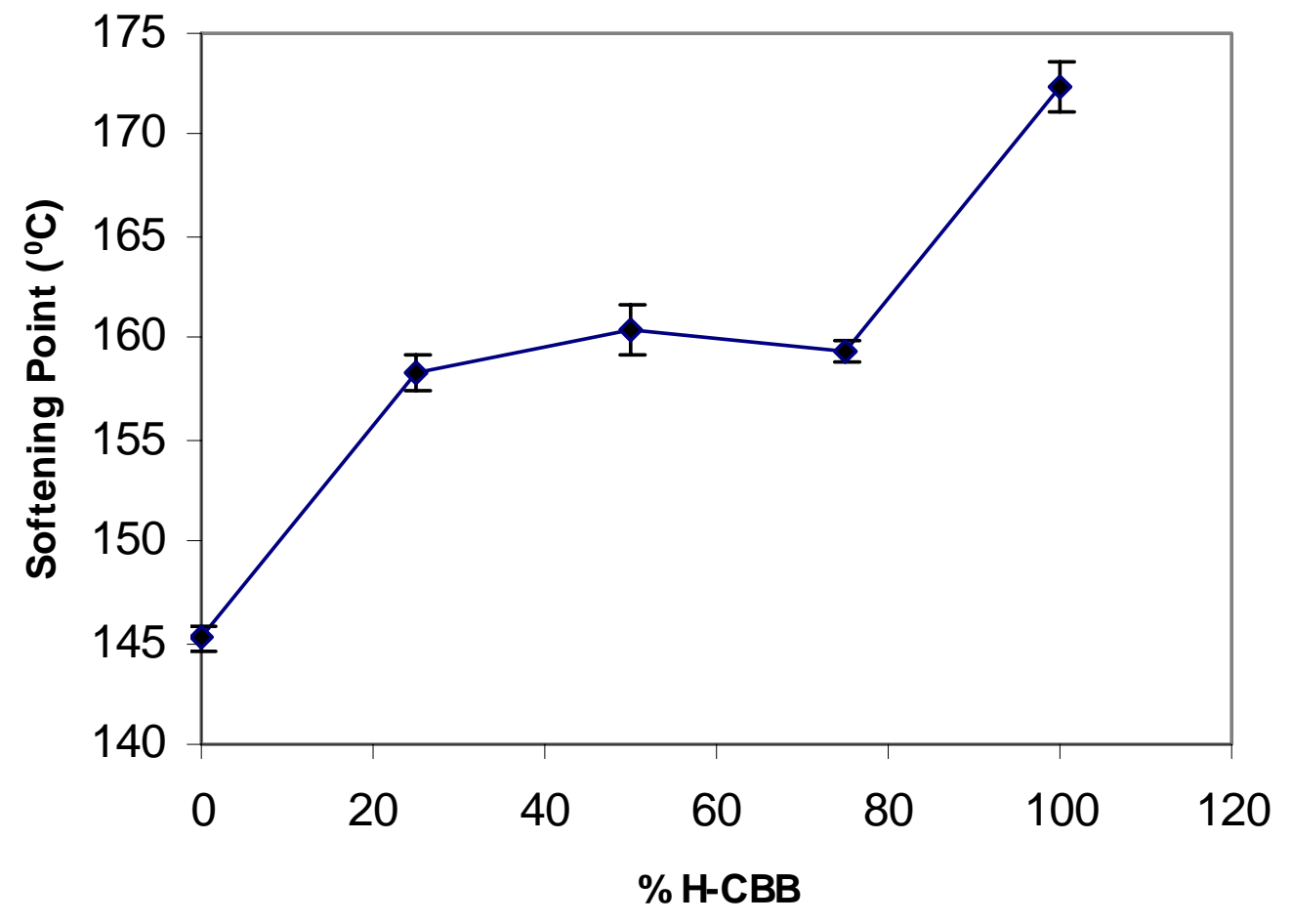

Figure 4. 17 Relationship between percent $\mathrm{H}-\mathrm{CBB}$ in CBB and softening point of pitches produced from coal hydrotreatment at $400^{\circ} \mathrm{C}$ and 500 psig N2 (cold) 
The high softening points that are seen in all these cases are a consequence of the severe distillation conditions. One way of reducing the softening point of the pitch is by reducing the severity of the distillation as it leaves more lighter species behind in the pitch. Therefore, it is important to strike a balance between the pitch yield and the softening point on the commercial scale.

Figure 4.18 shows the relationship between the coke yield and softening point of the pitches from fresh, hydrogenated, recovered and successive hydrotreatment reaction solvents. It can be seen from Figure 4.18 that, while there is some scatter in the data, there exists an approximate linear dependence between coke yield and softening points, irrespective of the solvents used and the hydrotreatment gaseous atmosphere.

\subsection{Optical Texture}

Optical texture of the coke is an important property that determines its end applications. As discussed earlier, the texture can be isotropic or anisotropic. It reveals any graphitization properties of the sample. The isotropic cokes are used for production of nuclear graphite while the anisotropic cokes are used for the production of graphite electrodes. The cokes that are produced using the WVU coking method are embedded in the epoxy and polished to view them under the optical microscope. Figures 4.19 $\mathrm{A}$ and B are optical micrographs of cokes from the coal hydrotreatment with solvents $\mathrm{HCO}$ and $\mathrm{CBB}$ respectively at $500 \mathrm{psig} \mathrm{N}_{2}$ (cold) and $400^{\circ} \mathrm{C}$. Figures 4.20 A and B are optical 


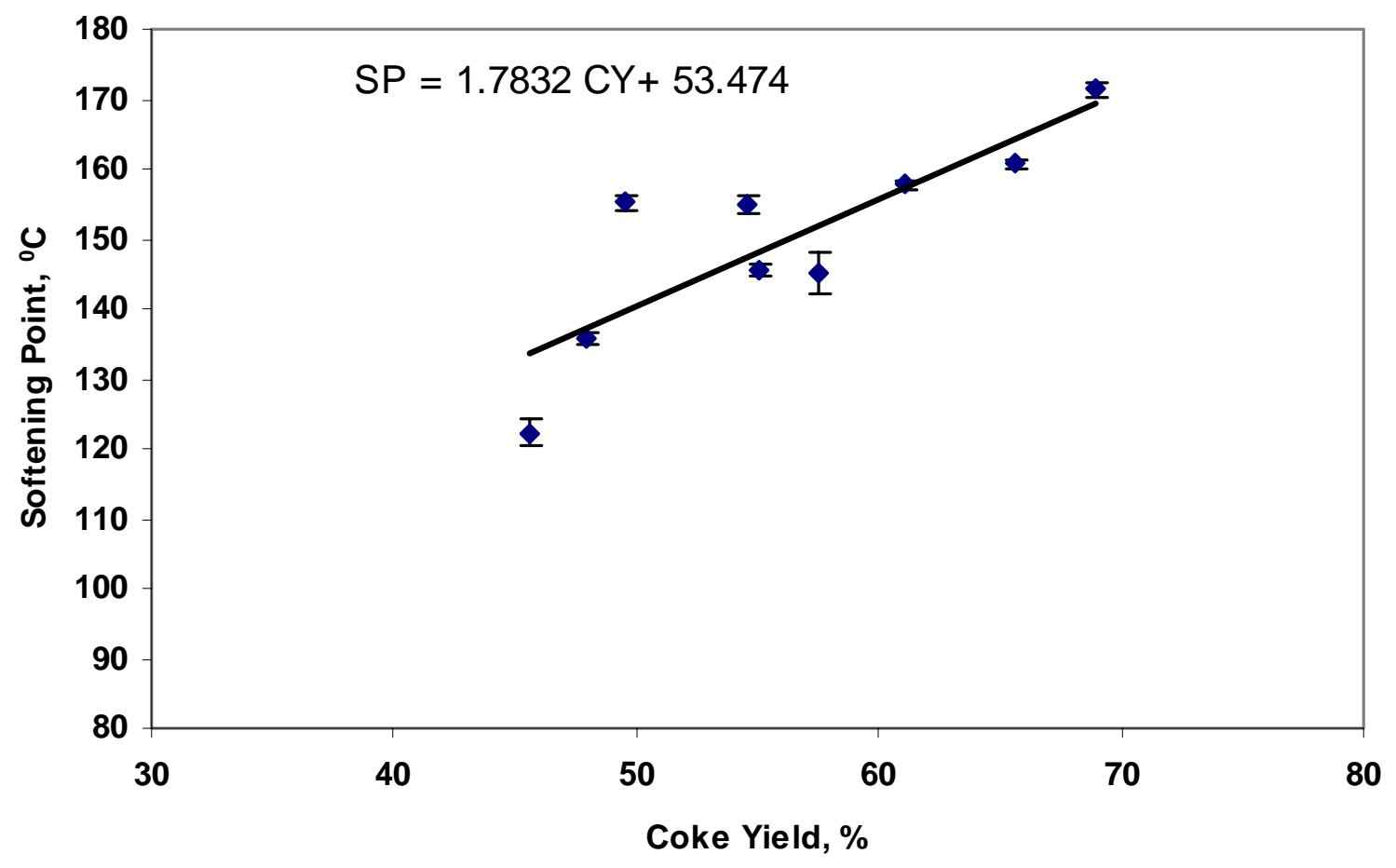

Figure 4. 18 Relationship between coke yield and softening point of the pitches produced from coal hydrotreatment at $400^{\circ} \mathrm{C}$ and 500 psig $\mathrm{N}_{2}$ or $\mathrm{H}_{2}$ (cold) 

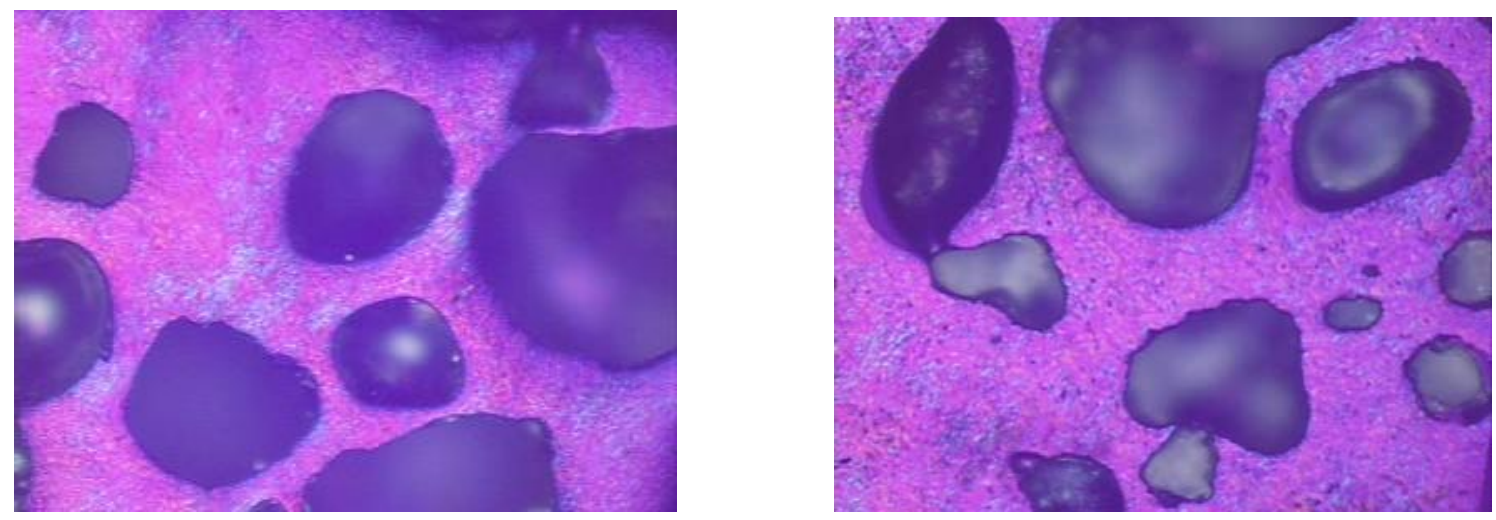

A

B

Figure 4. $19 \mathrm{~A}$ and B Optical micrographs of cokes from the coal hydrotreatment with solvents $\mathrm{HCO}$ and $\mathrm{CBB}$ respectively at 500 psig $\mathrm{N}_{2}$ (cold) and $400^{\circ} \mathrm{C}, 160 \mathrm{X}$, polarized light tinted plate

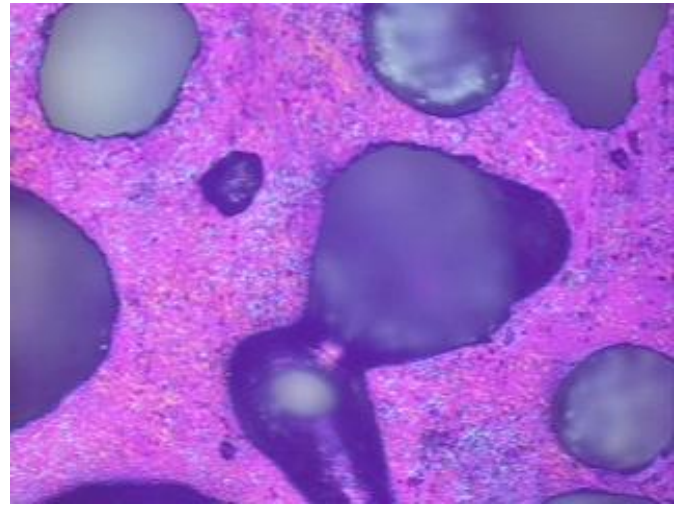

A

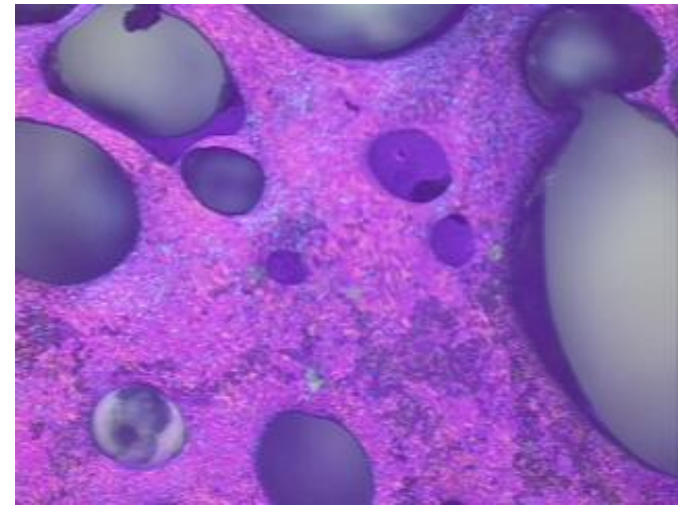

B

Figure 4. 20 A and B Optical micrographs of cokes from the coal hydrotreatment with solvents $\mathrm{HCO}$ and $\mathrm{CBB}$ at $500 \mathrm{psig}_{2}$ (cold) and $400^{\circ} \mathrm{C}, 160 \mathrm{X}$, polarized light tinted plate 
micrographs of cokes from the coal hydrotreatment with solvents $\mathrm{HCO}$ and $\mathrm{CBB}$ respectively at $500 \mathrm{psig} \mathrm{H}_{2}$ (cold) and $400^{\circ} \mathrm{C}$.

From Figures 4.19 and 4.20, it can be seen that all the cokes show an incipient mesophase indicating that they are more isotropic. Figures 4.21 A and B are the optical micrographs of cokes from the coal hydrotreatment with solvents $\mathrm{H}-\mathrm{HCO}$ and $\mathrm{H}-\mathrm{CBB}$ respectively at $500 \mathrm{psig} \mathrm{N}_{2}$ (cold) and $400^{\circ} \mathrm{C}$. It can be seen that the optical textures of all these coke samples are more anisotropic when compared to the cokes produced with their corresponding fresh solvents. Figures 4.22 A, B and C are the optical micrographs of cokes from the coal hydrotreatment with solvents recovered $\mathrm{H}-\mathrm{CBB}$, pass 1 and pass 2 solvents respectively at $500 \mathrm{psig} \mathrm{N}_{2}$ (cold) and $400^{\circ} \mathrm{C}$. The textures of the coke produced with recovered $\mathrm{H}-\mathrm{CBB}$ are isotropic and those produced with pass 1 and pass 2 solvents are more anisotropic.

Figures 4.23 A, B, C and D are the optical micrographs of cokes from the coal hydrotreatment with solvent $\mathrm{CBB}$ at $350^{\circ} \mathrm{C}$ and $450^{\circ} \mathrm{C}$ and $500 \mathrm{psig} \mathrm{N}_{2} / \mathrm{H}_{2}$. Figures 4.24 A and $\mathbf{B}$ are the optical micrographs of cokes from the coal hydrotreatment with solvent $\mathrm{H}-\mathrm{CBB}$ at $350^{\circ} \mathrm{C}$ and $450^{\circ} \mathrm{C}$ and $500 \mathrm{psig} \mathrm{N}_{2}$ respectively. From Figures 4.23 and 4.24, it can be seen that, irrespective of the solvent and gaseous atmosphere of coal hydrotreatment, the coke produced from runs at a hydrotreatment temperature of $450^{\circ} \mathrm{C}$ are more anisotropic and those produced at hydrotreatment temperature of $350^{\circ} \mathrm{C}$ are isotropic. Thus it is found that higher anisotropy is produced when the hydrotreated solvents are used or the reaction temperature is higher $\left(450^{\circ} \mathrm{C}\right)$. 


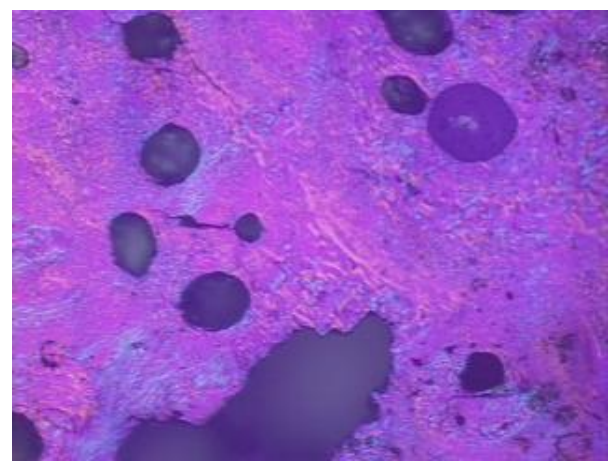

A

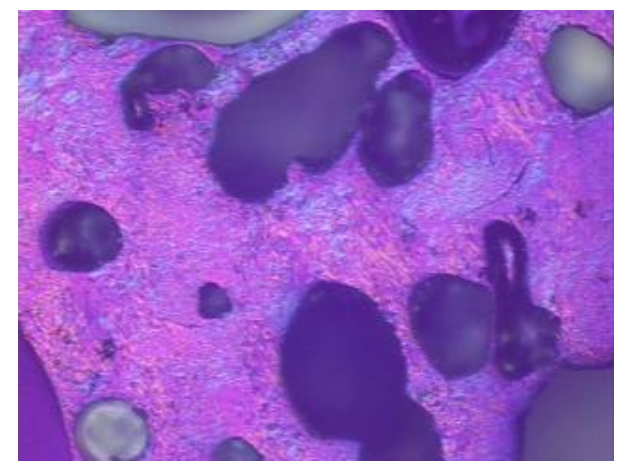

B

Figure 4. 21 A and B Optical micrographs of cokes from the coal hydrotreatment with solvents $\mathrm{H}-\mathrm{HCO}$ and $\mathrm{H}-\mathrm{CBB}$ at 500 psig $\mathrm{H}_{2}$ (cold) and $400^{\circ} \mathrm{C}, 160 \mathrm{X}$, polarized light tinted plate

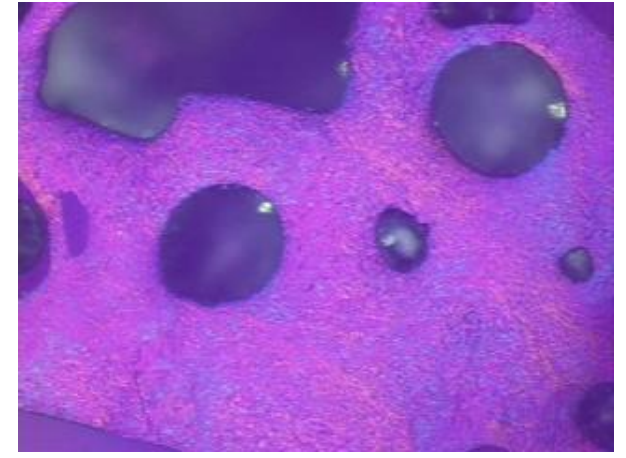

A

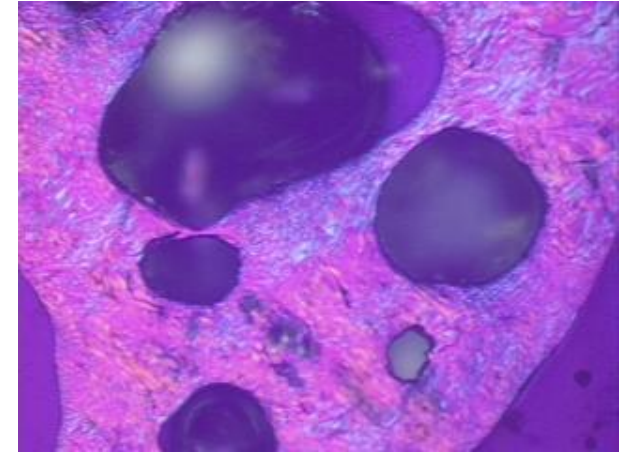

B

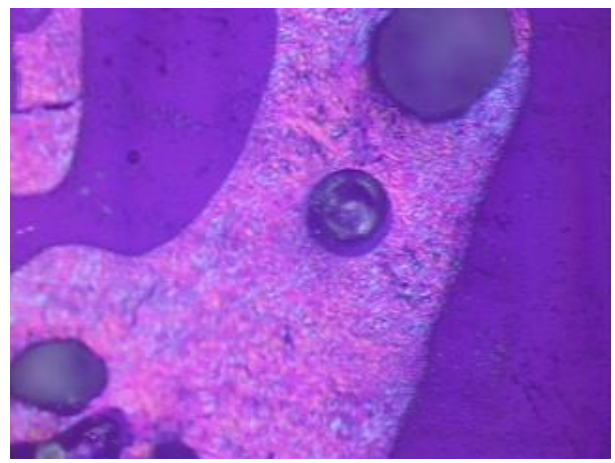

C

Figure 4. 22 A, B and C Optical micrographs of cokes from the coal hydrotreatment with solvents recovered $\mathrm{H}-\mathrm{CBB}$, pass 1 and pass 2 at $500 \mathrm{psig} \mathrm{H}_{2}$ (cold) and $400^{\circ} \mathrm{C}$, $160 \mathrm{X}$, polarized light tinted plate 


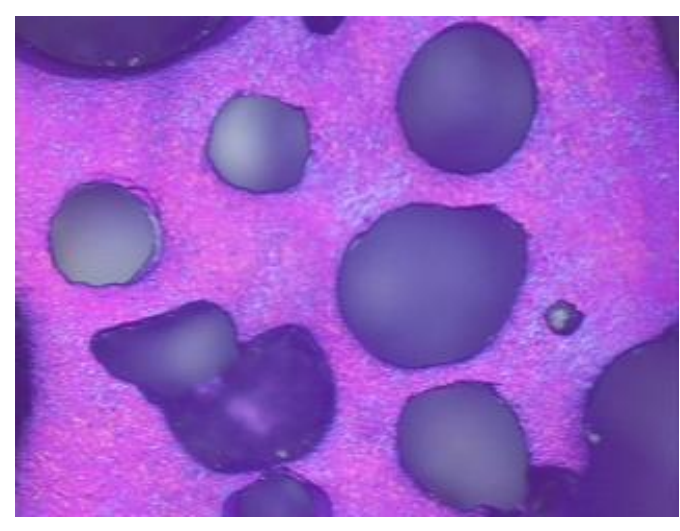

$350^{\circ} \mathrm{C}$ and 500 psig $\mathrm{N}_{2}$

A

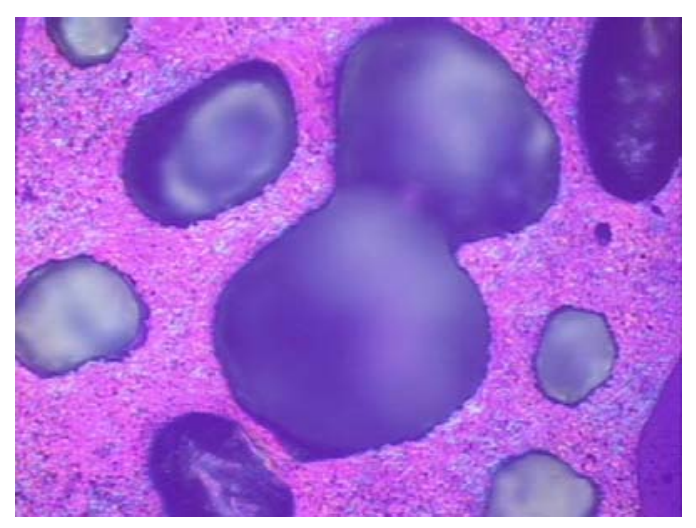

$350^{\circ} \mathrm{C}$ and 500 psig $\mathrm{H}_{2}$

C

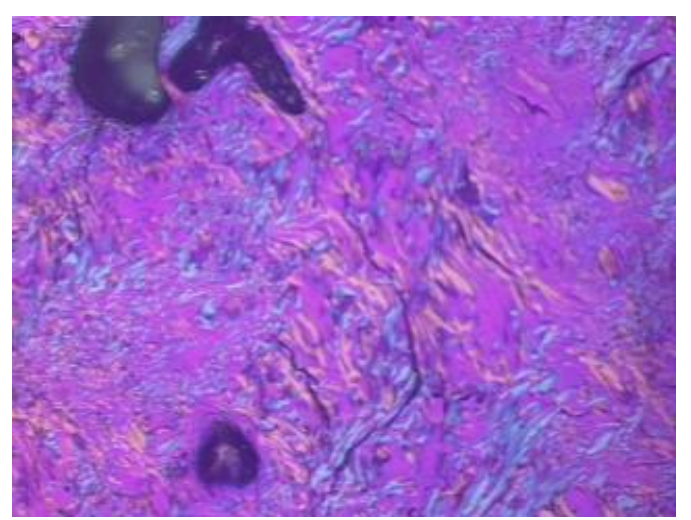

$450^{\circ} \mathrm{C}$ and $500 \mathrm{psi}_{2}$

B

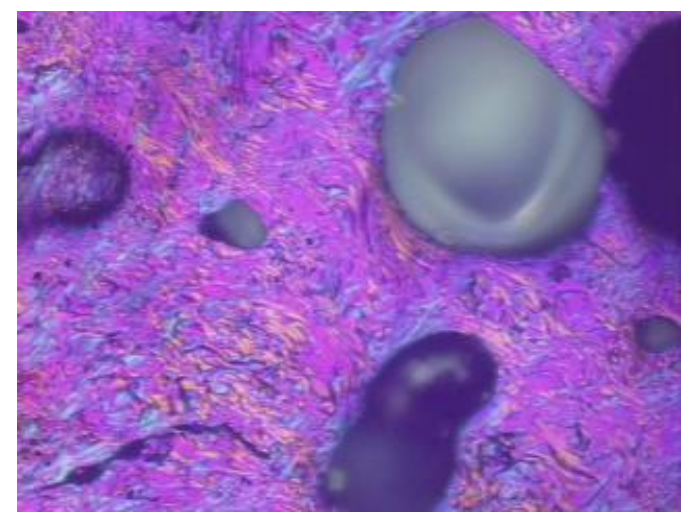

$450^{\circ} \mathrm{C}$ and 500 psig $\mathrm{H}_{2}$

D

Figure 4. 23 Optical micrographs of cokes from the coal hydrotreatment with solvent $\mathrm{CBB}$ at $350^{\circ} \mathrm{C}$ and $450^{\circ} \mathrm{C}$ and 500 psig $\mathrm{H}_{2} / \mathrm{N}_{2}$ (cold), $160 \mathrm{X}$, polarized light tinted plate 


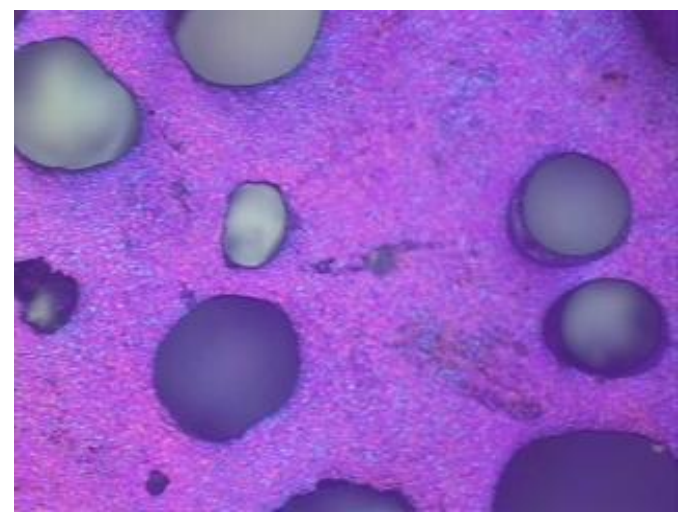

A

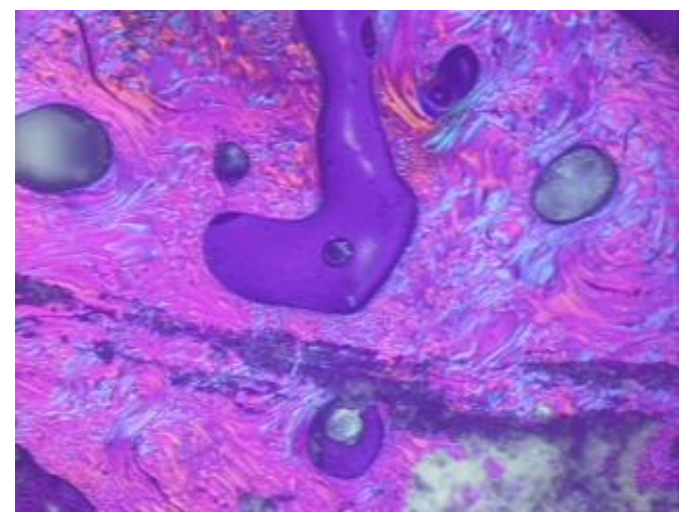

B

Figure 4. 24 A and B Optical micrographs of cokes from the coal hydrotreatment with solvent $\mathrm{H}-\mathrm{CBB}$ at $350^{\circ} \mathrm{C}$ and $450^{\circ} \mathrm{C}$ and $500 \mathrm{psig} \mathrm{N}_{2}$ (cold), $160 \mathrm{X}$, polarized light tinted plate 


\subsection{Elemental Analysis}

An elemental analysis was performed on both the input and output fractions of all the hydro-treatment reactions. The percentages of Carbon, Hydrogen, Nitrogen and Sulfur were determined for all the samples. The errors in the determination of nitrogen and sulfur are much higher when compared to that of carbon and hydrogen as the former are present in much smaller quantities. In some cases, a value of zero was shown for the pitches due to the very minute quantities of sulfur present in those samples. Due to the above reasons, only the carbon and hydrogen amounts were considered in the further discussion. Table 4.15 shows the elemental compositions for fresh solvent, THF insolubles, pitch and the recycle solvent with fresh, as-received solvents in $\mathrm{N}_{2}$ and $\mathrm{H}_{2}$ atmospheres at $400^{\circ} \mathrm{C}$. The following observations that can be made from Table 4.15 are:

1 The percentage of carbon increases from the coal $(81.04 \%)$ to the pitch material.

$2 \mathrm{H} / \mathrm{C}$ ratio of THF insoluble fraction is significantly less than that of the pitch product indicating that THF insoubles fraction is the heavier portion of the coal and the pith product is the lighter portion of the coal

$3 \mathrm{H} / \mathrm{C}$ ratio of the recycle solvent is same or slightly more than the starting solvent. This is probably because of the $\mathrm{H}$-shuttling in coal transferring hydrogen from the coal matrix to the solvent or because of some associated THF that is not totally separated during the roto-evaporation. 
Table 4. 15 Elemental compositions of fresh solvent, THF Insolubles, pitch and recycle solvent from hydrotreatment reactions with fresh, as-received solvents in $\mathbf{N}_{2}$ and $\mathrm{H}_{2}$ atmospheres at $400^{\circ} \mathrm{C}$

H/C Ratio of Coal: 0.76

\begin{tabular}{|c|c|c|c|c|c|c|}
\hline \multirow[b]{2}{*}{ SOLVENT } & \multirow[b]{2}{*}{$\begin{array}{c}\text { REACTION } \\
\text { ATMOSPHERE }\end{array}$} & \multirow[b]{2}{*}{ ELEMENT } & \multirow[b]{2}{*}{$\begin{array}{l}\text { FRESH } \\
\text { SOLVENT } \\
(\%)\end{array}$} & \multicolumn{3}{|c|}{ PRODUCT FRACTION } \\
\hline & & & & $\begin{array}{c}\text { THF } \\
\text { Insolubles } \\
\text { (\%) }\end{array}$ & $\begin{array}{l}\text { Pitch } \\
(\%)\end{array}$ & $\begin{array}{c}\text { Recycle } \\
\text { Solvent } \\
(\%)\end{array}$ \\
\hline \multirow{5}{*}{ HCO } & \multirow{5}{*}{$\mathrm{N}_{2}$} & C & 92.3 & 83.7 & 89.3 & 92.6 \\
\hline & & $\mathrm{H}$ & 5.8 & 4.6 & 5.3 & 6.1 \\
\hline & & N & 2.8 & 1.8 & 2.6 & 1.0 \\
\hline & & $\mathrm{s}$ & 0.4 & 0.1 & 0.0 & 0.0 \\
\hline & & $\begin{array}{l}\text { H/C Atomic } \\
\text { Ratio }\end{array}$ & 0.75 & 0.66 & 0.71 & 0.79 \\
\hline \multirow{5}{*}{ CBB } & \multirow{5}{*}{$\mathrm{N}_{2}$} & C & 91.6 & 80.4 & 89.7 & 91.1 \\
\hline & & $\mathrm{H}$ & 5.7 & 4.3 & 5.5 & 5.7 \\
\hline & & N & 1.1 & 2.1 & 2.0 & 1.3 \\
\hline & & $\mathrm{s}$ & 0.5 & 0.7 & 0.5 & 0.4 \\
\hline & & $\begin{array}{l}\text { H/C Atomic } \\
\text { Ratio }\end{array}$ & 0.74 & 0.64 & 0.74 & 0.75 \\
\hline \multirow{5}{*}{ HCO } & \multirow{5}{*}{$\mathrm{H}_{2}$} & c & 92.3 & 76.6 & 88.9 & 93.1 \\
\hline & & $\mathrm{H}$ & 5.8 & 4.1 & 5.4 & 6.0 \\
\hline & & N & 2.8 & 1.6 & 3.0 & 1.0 \\
\hline & & $\mathrm{s}$ & 0.4 & 0.4 & 0.0 & 0.0 \\
\hline & & $\begin{array}{l}\text { H/C Atomic } \\
\text { Ratio }\end{array}$ & 0.75 & 0.64 & 0.73 & 0.77 \\
\hline \multirow{5}{*}{ CBB } & \multirow{5}{*}{$\mathrm{H}_{2}$} & C & 91.6 & 57.5 & 90.2 & 90.6 \\
\hline & & $\mathrm{H}$ & 5.7 & 2.9 & 5.6 & 5.9 \\
\hline & & $\mathrm{N}$ & 1.1 & 1.0 & 1.3 & 1.1 \\
\hline & & S & 0.5 & 0.6 & 0.5 & 0.3 \\
\hline & & $\begin{array}{l}\text { H/C Atomic } \\
\text { Ratio }\end{array}$ & 0.74 & 0.61 & 0.75 & 0.78 \\
\hline
\end{tabular}


Table 4.16 shows the elemental compositions for fresh solvent, THF insolubles, pitch and the recycle solvent with hydrogenated solvents in $\mathrm{N}_{2}$ atmosphere at $400^{\circ} \mathrm{C}$. It can be seen that the $\mathrm{H} / \mathrm{C}$ ratio of the recycle solvent from $\mathrm{H}-\mathrm{CBB}$ is less compared to that of fresh $\mathrm{H}-\mathrm{CBB}$. This explains the lower coal-alone conversions with recovered $\mathrm{H}-\mathrm{CBB}$ compared to fresh H-CBB solvent.

Table 4. 16 Elemental compositions of fresh solvent, THF insolubles, pitch and recycle solvent from hydrotreatment reactions with hydrogenated solvents in $\mathrm{N}_{2}$ atmosphere at $400^{\circ} \mathrm{C}$

\section{H/C Ratio of Coal: 0.76}

\begin{tabular}{|c|c|c|c|c|c|}
\hline \multirow[b]{2}{*}{ SOLVENT } & \multirow[b]{2}{*}{ ELEMENT } & \multirow[b]{2}{*}{$\begin{array}{c}\text { FRESH } \\
\text { SOLVENT } \\
(\%) \\
\end{array}$} & \multicolumn{3}{|c|}{ PRODUCT FRACTION } \\
\hline & & & $\begin{array}{c}\text { THF } \\
\text { Insolubles } \\
\text { (\%) } \\
\end{array}$ & $\begin{array}{c}\text { Pitch } \\
(\%)\end{array}$ & $\begin{array}{c}\text { Recycle } \\
\text { Solvent } \\
\text { (\%) }\end{array}$ \\
\hline \multirow{5}{*}{ H-HCO } & C & 92.2 & 82.3 & 90.0 & 93.0 \\
\hline & $\mathrm{H}$ & 5.9 & 4.5 & 5.6 & 6.2 \\
\hline & $\mathrm{N}$ & 3.5 & 1.8 & 2.0 & 1.0 \\
\hline & $S$ & 0.2 & 0.2 & 0.0 & 0.0 \\
\hline & $\begin{array}{c}\mathrm{H} / \mathrm{C} \\
\text { Atomic Ratio }\end{array}$ & 0.77 & 0.66 & 0.75 & 0.80 \\
\hline \multirow{5}{*}{ H-CBB } & C & 92.7 & 73.0 & 89.4 & 92.6 \\
\hline & $\mathrm{H}$ & 6.8 & 3.7 & 5.8 & 5.7 \\
\hline & $\mathrm{N}$ & 0.8 & 1.6 & 2.0 & 0.9 \\
\hline & $\mathrm{S}$ & 0.0 & 0.7 & 0.4 & 0.5 \\
\hline & $\begin{array}{c}\mathrm{H} / \mathrm{C} \\
\text { Atomic Ratio }\end{array}$ & 0.88 & 0.61 & 0.78 & 0.74 \\
\hline
\end{tabular}




\subsection{Carbon Balance}

An elemental carbon balance was performed on the hydrotreatment reactions with fresh, as-received solvents in $\mathrm{N}_{2}$ and $\mathrm{H}_{2}$ atmospheres. These are shown in Table 4.17. The elemental balance was done only on the carbon as it is the major constituent of all the input and output fractions. The results were quite in agreement with their respective mass balances which showed a net mass loss. At the high hydrotreatment temperatures, carbon forms gaseous products like $\mathrm{CO}, \mathrm{CO}_{2}, \mathrm{CH}_{4}$ etc. Most of the carbon could be lost with the gas phase products produced during the hydrotreatment reaction.

Table 4. 17 Elemental carbon balance of hydrotreatment reactions with fresh, asreceived solvents in $\mathrm{N}_{2}$ and $\mathrm{H}_{2}$ atmospheres

\begin{tabular}{|c|c|c|c|c|}
\hline Solvent & $\begin{array}{c}\text { Reaction } \\
\text { Atmosphere }\end{array}$ & $\begin{array}{c}\text { Carbon } \\
\text { In (g) }\end{array}$ & $\begin{array}{c}\text { Carbon } \\
\text { Out (g) }\end{array}$ & Losses (\%) \\
\hline $\mathrm{HCO}$ & $\mathrm{N}_{2}$ & 21.7142 & 20.4804 & 5.7 \\
\hline $\mathrm{HCO}$ & $\mathrm{H}_{2}$ & 21.7040 & 20.4010 & 6.0 \\
\hline $\mathrm{CBB}$ & $\mathrm{N}_{2}$ & 21.5731 & 20.2567 & 6.1 \\
\hline $\mathrm{CBB}$ & $\mathrm{H}_{2}$ & 21.5836 & 19.7465 & 8.5 \\
\hline
\end{tabular}

\subsection{Nuclear Magnetic Resonance}

Figures 4.25 and 4.26 are the NMR spectrums for fresh H-CBB and recoverd $\mathrm{H}$ CBB. Chemical shifts differ for protons depending on whether they are aromatic or aliphatic, attached to a $\mathrm{C}-\mathrm{C}$ (alkane) or $\mathrm{C}=\mathrm{C}$ (alkene) unit, and hence shown as two different peaks in the spectrum. The aromatic and aliphatic contents of fresh $\mathrm{H}-\mathrm{CBB}$ are $82.08 \%$ and $18.58 \%$ respectively. The aromatic and aliphatic contents of recovered H- 
CBB are $71.85 \%$ and $28.34 \%$ respectively. It should be noted that the recovered solvent has some coal associated with it. Thus the observed behavior of the changes in aromatic/ aliphatic nature is confounded by the presence of reacted solvent on the one hand and the products from the coal on the other. Hence no definitive conclusions can be drawn on these NMR data. 


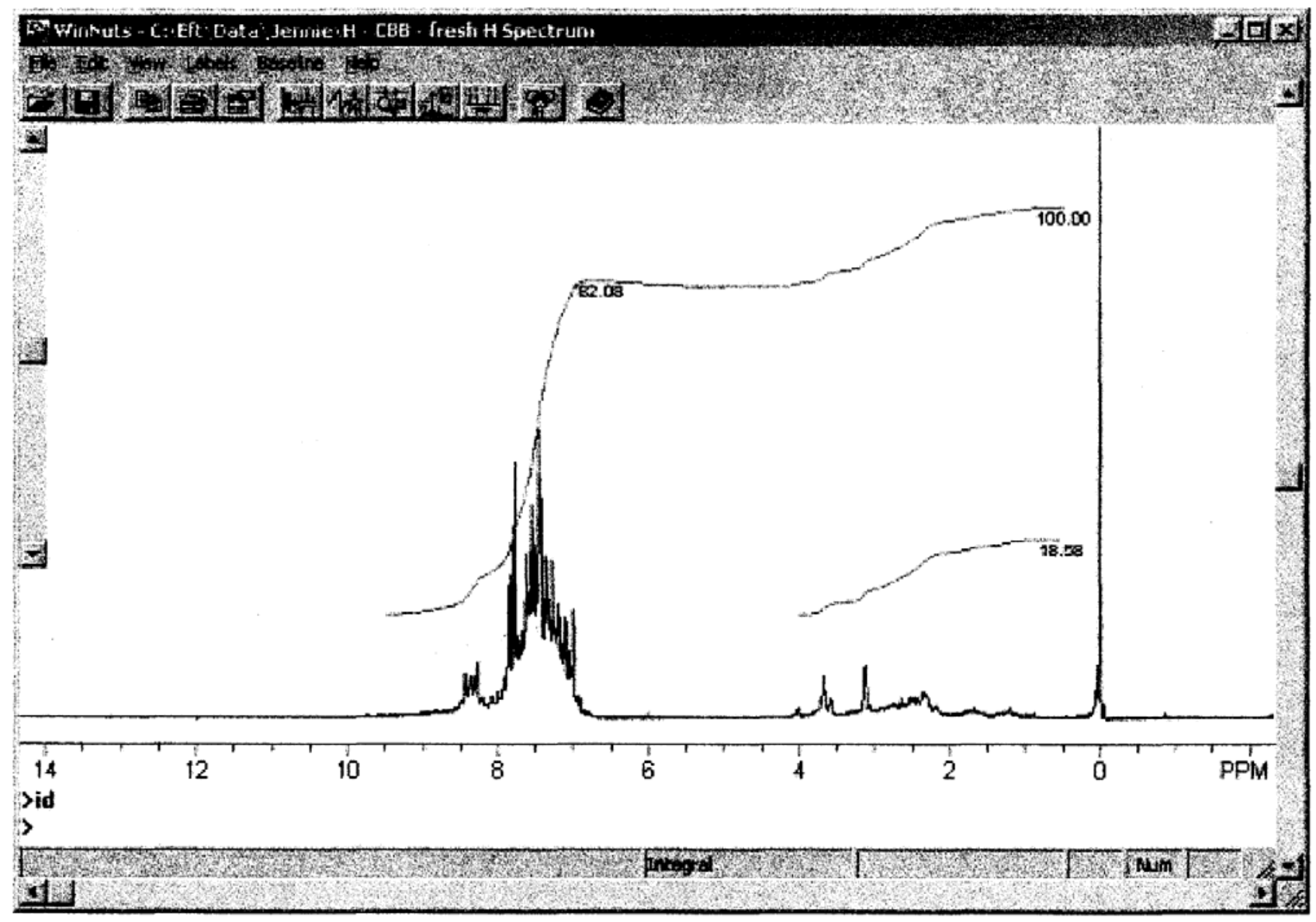

Figure 4. 25 NMR Spectra for fresh H-CBB 


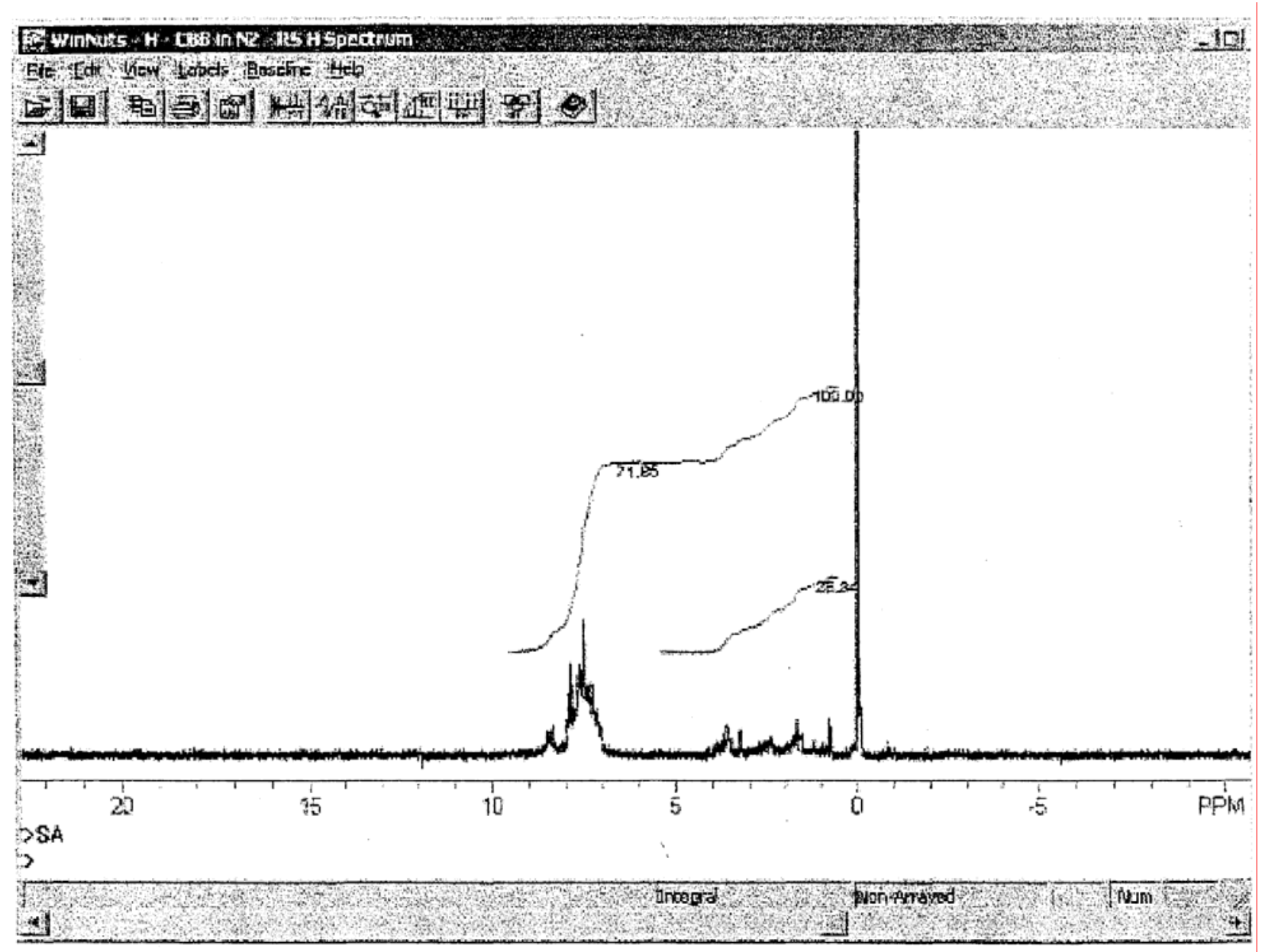

Figure 4. 26 NMR Spectra for recovered H-CBB 


\section{Chapter 5 \\ CONCLUSIONS AND FUTURE RECOMMENDATIONS}

The objective of this research is to investigate the effectiveness of two coalderived solvents as hydrogen donors in the coal hydrotreatment reaction. The two solvents $\mathrm{HCO}$ and $\mathrm{CBB}$ were tested both in $\mathrm{N}_{2}$ and $\mathrm{H}_{2}$ atmospheres in the coal hydrotreatment reaction. The effectiveness of two catalysts, unconverted residue and $\mathrm{NiO} / \mathrm{MoO}_{3}$, on solvent hydrogenation was investigated. Further, the effectiveness of these hydrogenated solvents as hydrogen donors in the coal hydrotreatment was investigated. The recovered solvent and successive hydrotreatment reactions with fresh make-up solvent added to the recovered solvent were also investigated as hydrogen-donor solvents in the coal hydrotreatment reactions. The products from all these coal hydrotreatment reactions were separated into THF insoblues (unconverted coal), pitch (distillation bottom) and recovered solvent (distillate). The pitch products were evaluated for use as carbon-product precursors. Finally, the effect of reaction temperature on the coal hydrotreatment reaction was investigated to understand its effect on the coal conversion and the properties of the products. From these experiments, the following conclusions can be drawn:

\subsection{Conclusions}

1. As-received $\mathrm{CBB}$ is more effective hydrogen donor solvent than as-received $\mathrm{HCO}$ in coal hydrotreatment both in $\mathrm{N}_{2}$ and $\mathrm{H}_{2}$ atmospheres. The increase in coal-alone conversion from $\mathrm{N}_{2}$ to $\mathrm{H}_{2}$ atmosphere was much more significant with the solvent 
$\mathrm{HCO}$ indicating that the presence of gaseous hydrogen is more critical for $\mathrm{HCO}$ to give better conversions.

2. The coal-alone conversion value (as opposed to the overall-conversion value) is a better representation of the extent to which the coal was converted in the hydrotreatment reactions.

3. The increase in $\mathrm{H} / \mathrm{C}$ ratio of the solvent $\mathrm{CBB}$ from 0.74 to 0.88 indicates that the catalyst $\mathrm{NiO} / \mathrm{MoO}_{3}$ was very effective in the solvent hydrogenation of $\mathrm{CBB}$.

4. The increase in $\mathrm{H} / \mathrm{C}$ ratio of the solvent $\mathrm{HCO}$ from 0.75 to 0.77 indicates that the unconverted residue catalyst was not very effective for the solvent hydrogenation of $\mathrm{HCO}$ or the solvent $\mathrm{HCO}$ was not more prone to hydrogenation.

5. From the coal-alone conversion, the hydrogenated solvents are better hydrogen donor solvents than their corresponding fresh forms for both the solvents, the effect being much more significant in case of CBB than for HCO.

6. The percent coal-alone conversion increased with the increase in \% $\mathrm{H}$-CBB added in the blends of fresh $\mathrm{CBB}$ and $\mathrm{H}-\mathrm{CBB}$.

7. The recovered H-CBB did not perform as well as the fresh $\mathrm{H}-\mathrm{CBB}$ in coal hydrotreatment reactions.

8. Regardless of the solvent and the gaseous atmosphere $\left(\mathrm{N}_{2}\right.$ or $\left.\mathrm{H}_{2}\right), 400^{\circ} \mathrm{C}$ is the optimum temperature for the coal hydrotreatment reactions of the three hydrotreatment temperatures $350^{\circ} \mathrm{C}, 400^{\circ} \mathrm{C}$ and $450^{\circ} \mathrm{C}$ that were investigated for a reaction time of one hour. 
9. The mass balances for all the coal hydrotreatment reactions were found to be negative as expected as the product gases produced during the hydrotreatment reaction were not recovered.

10. The increase in percentage of ash in THF insolubles from all the coalhydrotreatment reactions followed the increase of the coal-alone conversions. The ash in the recovered pitch product was always low and in the range of $0.1 \%$.

11. When the extent of vacuum distillation remained the same, the softening points of all the pitches with fresh and hydrogenated solvents from the coal hydrotreatment at $400^{\circ} \mathrm{C}$ were in the range $120^{\circ} \mathrm{C}-170^{\circ} \mathrm{C}$ with coke yield between 45 and $70 \%$.

12. The optical texture of the cokes produced from the coal hydrotreatment with fresh $\mathrm{HCO}$ and $\mathrm{CBB}$ solvents are more isotropic and those produced with hydrogenated $\mathrm{HCO}$ and hydrogenated $\mathrm{CBB}$ are more anisotropic.

13. Irrespective of the solvent and the gaseous atmosphere used in the coal hydrotreatment reactions, the optical texture of the cokes produced from the coal hydrotreatment at $350^{\circ} \mathrm{C}$ are more isotropic and those produced at the hydrotreatment temperature of $450^{\circ} \mathrm{C}$ are more anisotropic.

\subsection{Recommendations for Future Work}

Based on the above results, the following recommendations can be made for future work:

1. As the first step, the solvent hydrogenation of $\mathrm{CBB}$ with the unconverted residue and the hydrogenation of $\mathrm{HCO}$ with $\mathrm{NiO} / \mathrm{MoO}_{3}$ should be investigated to determine if the unconverted residue is not an effective catalyst or if the solvent 
HCO is not more prone to hydrogenation. Also, some attempt should be made to concentrate the mineral matter catalyst so it can be run at higher concentration to see its catalytic effect.

2. The pitches showed very high softening points when $80-85 \%$ of the solvent was recovered. The effect of distilling varied amounts of recovered solvent should be studied to ascertain the variation of coke yields and softening point for all the hydrotreatment reactions under investigation.

3. The quantitative determination of carbon, hydrogen, nitrogen and sulphur of the products fraction can be compared with those of the input fraction meaningfully if the product gases were recovered and quantified. So, the gaseous products should be recovered and a gas-phase analysis should be performed on them. 


\section{REFERENCES}

1. A university, Industry, Government Cooperative Research Partnership. "Non-Fuel Use Of Coal: Coal-Derived Carbon Materials". Nov 12, 1993. The National Research Center for Coal and Energy (NRCCE), West Virginia University, P.O.Box 6064, Morgantown, WV 26505-6064.

2. Berkowitz, N. An Introduction to Coal Technology. Academic Press, Inc., Sandiego, 1994.

3. Schobert, H. Coal: The Energy Source of the Past and Future. American Chemical society, USA, 1987.

4. Whitehurst, D.D., Mitchell, T. O., and Farcasiu, M., Coal Liquefaction: The Chemistry and Technology of Thermal Processes, Mobil Research and Development Corporation, Central Research Division, Princeton, New Jersey, 1980.

5. Wiser, W. Preprints Fuel Division ACS Meeting, 20 (2), 122, 1975.

6. Whitehurst, D.D., Farcasiu, M., Mitchell, T.O., Dickert, J.J., "The Nature and Origin of Asphaltenes in Processed coals", EPRI AF-252, Project 410-1, Annual Report, July 1977.

7. Edwards, I.A.S., "Structure in Carbon and Carbon Forms." Introduction to Carbon Science. Ed. H. Marsh, Butterworths, 1989.

8. Merrick, D. "Coal Combustion and Conversion Technology," Elsevier: New York, 1984.

9. Lee, E.S., "Coal Liquefaction" Coal Conversion Technology. Ed. C.Y. Wen and E.S. lee. Addison-Wesley: Reading Mass., 1979, pp. 428-545.

10. Curran, G.P., Struck, R.T., and Gorin, E., "Mechanism of the Hydrogen Transfer Process to Coal and Coal Extract," Industrial Engineering Chemical Process Des. Dev., 6, 166 (1967).

11. Given, P.H., and Peover, M.E., Fuel, 39, 463, 1960. 
12. Wiser, W.H., "A Kinetic Comparison of Coal Pyrolysis and Coal Dissolution," Fuel , 47, 475, 1968.

13. Whitehurst, D.D., "The Nature and Origin of Asphaltenes In Process Coals," EPRI Final Report AF-1298, Project 410, December 1979.

14. Whitehurst, D.D., Farcasiu, M., Mitchell, T.O., Dickert, J.J., "The Nature and Origin of Asphaltenes in Processed Coals",EPRI AF-252, Project 410-1, Annual Report, July 1977- December 1979.

15. Yen, Y.K., Furlani, D.E., and Weller,S.W.," Batch Autoclave Studies of Catalytic Hydrodesulfurization of Coal” Ind. Eng. Chem. Prod. Res. Dev., 15, 24(1976)

16. Curran, G.P., Struck,R.T., and Gorin, E., “ Mechanism of Hydrogen-Transfer to Coal and Coal Extract,” Ind. Eng. Chem. Process Des. Dev., 6, 166,1967

17. Neavel, R.C., “ Liquefaction of Coal in Hydrogen-Donor and Nondonor Vehicles,” Fuel, 55, 237, 1976

18. Caballero, B.M., Marco, I, Chomon, M.J., Legarret, J.A., "Coal Liquefaction with Anthracene oil- Influence of Solvent Pretreatment, Temperature, Catalyst and Pressure," Fuel Science and Technology Int'l.,12 (7 \& 8),1067-1079,1994.

19. Wu, W.R.K., and Storch, H.H., "Hydrogenation of Coal and Tar," U.S.Bur.Min., Bull.,633.

20. Donath, E.E., Fuel Processing Technology, 1, 3, 1997

21. Diwakar, G. and Givens, E. N., Fuel Procesing Technology, 8 (1984) 123-134

22. Voorhoeve, R.J.H., and Stuiver, J.C.M., J.Catal. 23, 228, 1971

23. Shah, Y.T., "Reaction Engineering in Direct Coal Liquefaction," Addison-Wesley Publishing Company, Massachusetts, 1981. 
APPENDIX A 


\section{Appendix A}

Table A1 Coal-alone conversions for hydrotreatment reactions with fresh and recovered solvents at $400^{\circ} \mathrm{C}$

\begin{tabular}{|c|c|c|c|c|c|}
\hline Solvent & $\begin{array}{c}\text { Reaction } \\
\text { Atmosphere }\end{array}$ & $\begin{array}{l}\text { Coal } \\
\text { In (g) }\end{array}$ & $\begin{array}{c}\text { THF } \\
\text { Insolubles } \\
\text { (g) }\end{array}$ & $\begin{array}{c}\text { Conversion, } \\
\%\end{array}$ & $\begin{array}{c}\text { Avg. } \\
\%\end{array}$ \\
\hline HCO & $\mathrm{N}_{2}$ & 4.0013 & 2.7058 & 34.78 & \multirow{4}{*}{33.75} \\
\hline HCO & $\mathrm{N}_{2}$ & 4.0047 & 2.7442 & 33.79 & \\
\hline HCO & $\mathrm{N}_{2}$ & 4.0102 & 2.7584 & 33.51 & \\
\hline HCO & $\mathrm{N}_{2}$ & 4.0120 & 2.7865 & 32.79 & \\
\hline HCO & $\mathrm{H}_{2}$ & 4.0025 & 2.0769 & 51.63 & \multirow{4}{*}{51.75} \\
\hline HCO & $\mathrm{H}_{2}$ & 4.0095 & 2.0360 & 52.80 & \\
\hline HCO & $\mathrm{H}_{2}$ & 4.0294 & 2.0777 & 52.15 & \\
\hline HCO & $\mathrm{H}_{2}$ & 4.0010 & 2.1233 & 50.40 & \\
\hline CBB & $\mathrm{N}_{2}$ & 4.0023 & 2.1760 & 48.90 & \multirow{4}{*}{47.83} \\
\hline CBB & $\mathrm{N}_{2}$ & 4.0039 & 2.2352 & 47.40 & \\
\hline CBB & $\mathrm{N}_{2}$ & 4.0066 & 2.2111 & 484.12 & \\
\hline CBB & $\mathrm{N}_{2}$ & 4.0102 & 2.2589 & 46.89 & \\
\hline CBB & $\mathrm{H}_{2}$ & 4.0041 & 1.8581 & 57.50 & \multirow{4}{*}{57.22} \\
\hline CBB & $\mathrm{H}_{2}$ & 4.2406 & 1.9836 & 57.15 & \\
\hline CBB & $\mathrm{H}_{2}$ & 4.0084 & 1.8884 & 56.79 & \\
\hline CBB & $\mathrm{H}_{2}$ & 4.0112 & 1.8662 & 57.42 & \\
\hline H-HCO & $\mathrm{N}_{2}$ & 3.2002 & 2.0341 & 39.10 & \multirow{4}{*}{38.71} \\
\hline H-HCO & $\mathrm{N}_{2}$ & 3.2020 & 2.0191 & 39.60 & \\
\hline H-HCO & $\mathrm{N}_{2}$ & 4.0027 & 2.5743 & 38.32 & \\
\hline H-HCO & $\mathrm{N}_{2}$ & 4.0270 & 2.6072 & 37.85 & \\
\hline H-CBB & $\mathrm{N}_{2}$ & 4.0015 & 1.8591 & 61.01 & \multirow{4}{*}{60.99} \\
\hline H-CBB & $\mathrm{N}_{2}$ & 4.0023 & 1.7279 & 61.02 & \\
\hline H-CBB & $\mathrm{N}_{2}$ & 4.0185 & 1.7046 & 60.70 & \\
\hline H-CBB & $\mathrm{N}_{2}$ & 4.0077 & 1.7224 & 61.23 & \\
\hline Recovered H-CBB & $\mathrm{N}_{2}$ & 4.0023 & 2.4238 & 42.35 & \multirow{4}{*}{43.02} \\
\hline Recovered H-CBB & $\mathrm{N}_{2}$ & 4.0011 & 2.3902 & 43.23 & \\
\hline Recovered H-CBB & $\mathrm{N}_{2}$ & 4.0002 & 2.4083 & 42.73 & \\
\hline Recovered H-CBB & $\mathrm{N}_{2}$ & 4.0035 & 2.3720 & 43.75 & \\
\hline Pass 1 & $\mathrm{~N}_{2}$ & 4.0004 & 2.2018 & 48.28 & \multirow{4}{*}{48.74} \\
\hline Pass 1 & $\mathrm{~N}_{2}$ & 4.0003 & 2.1771 & 48.93 & \\
\hline Pass 1 & $\mathrm{~N}_{2}$ & 4.0012 & 2.1734 & 49.05 & \\
\hline Pass 1 & $\mathrm{~N}_{2}$ & 4.0017 & 2.1860 & 48.72 & \\
\hline Pass 2 & $\mathrm{~N}_{2}$ & 4.0022 & 2.0744 & 51.72 & \multirow{4}{*}{51.00} \\
\hline Pass 2 & $\mathrm{~N}_{2}$ & 4.0015 & 2.1252 & 50.35 & \\
\hline Pass 2 & $\mathrm{~N}_{2}$ & 4.0007 & 2.0923 & 51.22 & \\
\hline Pass 2 & $\mathrm{~N}_{2}$ & 4.0013 & 2.1108 & 50.73 & \\
\hline
\end{tabular}


Table A2 Coal-alone conversions for hydrotreatment reactions with fresh and hydrogenated solvents at $350^{\circ} \mathrm{C}$ and $450^{\circ} \mathrm{C}$

\begin{tabular}{|c|c|c|c|c|c|c|}
\hline Solvent & $\begin{array}{c}\text { Reaction } \\
\text { Atmosphere }\end{array}$ & $\begin{array}{c}\text { Reaction } \\
\text { Temperature }\end{array}$ & $\begin{array}{l}\text { Coal } \\
\text { In (g) }\end{array}$ & $\begin{array}{c}\text { THF } \\
\text { Insolubles } \\
\text { (g) }\end{array}$ & $\begin{array}{c}\text { Conversion, } \\
\%\end{array}$ & $\begin{array}{c}\text { Avg. } \\
\%\end{array}$ \\
\hline CBB & $\mathrm{N}_{2}$ & $350^{\circ} \mathrm{C}$ & 4.0225 & 3.1068 & 23.00 & \multirow{4}{*}{23.08} \\
\hline CBB & $\mathrm{N}_{2}$ & $350^{\circ} \mathrm{C}$ & 4.0205 & 3.1595 & 22.9 & \\
\hline CBB & $\mathrm{N}_{2}$ & $350^{\circ} \mathrm{C}$ & 4.0047 & 3.1588 & 22.68 & \\
\hline CBB & $\mathrm{N}_{2}$ & $350^{\circ} \mathrm{C}$ & 4.0082 & 3.1220 & 23.74 & \\
\hline CBB & $\mathrm{N}_{2}$ & $450^{\circ} \mathrm{C}$ & 4.0199 & 3.0954 & 24.69 & \multirow{4}{*}{24.04} \\
\hline CBB & $\mathrm{N}_{2}$ & $450^{\circ} \mathrm{C}$ & 4.0231 & 3.1516 & 23.26 & \\
\hline CBB & $\mathrm{N}_{2}$ & $450^{\circ} \mathrm{C}$ & 4.0092 & 3.1190 & 23.84 & \\
\hline CBB & $\mathrm{N}_{2}$ & $450^{\circ} \mathrm{C}$ & 4.0107 & 3.1002 & 24.37 & \\
\hline CBB & $\mathrm{H}_{2}$ & $350^{\circ} \mathrm{C}$ & 4.0050 & 3.0639 & 25.23 & \multirow{4}{*}{25.64} \\
\hline CBB & $\mathrm{H}_{2}$ & $350^{\circ} \mathrm{C}$ & 4.0072 & 3.0410 & 25.87 & \\
\hline CBB & $\mathrm{H}_{2}$ & $350^{\circ} \mathrm{C}$ & 4.0008 & 3.0275 & 26.12 & \\
\hline CBB & $\mathrm{H}_{2}$ & $350^{\circ} \mathrm{C}$ & 4.0082 & 3.0619 & 25.35 & \\
\hline CBB & $\mathrm{H}_{2}$ & $450^{\circ} \mathrm{C}$ & 4.0040 & 2.2324 & 47.51 & \multirow{4}{*}{47.21} \\
\hline CBB & $\mathrm{H}_{2}$ & $450^{\circ} \mathrm{C}$ & 4.0102 & 2.2232 & 47.84 & \\
\hline CBB & $\mathrm{H}_{2}$ & $450^{\circ} \mathrm{C}$ & 4.0073 & 2.2551 & 46.95 & \\
\hline CBB & $\mathrm{H}_{2}$ & $450^{\circ} \mathrm{C}$ & 4.0017 & 2.2679 & 46.52 & \\
\hline H-CBB & $\mathrm{N}_{2}$ & $350^{\circ} \mathrm{C}$ & 4.0190 & 2.8288 & 31.79 & \multirow{4}{*}{31.63} \\
\hline H-CBB & $\mathrm{N}_{2}$ & $350^{\circ} \mathrm{C}$ & 4.0063 & 2.7914 & 32.56 & \\
\hline Н-CВB & $\mathrm{N}_{2}$ & $350^{\circ} \mathrm{C}$ & 4.0105 & 2.8597 & 30.81 & \\
\hline H-CBB & $\mathrm{N}_{2}$ & $350^{\circ} \mathrm{C}$ & 4.0072 & 2.8372 & 31.35 & \\
\hline Н-CВB & $\mathrm{N}_{2}$ & $450^{\circ} \mathrm{C}$ & 4.0160 & 2.4841 & 40.95 & \multirow{4}{*}{41.18} \\
\hline H-CBB & $\mathrm{N}_{2}$ & $450^{\circ} \mathrm{C}$ & 4.0161 & 2.4694 & 41.3 & \\
\hline H-CBB & $\mathrm{N}_{2}$ & $450^{\circ} \mathrm{C}$ & 4.0078 & 2.4866 & 40.75 & \\
\hline H-CBB & $\mathrm{N}_{2}$ & $450^{\circ} \mathrm{C}$ & 4.0005 & 2.3460 & 41.72 & \\
\hline
\end{tabular}


Table A3 Pressure -Time data for coal hydrotreatment reactions with fresh HCO and $C B B$ solvents in $\mathrm{N}_{2}$ atmosphere

\begin{tabular}{|c|c|c|}
\hline Time & HCO & CBB \\
\hline 0 & 500 & 500 \\
\hline 1 & 800 & 850 \\
\hline 2 & 950 & 950 \\
\hline 3 & 1000 & 1050 \\
\hline 5 & 1050 & 1100 \\
\hline 10 & 1050 & 1125 \\
\hline 20 & 1100 & 1150 \\
\hline 30 & 1150 & 1150 \\
\hline 40 & 1175 & 1150 \\
\hline 50 & 1175 & 1150 \\
\hline 60 & 1175 & 1150 \\
\hline 61 & 525 & 550 \\
\hline
\end{tabular}

Table A4 Pressure -Time data for coal hydrotreatment reactions with fresh HCO and $\mathrm{CBB}$ solvents in $\mathrm{H}_{2}$ atmosphere

\begin{tabular}{|c|c|c|}
\hline Time & HCO & CBB \\
\hline 0 & 500 & 500 \\
\hline 1 & 850 & 900 \\
\hline 2 & 975 & 950 \\
\hline 3 & 1025 & 975 \\
\hline 5 & 1050 & 1000 \\
\hline 10 & 1050 & 1000 \\
\hline 20 & 1050 & 1000 \\
\hline 30 & 1025 & 975 \\
\hline 40 & 1000 & 925 \\
\hline 50 & 950 & 900 \\
\hline 60 & 925 & 875 \\
\hline 61 & 425 & 400 \\
\hline
\end{tabular}


Table A5 Pressure -Time data for coal hydrotreatment reactions with blends of fresh CBB and $\mathrm{H}-\mathrm{CBB}$ solvents in $\mathrm{N}_{2}$ atmosphere

\begin{tabular}{|c|c|c|c|}
\hline Time & $\begin{array}{c}\text { 25 \% H-CBB } \\
\text { +75 \% CBB }\end{array}$ & $\begin{array}{c}\mathbf{5 0} \text { \% H-CBB } \\
\text { +50 \% CBB }\end{array}$ & $\begin{array}{c}\text { 75 \% H-CBB } \\
\text { +25 \% CBB }\end{array}$ \\
\hline 0 & 500 & 800 & 500 \\
\hline 1 & 800 & 800 & 800 \\
\hline 2 & 875 & 850 & 875 \\
\hline 3 & 975 & 925 & 975 \\
\hline 5 & 1000 & 1050 & 1050 \\
\hline 10 & 1100 & 1150 & 1150 \\
\hline 20 & 1125 & 1150 & 1100 \\
\hline 30 & 1125 & 1150 & 1175 \\
\hline 40 & 1125 & 1150 & 1175 \\
\hline 50 & 1125 & 1150 & 1175 \\
\hline 60 & 1125 & 1150 & 1175 \\
\hline 61 & 550 & 525 & 550 \\
\hline
\end{tabular}

Table A6 Pressure -Time data for coal hydrotreatment reactions with Tetralin solvent in $\mathrm{N}_{2}$ and $\mathrm{H}_{2}$ atmospheres

\begin{tabular}{|c|c|c|}
\hline Time & $\mathbf{N}_{\mathbf{2}}$ & $\mathbf{H}_{\mathbf{2}}$ \\
\hline 0 & 500 & 500 \\
\hline 1 & 900 & 900 \\
\hline 2 & 1000 & 1050 \\
\hline 3 & 1100 & 1150 \\
\hline 5 & 1150 & 1200 \\
\hline 10 & 1150 & 1300 \\
\hline 20 & 1200 & 1300 \\
\hline 30 & 1200 & 1250 \\
\hline 40 & 1250 & 1200 \\
\hline 50 & 1250 & 1200 \\
\hline 60 & 1250 & 1200 \\
\hline 61 & 650 & 450 \\
\hline
\end{tabular}


Table A7 Softening points of the pitches from all the Coal hydrotreatment reactions

\begin{tabular}{|c|c|c|c|c|c|}
\hline Solvent & $\begin{array}{c}\text { Reaction } \\
\text { Atmosphere }\end{array}$ & $\begin{array}{c}\text { Reaction } \\
\text { Temperature }\end{array}$ & Run 1 & Run 2 & $\begin{array}{c}\text { Softening } \\
\text { Point } \\
\text { ( avg) }\end{array}$ \\
\hline $\mathrm{HCO}$ & $\mathrm{N}_{2}$ & $400^{\circ} \mathrm{C}$ & 156.7 & 152.9 & 154.8 \\
\hline $\mathrm{HCO}$ & $\mathrm{H}_{2}$ & $400^{\circ} \mathrm{C}$ & 147.9 & 142.5 & 145.2 \\
\hline $\mathrm{CBB}$ & $\mathrm{N}_{2}$ & $400^{\circ} \mathrm{C}$ & 156.9 & 158.5 & 157.7 \\
\hline CBB & $\mathrm{H}_{2}$ & $400^{\circ} \mathrm{C}$ & 120.8 & 123.7 & 122.3 \\
\hline $\mathrm{H}-\mathrm{HCO}$ & $\mathrm{N}_{2}$ & $400^{\circ} \mathrm{C}$ & 146.9 & 144.1 & 145.5 \\
\hline H-CBB & $\mathrm{N}_{2}$ & $400^{\circ} \mathrm{C}$ & 170.3 & 174.2 & 171.3 \\
\hline $\begin{array}{c}\text { Recovered } \\
\text { H-CBB }\end{array}$ & $\mathrm{N}_{2}$ & $400^{\circ} \mathrm{C}$ & 159.7 & 161.7 & 160.7 \\
\hline Pass 1 & $\mathrm{~N}_{2}$ & $400^{\circ} \mathrm{C}$ & 154.0 & 156.4 & 155.2 \\
\hline Pass 2 & $\mathrm{~N}_{2}$ & $400^{\circ} \mathrm{C}$ & 136.9 & 134.6 & 135.8 \\
\hline $\begin{array}{c}25 \% \mathrm{H}-\mathrm{CBB} \\
+75 \% \mathrm{H}-\mathrm{CBB} \\
\end{array}$ & $\mathrm{N}_{2}$ & $400^{\circ} \mathrm{C}$ & 159.5 & 156.8 & 158.2 \\
\hline $\begin{array}{c}50 \% \mathrm{H}-\mathrm{CBB} \\
+50 \% \mathrm{H}-\mathrm{CBB} \\
\end{array}$ & $\mathrm{N}_{2}$ & $400^{\circ} \mathrm{C}$ & 162.4 & 158.6 & 160.5 \\
\hline $\begin{array}{r}75 \% \mathrm{H}-\mathrm{CBB} \\
+25 \% \mathrm{H}-\mathrm{CBB} \\
\end{array}$ & $\mathrm{N}_{2}$ & $400^{\circ} \mathrm{C}$ & 159.7 & 159.1 & 159.4 \\
\hline $\mathrm{CBB}$ & $\mathrm{N}_{2}$ & $350^{\circ} \mathrm{C}$ & 100.8 & 97.5 & 91.2 \\
\hline $\mathrm{CBB}$ & $\mathrm{N}_{2}$ & $450^{\circ} \mathrm{C}$ & 147.1 & 150.8 & 148.9 \\
\hline $\mathrm{CBB}$ & $\mathrm{H}_{2}$ & $350^{\circ} \mathrm{C}$ & 100.1 & 98.5 & 99.3 \\
\hline $\mathrm{CBB}$ & $\mathrm{H}_{2}$ & $450^{\circ} \mathrm{C}$ & 96.2 & 97.4 & 96.8 \\
\hline $\mathrm{H}-\mathrm{CBB}$ & $\mathrm{N}_{2}$ & $350^{\circ} \mathrm{C}$ & 157.9 & 156.7 & 157.3 \\
\hline $\mathrm{H}-\mathrm{CBB}$ & $\mathrm{N}_{2}$ & $450^{\circ} \mathrm{C}$ & 170.9 & 169.5 & 170.2 \\
\hline
\end{tabular}


Table A8 Elemental compositions of fresh solvent, THF Insolubles, pitch and recycle solvent from hydrotreatment reactions with solvent $C B B$ in $\mathrm{N}_{2}$ and $\mathrm{H}_{2}$ atmospheres at temperatures $350^{\circ} \mathrm{C}$ and $450^{\circ} \mathrm{C}$

\begin{tabular}{|c|c|c|c|c|c|c|}
\hline \multirow[b]{2}{*}{$\begin{array}{c}\text { Reaction } \\
\text { Temperature }\end{array}$} & \multirow[b]{2}{*}{$\begin{array}{c}\text { Reaction } \\
\text { Atmosphere }\end{array}$} & \multirow[b]{2}{*}{ Element } & \multirow[b]{2}{*}{$\begin{array}{c}\text { Fresh } \\
\text { Solvent } \\
(\%)\end{array}$} & \multicolumn{3}{|c|}{ Product Fraction } \\
\hline & & & & $\begin{array}{c}\text { THF } \\
\text { Insolubles } \\
(\%)\end{array}$ & $\begin{array}{c}\text { Pitch } \\
(\%)\end{array}$ & $\begin{array}{c}\text { Recycle } \\
\text { Solvent } \\
(\%)\end{array}$ \\
\hline \multirow{5}{*}{$350^{\circ} \mathrm{C}$} & \multirow{5}{*}{$\mathrm{N}_{2}$} & $\mathrm{C}$ & 91.6 & 77.2 & 90.5 & 93.5 \\
\hline & & $\mathrm{H}$ & 5.7 & 4.4 & 5.6 & 6.0 \\
\hline & & $\mathrm{N}$ & 1.1 & 1.7 & 1.8 & 1.2 \\
\hline & & $\mathrm{S}$ & 0.5 & 0.1 & 0.0 & 0.0 \\
\hline & & $\begin{array}{c}\text { H/C Atomic } \\
\text { Ratio }\end{array}$ & 0.74 & 0.68 & 0.74 & 0.77 \\
\hline \multirow{5}{*}{$450^{\circ} \mathrm{C}$} & \multirow{5}{*}{$\mathrm{N}_{2}$} & $\mathrm{C}$ & 91.6 & 86.7 & 91.8 & 93.2 \\
\hline & & $\mathrm{H}$ & 5.7 & 4.0 & 5.0 & 6.0 \\
\hline & & $\mathrm{N}$ & 1.1 & 1.8 & 1.7 & 1.1 \\
\hline & & $\mathrm{S}$ & 0.5 & 0.0 & 0.0 & 0.0 \\
\hline & & $\begin{array}{c}\mathrm{H} / \mathrm{C} \text { Atomic } \\
\text { Ratio }\end{array}$ & 0.74 & 0.55 & 0.65 & 0.77 \\
\hline \multirow{5}{*}{$350^{\circ} \mathrm{C}$} & \multirow{5}{*}{$\mathrm{H}_{2}$} & $\mathrm{C}$ & 91.6 & 79.6 & 90.0 & 92.3 \\
\hline & & $\mathrm{H}$ & 5.7 & 4.8 & 5.7 & 6.0 \\
\hline & & $\mathrm{N}$ & 1.1 & 1.6 & 1.7 & 1.0 \\
\hline & & $\mathrm{S}$ & 0.5 & 0.2 & 0.0 & 0.0 \\
\hline & & $\begin{array}{c}\mathrm{H} / \mathrm{C} \text { Atomic } \\
\text { Ratio }\end{array}$ & 0.74 & 0.72 & 0.76 & 0.78 \\
\hline \multirow{5}{*}{$450^{\circ} \mathrm{C}$} & \multirow{5}{*}{$\mathrm{H}_{2}$} & $\mathrm{C}$ & 91.6 & 75.4 & 91.6 & 92.6 \\
\hline & & $\mathrm{H}$ & 5.7 & 3.4 & 5.4 & 6.1 \\
\hline & & $\mathrm{N}$ & 1.1 & 1.7 & 1.7 & 1.0 \\
\hline & & $\mathrm{S}$ & 0.5 & 0.7 & 0.0 & 0.0 \\
\hline & & $\begin{array}{c}\mathrm{H} / \mathrm{C} \text { Atomic } \\
\text { Ratio }\end{array}$ & 0.74 & 0.54 & 0.71 & 0.79 \\
\hline
\end{tabular}


Table A9 Elemental compositions of THF insolubles, pitch and recycle solvent from hydrotreatment reactions with recovered solvent and successive hydrotreatment reactions of $\mathrm{H}-\mathrm{CBB}$ in $\mathrm{N}_{2}$ atmosphere at $400^{\circ} \mathrm{C}$

\begin{tabular}{|c|c|c|c|c|c|}
\hline \multirow{2}{*}{ SOLVENT } & \multirow[b]{2}{*}{$\begin{array}{c}\text { REACTION } \\
\text { ATMOSPHERE }\end{array}$} & \multirow[b]{2}{*}{ ELEMENT } & \multicolumn{3}{|c|}{ PRODUCT FRACTION } \\
\hline & & & $\begin{array}{c}\text { THF } \\
\text { Insolubles } \\
(\%)\end{array}$ & $\begin{array}{c}\text { Pitch } \\
(\%)\end{array}$ & $\begin{array}{c}\text { Recycle } \\
\text { Solvent } \\
(\%)\end{array}$ \\
\hline \multirow{5}{*}{$\begin{array}{l}\text { Recovered } \\
\text { H-CBB }\end{array}$} & \multirow{5}{*}{$\mathrm{N}_{2}$} & $\mathrm{C}$ & 77.7 & 89.4 & 92.9 \\
\hline & & $\mathrm{H}$ & 4.0 & 5.9 & 6.1 \\
\hline & & $\mathrm{N}$ & 1.7 & 2.6 & 1.0 \\
\hline & & $\mathrm{S}$ & 0.3 & 0.0 & 0.0 \\
\hline & & $\begin{array}{c}\mathrm{H} / \mathrm{C} \text { Atomic } \\
\text { Ratio }\end{array}$ & 0.62 & 0.79 & 0.79 \\
\hline \multirow{5}{*}{ Pass 1} & \multirow{5}{*}{$\mathrm{N}_{2}$} & $\mathrm{C}$ & 81.6 & 90.2 & 93.0291 \\
\hline & & $\mathrm{H}$ & 4.6 & 6.0 & 6.1649 \\
\hline & & $\mathrm{N}$ & 1.9 & 1.7 & 1.1872 \\
\hline & & $\mathrm{S}$ & 0.2 & 0.0 & 0.0000 \\
\hline & & $\begin{array}{c}\text { H/C Atomic } \\
\text { Ratio }\end{array}$ & 0.68 & 0.8 & 0.780 \\
\hline \multirow{5}{*}{ Pass 2} & \multirow{5}{*}{$\mathrm{N}_{2}$} & $\mathrm{C}$ & 78.3 & 89.8 & 92.7 \\
\hline & & $\mathrm{H}$ & 4.4 & 5.7 & 6.3 \\
\hline & & $\mathrm{N}$ & 1.6 & 1.7 & 1.5 \\
\hline & & $\mathrm{S}$ & 0.3 & 0.0 & 0.0 \\
\hline & & $\begin{array}{c}\mathrm{H} / \mathrm{C} \text { Atomic } \\
\text { Ratio }\end{array}$ & 0.67 & 0.76 & 0.82 \\
\hline
\end{tabular}




\section{APPENDIX B: Material Safety Data Sheets}




\section{Material Safety Data Sheet}

Tetrahydrofuran (uninhibited)

\section{Section 1 - Chemical Product and Company Identification}

MSDS Name: Tetrahydrofuran (uninhibited)

Synonyms: Diethylene oxide; 1,4-Epoxybutane; Tetramethylene oxide; THF; Oxacyclopentane.

Company Identification: Fisher Scientific

1 Reagent Lane

Fair Lawn, N] 07410

For information, call: $201-796-7100$

Emergency Number: 201-796-7100

For CHEMTREC assistance, call: $800-424-9300$

For International CHEMTREC assistance, call: 703-527-3887

Section 2 - Composition, Information on Ingredients

\begin{tabular}{|c|c|c|c|}
\hline CAS\# & Chemical Name & Percent & EINECS/ELINCS \\
\hline $109-99-9$ & Tetrahydrofuran & 100 & $203-726-8$ \\
\hline
\end{tabular}

Hazard Symbols: XI F

Risk Phrases: 1119 36/37

Section 3 - Hazards Identification

EMERGENCY OVERVIEW

Appearance: colorless liquid. Flash Point: - 14 deg C. Danger! May cause central nervous system depression. Uninhibited material, or material from which the inhibitor has been removed or reacted, may form explosive peroxides. May cause liver and kidney damage. May cause lung damage. May be harmful if swallowed. Hygroscopic (absorbs moisture from the air). Extremely flammable liquid and vapor. Vapor may cause flash fire. Causes severe eye irritation and possible eye injury. Causes skin and respiratory tract irritation.

May be absorbed through intact skin.

Target Organs: Kidneys, central nervous system, liver, lungs, respiratory system, eyes, skin.

Potential Health Effects

Eye: Contact with eyes may cause severe irritation, and possible eye burns. Vapors may cause eye irritation. Damage may be permanent.

Skin: Causes skin irritation. May be absorbed through the skin. If absorbed, causes symptoms similar to those of inhalation. THF is not a skin sensitizer in animals.

Ingestion: May cause gastrointestinal irritation with nausea, vomiting and diarrhea. May cause central nervous system depression. May be harmful if swallowed. 


\section{$\star \star \star \star$ MATERIAI SAFETY DATA SHEET}

$1,2,3,4-$ Tetrahydronaphthalene 23050

$\star \star \star \star$ SECTION 1 - CHEMICAL PRODUCT AND COMPANY IDENTIFICATION

$* * * *$

MSDS Name: 1,2,3,4-Tetrahydronaphthalene

Catalog Numbers: T/0850

Synonyms: THN; Tetrahydronaphthalene; Tetralin.

Company Identification: Fisher Scientific UK

Bishop Meadow Road

Loughborough, Leicestershire

LEII 5RG, UK

For information, call: 01509231166

For emergencies, call: 01509231166

$* * * *$ SECTION 2 - COMPOSITION, INFORMATION ON INGREDIENTS ****

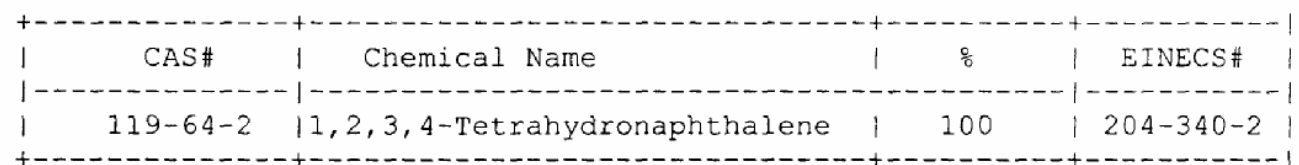

Hazard Symbols: XI N Risk Phrases: 19 36/38 51/53

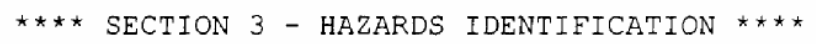

EMERGENCY OVERVIEW

May form explosive peroxides. Irritating to eyes and skin. Toxic to aquatic organisms; may cause long-term adverse effects in the aquatic environment. Air sensitive.

Potential Health Effects

Eye: May cause eye irritation.

Skin: May cause skin irritation.

Ingestion: Aspiration hazard. Causes gastrointestinal irritation with nausea, vomiting and diarrhea. May cause central nervous system depression, characterized by excitement, followed by headache, dizziness, drowsiness, and nausea. Advanced stages may cause collapse, unconsciousness, coma and possible death due to respiratory failure.

Inhalation: Inhalation of high concentrations may cause central nervous system effects characterized by nausea, headache, dizziness, unconsciousness and coma. Inhalation of vapor may cause respiratory tract irritation. May cause narcotic effects in high concentration. Exposure produces central nervous system depression. May cause dizziness, incoordination, and unconsciousness.

Chronic: Overexposure may cause delayed kidney injury. Chronic ingestion may cause liver damage. 


\section{Material Safety Data Sheet}

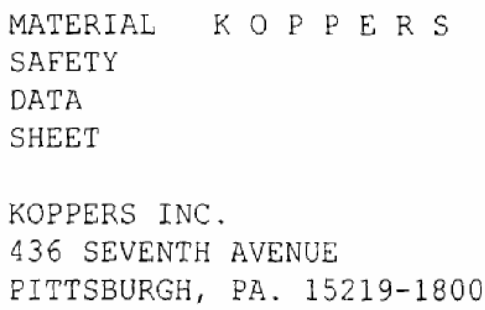

\section{SECTION I - PRODUCT IDENTIFICATION}

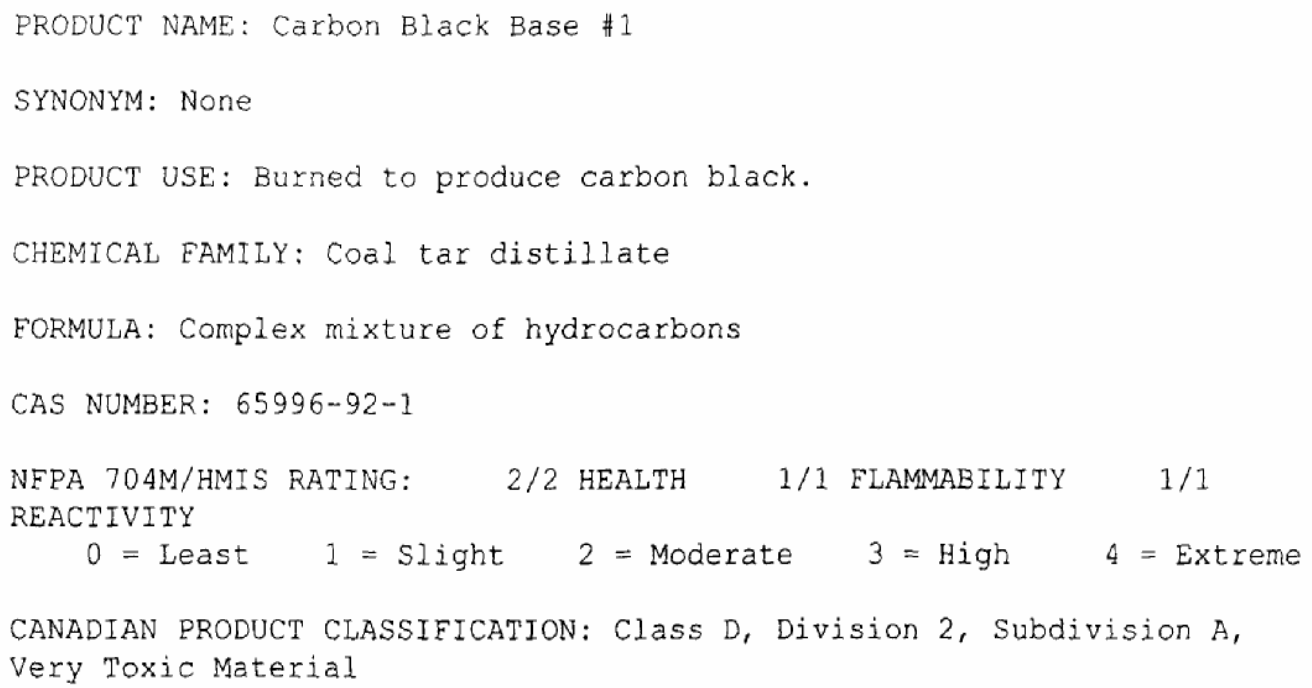

\section{SECTION II - HEALTH/SAFETY ALERT}

WARNING

MAY BE FATAL IF SWALLOWED

HARMFUL TO THE SKIN OR IF INHALED

CAUSES EYE AND SKIN IRRITATION AVOID PROLONGED OR REPEATED CONTACT

OBSERVE GOOD HYGIENE AND SAFETY PRACTICES WHEN HANDLING THIS

PRODUCT DO NOT USE THIS PRODUCT UNTIL MSDS HAS BEEN READ AND UNDERSTOOD WARNING: THIS PRODUCT CONTAINS A CHEMICAL KNOWN TO THE STATE OF CALIFORNIA TO CAUSE CANCER. 
KOPPERS
INDUSTRIES

\section{Material Safety Data Sheet}

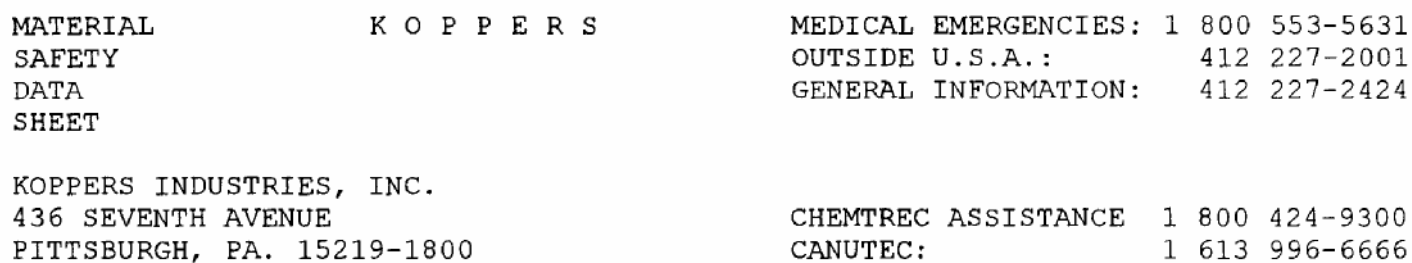

\section{SECTION I - PRODUCT IDENTIFICATION}

PRODUCT NAME: Coal Tar Distillate - HCO

SYNONYM: None

PRODUCT USE: Coal tar solvent; correction oil; fuel

CHEMICAL FAMILY: Coal tar distillate

FORMULA: Complex mixture of hydrocarbons

CAS NUMBER: 65996-92-1

NFPA 704M/HMIS RATING: 2/2 HEALTH $1 / 1$ FLAMMABILITY $1 / 1$ REACTIVITY
$0=$ Least
$1=$ Slight
$2=$ Moderate $3=$ High
$4=$ Extreme

CANADIAN PRODUCT CLASSIFICATION: Class D, Division 2, Subdivision A, Very Toxic Material

\section{SECTION II - HEALTH/SAFETY ALERT}

CHRONIC OVEREXPOSURE (as defined bY OSHA recommended standards) MAY CAUSE CANCER

WARNING

MAY BE FATAL IF SWALLOWED

HARMFUL TO THE SKIN OR IF INHALED

CAUSES EYE AND SKIN IRRITATION

AVOID PROLONGED OR REPEATED CONTACT

OBSERVE GOOD HYGIENE AND SAFETY PRACTICES WHEN HANDLING THIS PRODUCT

DO NOT USE THIS PRODUCT UNTIL MSDS HAS BEEN READ AND UNDERSTOOD

WARNING: THIS PRODUCT CONTAINS A CHEMICAL KNOWN TO THE STATE OF CALIFORNIA TO CAUSE CANCER. 


\section{/ SECTION III - HEALTH HAZARD INFORMATION}

EYE: Direct contact with liquid or vapor may cause moderate irritation.

SKIN: Contact with skin can result in severe irritation which when accentuated by sunlight may result in phototoxic skin reaction. This material or similar materials when administered throughout the major portion of their lifetime has caused cancer in laboratory animals.

INHALATION: Acute overexposure to vapor may result in respiratory tract irritation. Repeated and/or prolonged contact to high concentrations of vapor may result in respiratory difficulties, central nervous system (CNS) effects characterized by headache, drowsiness, dizziness, weakness, incoordination, circulatory collapse, coma and possible death.

INGESTION: Ingestion of material may cause gastrointestinal disturbances including irritation, nausea, vomiting, abdominal pain. Systemic effects are similar to those described under INHALATION.

OTHER: See Section XIII (Comments) for additional information on heatlh effects.

\section{SECTION IV - EMERGENCY AND FIRST AID PROCEDURES}

EYE CONTACT: Immediately flush with large amounts of water for 15 minutes. Seek medical aid.

SKIN CONTACT: Remove contaminated clothing. Wipe material from skin. Wash thoroughly with soap and water or waterless hand cleaner. If irritation persists, seek medical aid.

INHALATION: Remove from exposure. If breathing has stopped or is difficult, administer artificial respiration or oxygen as indicated. Seek medical aid.

INGESTION: If victim is conscious and alert, give 1-2 glasses of water or milk. Induce vomiting using ipecac syrup as directed on the label. After vomiting, the victim may be given a slurry of $100 \mathrm{~g}$ of activated charcoal in $8 \mathrm{oz}$. of water. Seek medical aid.

NOTE TO PHYSICIAN: Due to the possibility of sensitization of the myocardium following extreme acute overexposures, cardiorespiratory support should be available.

INGESTION: DO NOT INDUCE VOMITING OR GIVE ANYTHING BY MOUTH TO AN UNCONSCIOUS PERSON. 